\title{
Matrine Exerts Pharmacological Effects Through Multiple Signaling Pathways: A Comprehensive Review
}

\author{
Yingda Lin ${ }^{1,2, *}$, Fuming $\mathrm{He}^{2}$, Ling $\mathrm{Wu}^{\prime}$, Yuan $\mathrm{Xu}{ }^{\prime}$, Qiu Du $\mathbb{D}^{3,4 *}$ \\ 'Department of Pharmacy, the Affiliated Hospital of Yangzhou University, Yangzhou University, Yangzhou, 2250I2, People's Republic of China; \\ ${ }^{2}$ Medical College, Yangzhou University, Yangzhou, 22500I, People's Republic of China; ${ }^{3}$ Department of Neurosurgery, the Affiliated Hospital of \\ Yangzhou University, Yangzhou University, Yangzhou, 2250I2, People's Republic of China; ${ }^{4}$ Department of Central Laboratory, the Affiliated Hospital \\ of Yangzhou University, Yangzhou University, Yangzhou, 225012, People's Republic of China
}

*These authors contributed equally to this work

Correspondence: Qiu Du, Department of Neurosurgery, the Affiliated Hospital of Yangzhou University, Yangzhou University, 368 Hanjiang Middle Road, Yangzhou, 225012, People's Republic of China, Email 092102@yzu.edu.cn; Yuan Xu, Department of pharmacy, the Affiliated Hospital of Yangzhou University, Yangzhou University, 368 Hanjiang Middle Road, Yangzhou, 2250I2, People's Republic of China, Email feebyxuyuan@I63.com

\begin{abstract}
As The main effective monomer of the traditional Chinese medicine Sophora flavescens Ait, matrine has a broad scope of pharmacological activities such as anti-tumor, anti-inflammatory, analgesic, anti-fibrotic, anti-viral, anti-arrhythmia, and improving immune function. These actions explain its therapeutic effects in various types of tumors, cardiopathy, encephalomyelitis, allergic asthma, rheumatoid arthritis (RA), osteoporosis, and central nervous system (CNS) inflammation. Evidence has shown that the mechanism responsible for the pharmacological actions of matrine may be via the activation or inhibition of certain key molecules in several cellular signaling pathways including the phosphatidylinositol 3-kinase/protein kinase B/mammalian target of rapamycin (PI3K/ $\mathrm{AKT} / \mathrm{mTOR}$ ), transforming growth factor- $\beta /$ mothers against decapentaplegic homolog (TGF- $\beta / \mathrm{Smad})$, nuclear factor kappa B (NF- $\kappa \mathrm{B})$, Wnt (wingless/ integration 1)/ $\beta$-catenin, mitogen-activated protein kinases (MAPKs), and Janus kinase/signal transducer and activator of transcription (JAK/STAT) signaling pathways. This review comprehensively summarizes recent studies on the pharmacological mechanisms of matrine to provide a theoretical basis for molecular targeted therapies and further development and utilization of matrine.
\end{abstract} Keywords: matrine, pharmacological effects, signaling pathways, review

\section{Introduction}

Sophora flavescens Ait is a well-known traditional Chinese herbal medicine and has been widely utilized in the clinical practice for its effects on various damp-heat syndromes, heat-toxin syndromes like carbuncle and sore, and skin itching. ${ }^{1}$ Modern pharmacological studies have shown that matrine (molecular formula: $\mathrm{C} 15 \mathrm{H} 24 \mathrm{~N} 2 \mathrm{O}$, molecular weight: $248.36 \mathrm{~g} / \mathrm{mol}$ ) is a naturally occurring quinolizidine alkaloids rich in Sophora flavescens Ait as well as Sophora alopecuroides Linn, Sophora tonkinensis, which mediates a variety of biological effects such as anti-tumor, anti-inflammatory, analgesic, anti-fibrotic, antiviral, anti-arrhythmia, antimicrobial, and insecticidal, illustrating that it has immense potential for clinical application with various pharmacological activities. ${ }^{1,2}$ At present, studies have reported that the pharmacological effects of matrine involve the PI3K/AKT/mTOR, TGF- $\beta /$ Smad, NF- $\mathrm{kB}, \mathrm{Wnt} / \beta$-catenin, MAPKs, JAK/STAT, and other significant signaling pathways, and closely related to multiple biological processes such as cell proliferation, differentiation, apoptosis, and immune regulation. ${ }^{1-3}$

However, few studies have classified and summarized the underlying molecular mechanisms by which matrine exerts its pharmacological effects through different signaling pathways. In this review, the pharmacological activities of matrine and the molecular mechanisms of its pharmacological effects through the targeted regulation of different signaling pathways will be comprehensively expounded, so as to provide theoretical support for further expanding the potential clinical application of matrine. 


\section{Matrine Exerts Pharmacological Effects Through the PI3K/AKT/mTOR Signaling Pathway}

PI3K is a heterodimeric lipid kinase composed of a catalytic subunit ( $110 \alpha, \mathrm{p} 110 \beta$, or $\mathrm{p} 110 \delta$; encoded by the PIK3CA, PIK3CB, and PIK3CD genes, respectively) and a regulatory subunit (p85). ${ }^{4} \mathrm{PI} 3 \mathrm{~K}$ is mainly activated by receptor tyrosine kinase (RTK) signaling, via phosphorylation of the inositol lipid phosphatidylinositol 4, 5-bisphosphate (PI $(4,5)$ P2). It then forms the second messenger molecule phosphatidylinositol $(3,4,5)$-trisphosphate (PI $(3,4,5)$ P3) that recruits and activates pleckstrin homology $(\mathrm{PH})$ domain-containing proteins such as AKT and phosphoinositide-dependent kinases (PDK) 1, which leads to downstream signaling events crucial for proliferation, survival, and migration. ${ }^{5,6}$ The serine/ threonine-protein kinase AKT is a critical mediator of signaling downstream of PI3K, which is rapidly activated by PI3K or PDK as well as growth factors, inflammation, and DNA damage. ${ }^{7}$ AKT is recruited to the plasma membrane through the interaction of its $\mathrm{PH}$ domain with PI $(3,4,5) \mathrm{P}$, resulting in a conformational change and activation by phosphorylation, and plays a central role in multiple cellular processes essential for cell growth, metabolism, and survival. ${ }^{8}$ mTOR is a key kinase downstream of PI3K/AKT. It is an evolutionarily conserved atypical serine/threonine-protein kinase that belongs to the PI3K-related kinase (PIKK) protein family. mTOR participates in two distinct complexes, mTOR complex 1 (mTORC1) and mTORC2. Both complexes consist of a structure of many large proteins that aid in the stimulation and inhibition of key pathways and cascades in the cell. mTOR is the molecule that activates, regulates, and inhibits the functions of the two large complexes and has important functions in regulating cell growth, proliferation, motility, survival, protein synthesis, and transcription. ${ }^{9}$

The PI3K/AKT/mTOR pathway is crucial to many aspects of cell growth and survival in physiological as well as pathological conditions. Phosphorylation of PI3K leads to activation of AKT, which regulates several downstream molecules, including mTOR. These pathways are interconnected and therefore, in a certain sense, could be regarded as a single, unique pathway. ${ }^{10}$ The PI3K/AKT/mTOR pathway serves important roles in cellular processes such as survival, proliferation, growth, metabolism, angiogenesis, and metastasis. It is frequently hyper-activated or altered in many types of human cancer, and may serve as a valuable target for disease therapy. ${ }^{11,12}$

Chinese medicine plays a unique role in anti-tumor research. Studies have shown that matrine may be widely utilized in the inhibition of malignant tumors and adjuvant chemoradiotherapy through modulation of the PI3K/AKT/mTOR pathway. Matrine is a promising treatment for lung cancer, either alone or in combination with chemotherapeutic agents. Niu et $\mathrm{al}^{13}$ found that matrine inhibited cell proliferation and induced apoptosis in A549 and 95D lung cancer cells in a dose- and time-dependent manner and exerted its cancer-killing effect by promoting apoptosis in lung cancer cells via the $\mathrm{PI} 3 \mathrm{~K} / \mathrm{AKT} / \mathrm{mTOR}$ signaling pathway and downregulation of the expression of the inhibitor of apoptosis protein (IAP) family proteins. Wan et $\mathrm{al}^{14}$ evaluated the anti-lung adenocarcinoma effect of matrine and found that matrine suppressed the proliferation of A549 lung adenocarcinoma cells by inducing apoptosis and autophagy, accompanied by the upregulation of Bcl-2 associated X (Bax), microtubule associated protein 1 light chain 3-II (LC3-II), and Beclin-1, as well as the suppression of B cell leukemia/lymphoma 2 (Bcl-2) and sequestosome 1 (p62). This study demonstrated that mechanistically, the growth inhibitory effects of matrine were dependent on the suppression of PI3K/AKT and the upregulation of caveolae associated protein 3 (Cavin3). Xie et $\mathrm{al}^{15}$ showed that matrine significantly suppressed proliferation and colony formation, induced cellular apoptosis, and inhibited the migration of lung cancer cells, and

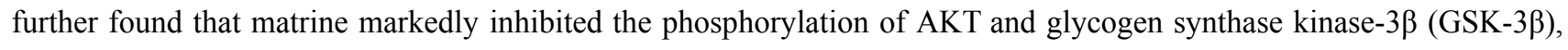
indicating that the inhibitory effects of matrine in lung cancer are possibly through suppression of the AKT/GSK-3 $\beta$ signaling pathway. Liao et $\mathrm{al}^{16}$ found that matrine treatment significantly inhibited the proliferation, migration, and invasion of human NCI-H1299 lung cancer cells in a concentration-dependent manner, and the mechanism may be related to the upregulation of microRNA (miR)-133a expression and inhibition of the epidermal growth factor receptor (EGFR)/AKT/matrix metallopeptidase (MMP) -9 pathway.

For breast cancer, matrine has shown therapeutic and/or adjuvant therapeutic effects, but its anti-breast cancer mechanism remains unclear. Du et $\mathrm{al}^{17}$ showed that matrine significantly inhibited MCF-7 cells growth by inducing apoptosis and autophagy, and suppressed the phosphorylation of AKT and mTOR, suggesting that matrine may achieve its anti-breast cancer effect by inhibiting AKT/mTOR pathway. Yu et al ${ }^{18}$ demonstrated that matrine markedly 
suppressed the proliferation of highly metastatic breast cancer cells mDA-MB-231, and displayed synergistic effects with existing anticancer drugs such as celecoxib, trocomycin A, and rosiglitazone. They also found that matrine induced apoptosis and cell cycle arrest, and significantly reduced the invasion of MDA-MB-231 cells, mechanistically, the antibreast cancer effects of matrine may via the EGF/vascular endothelial growth factor (VEGF)/VEGFR1/AKT/NF-kB signaling pathway. Li et al ${ }^{19}$ verified that matrine inhibited MCF-7 cell growth in a concentration-and time-dependent manner, and upregulated phosphatase and tensin homolog (PTEN) by downregulating miR-21 which in turn dephosphorylated AKT, resulting in accumulation of Bcl-2 associated agonist of cell death (Bad), Cyclin dependent kinase inhibitor 1A (p21, Cip1) and Cyclin dependent kinase inhibitor 1B (p27, Kip1), revealing that miR-21/PTEN/AKT pathway is a signaling mechanism for the anti-breast cancer action of matrine.

Studies have evaluated the therapeutic effects of matrine on hepatocellular carcinoma (HCC). Wang et $\mathrm{al}^{20}$ investigated the effects and related mechanisms of matrine in hepatoma HepG2 and Bel7402 cells and showed that both autophagy and apoptosis were induced by treatment with matrine. They also found that autophagy was induced via inhibition of the PI3K/AKT/mTOR pathway and upregulation of Beclin-1. In addition, apoptosis induced by matrine was enhanced in a caspase-dependent manner via treatment with the autophagy inhibitor chloroquine (CHQ) and Beclin-1 small-interfering RNA. These results indicated that inhibition of autophagy may promote matrine-induced apoptosis in

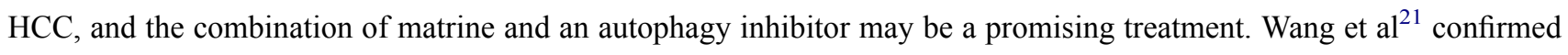
the inhibitory function of matrine on the invasive and metastatic capabilities of HCC. Additionally, increased epithelial (E)-cadherin expression and decreased Vimentin, MMP-2, MMP-9, snail family transcriptional repressor (Snai)-1, and Snai-2 expression induced by matrine are attributed to enhanced PTEN activity and inhibited AKT signaling. This may contribute to the inhibitory effects of matrine on invasion and metastasis in HCC, revealing the potential therapeutic application of matrine as an anti-metastatic treatment for HCC.

Chi et $\mathrm{al}^{22}$ explored the anti-tumor effects of matrine in glioma cells and confirmed that matrine suppressed cell viability and induced apoptosis and autophagy, decreased the expression of circular RNA (circRNA)-104075 and Bcl-9, while overexpression of circRNA-104075 or Bcl-9 counteracted the effects of matrine and activated the PI3K/AKT and $\mathrm{Wnt} / \beta$-catenin signaling pathways inhibited by matrine. This study indicated that matrine down-regulated the expression of circ-104075 and Bcl-9 via inhibition of the PI3K/AKT and Wnt/ $\beta$-catenin pathways to induce apoptosis and autophagy in glioma cells, providing a potential candidate drug for the treatment of glioma. Wang et $\mathrm{al}^{23}$ treated human glioma U251 and U87 cell lines with matrine, and found that matrine significantly inhibited the proliferation, migration and invasion of glioma cells, and decreased the phosphorylation of mitogen-activated protein kinase 14 (p38 MAPK) and AKT, as well as the expression of N-cadherin, increased the expression of E-cadherin, suggesting that matrine play an anti-tumor metastasis role by inhibiting the p38-MAPK and AKT signaling. Zhou et $\mathrm{al}^{24}$ showed that matrine treatment effectively suppressed the proliferation of glioblastoma cells by inducing cellular senescence, inhibited the growth of orthotopic xenografts and prolonged the overall survival of mice, and decreased the expression of insulin like growth factor 1 (IGF1), PI3K, and phosphorylated (p-)AKT. This study suggested that matrine may inhibit cell growth by inhibiting the IGF1/PI3K/AKT signaling pathway, providing a potential treatment for glioblastoma. Shen et al ${ }^{25}$ found that matrine obviously inhibited neuroblastoma cells proliferation, induced G2/M cell cycle arrest, and suppressed cell migration by upregulating the expression of tribbles pseudokinase 3 (TRB3) and thereby blocking the activation of the PI3K/AKT pathway, indicating the potential therapeutic effects of matrine on neuroblastoma.

Several studies have explored the therapeutic effects of matrine on leukemia. Wu et $\mathrm{al}^{26}$ demonstrated that matrine inhibited the growth acute myelocytic leukemia (AML) cells by inducing apoptosis and autophagy both in vitro and in vivo. They also found that matrine inhibited the phosphorylation of AKT, mTOR and downstream substrates ribosomal protein S6 kinase B1 (p70S6K) and eukaryotic translation initiation factor 4E binding protein 1 (4EBP1), suggesting that matrine exerts anti-tumor effects through the AKT/mTOR pathway. Hao et $\mathrm{al}^{27}$ revealed that matrine treatment inhibited the proliferation of AML THP-1 cells and induced apoptosis, and decreased the expression of p-PI3K, p-AKT, and p-mTOR in a concentration-dependent manner, indicating that the inhibition of PI3K/AKT/mTOR signaling pathway may be related to the anti-tumor effects of matrine. Zhang et $\mathrm{al}^{28}$ proved that matrine exerted excellent anti-leukemic effects, they found that matrine could inhibit cell viability and induce apoptosis of AML cells through mitochondria- 
mediated pathway and inhibition of the AKT and extracellular regulated protein kinases (ERK)1/2 pathways. Given these findings, matrine may serve as a promising candidate chemotherapeutic agent against AML.

Yang et $\mathrm{al}^{29}$ treated human $\mathrm{T} 24$ bladder cancer (BC) cells with matrine and found that matrine inhibited cell proliferation and invasion, decreased the p-PI3K and p-AKT expression in a dose-dependent manner, and subsequently increased the expression of cell cycle-inhibiting molecules cyclin dependent kinase inhibitor 2A (p16), p21 and p27, but decreased the expression of invasion genes MMP-2 and MMP-9, indicating that matrine could play an anti-bladder cancer role through the $\mathrm{PI} 3 \mathrm{~K} / \mathrm{AKT}$ signaling pathway. $\mathrm{Li}$ et $\mathrm{al}^{30}$ verified that matrine restrained tumor growth in vivo and inhibited $\mathrm{BC}$ cell proliferation, migration, invasion but promoted apoptosis via upregulation of long intergenic non-coding RNA (LINC) 00472/programmed cell death protein 4 (PDCD4) by blocking PTEN/PI3K/AKT pathways. Liao et al ${ }^{31}$ confirmed that $^{2}$ matrine combined with cisplatin has better anti-tumor effect by downregulating the VEGF/PI3K/AKT signaling pathway. They found that matrine and cisplatin combined treatment of urothelial bladder cancer (UBC) EJ and T24 cells, synergistically and significantly inhibited cell proliferation, migration and invasion, induced G1/S cell cycle arrest and apoptosis, and increased reactive oxygen species (ROS) levels, suggesting that matrine may be a potential option for combination therapy of UBC.

Peng et $\mathrm{al}^{32}$ examined the anti-tumor effect of matrine on gastric cancer (GC) cells and found that matrine significantly inhibited the proliferation and migration of SGC 7901 cells, downregulated the protein level of U-plasminogen activator (uPA) and the phosphorylation of ERK and AKT. Further studies showed that blocking the PI3K/AKT pathway with PI3K inhibitor LY294002 suppressed cell growth and uPA expression. This study indicates that matrine may inhibit GC cells by inactivating the PI3K/AKT/uPA signaling pathway, suggesting that matrine may be a potential drug for GC treatment. Li et $\mathrm{al}^{33}$ found that autophagy increased in a dose- and time-dependent manner in GC cells exposed to matrine, and inhibition of autophagy increased matrine-induced apoptosis; in addition, matrine treatment did not inhibit the phosphorylation of AKT and its downstream effectors mTOR and p70S6K, whereas the total levels of AKT and mTOR decreased. These results suggest that the AKT/mTOR/p70S6K signaling pathway may not be involved in matrine-induced autophagy in SGC-7901 cells, but inhibition of autophagy may be a promising strategy to enhance the anti-GC potential of matrine.

Bai et $\mathrm{al}^{34}$ demonstrated that matrine effectively inhibited the proliferation of prostate cancer PC-3 and RWPE1 cells, activated forkhead box O3 (FoxO3a), and then upregulated the expression of downstream target proteins Bcl-2 like 11 (Bim) and p27, leading to apoptosis and cell cycle arrest. Additionally, the expression of p-AKT and AKT were decreased after matrine treatment, resulting in the retention of FoxO3a, indicating that AKT and FoxO3a signaling pathways may be involved in matrine-mediated suppression of prostate cancer. Through high-throughput sequencing analysis, Li et al ${ }^{35}$ found that matrine exhibited extensive regulatory effects on the mRNA expression profile of PC-3 and DU145 cells, and differentially expressed genes played important roles in cell metabolism, growth, anatomical structure formation, cell component organization and biological regulation; besides, the forkhead box sub-group O (FOXO) and PI3K/AKT signaling pathways showed significant differences. They further found that matrine treatment obviously inhibited the proliferation, migration and invasion but promoted apoptosis of PC-3 and DU145 cells through FOXO and PI3K/AKT signaling pathways, suggesting that matrine may be used as a complementary agent for prostate cancer chemotherapy.

The antitumor activity of matrine in colon cancer has been testified, but the latent mechanism is still indistinct. Zhang et al ${ }^{36}$ treated colon cancer LoVo cells with matrine and found that matrine inhibited cell proliferation in a dose- and time-dependent manner, induced cell cycle arrest in G1 phase and apoptosis, and significantly reduced AKT phosphorylation; further studies showed that specific inhibition of p-AKT induced cell apoptosis and synergistically inhibited LoVo cell proliferation with matrine, while activation of AKT counteracted the inhibitory effect of matrine on cell proliferation. This study suggests that matrine exerts an anti-colon cancer effect by inhibiting the AKT signaling pathway, and may serve as a potential treatment for colon cancer.

Among gynecological cancers, ovarian cancer displays the highest mortality rate and a poor response to anticancer therapy. Therefore, Zhang et $\mathrm{al}^{37}$ used epithelial ovarian cancer cells A2780, SKOV3, and cisplatin-resistant cells A2780/ DDP to test the therapeutic effect of matrine, and found that matrine retarded cancer-related signaling transduction by reducing the phosphorylation levels of ERK1/2, mitogen-activated extracellular signal-regulated kinase (MEK)1/2, PI3K, 
AKT, mTOR, Focal adhesion kinase (FAK), Ras homolog family member A (RhoA), VEGFR2, and TEK receptor tyrosine kinase (Tie2) in vitro and in vivo, and then modulated cell proliferation, apoptosis, and autophagy to inhibit the occurrence and progression of ovarian cancer, indicating that matrine, as a natural agent, is expected to be a targeted drug against ovarian cancer with the potential to overcome chemotherapy resistance and reduce toxic side effects.

Jin et $\mathrm{al}^{38}$ evaluated the anti-tumor potential of matrine in V600EBRAF harboring melanoma M21 cells and found that matrine effectively inhibited cell proliferation, induced cell cycle arrest at G0/G1 phase and apoptosis in a dosedependently manner; mechanistically, matrine inhibited the PI3K/AKT pathway by activating PTEN, ultimately leading to upregulation of P21 and Bax in M21 cells. These findings suggest that activation of PTEN holds promise as a practicable strategy for melanoma treatment, and matrine may serve as a potent drug candidate.

$\mathrm{Xu}$ et $\mathrm{al}^{39}$ found that matrine inhibited the proliferation, induced apoptosis and $\mathrm{G} 0 / \mathrm{G} 1$ phase cell cycle arrest of human osteosarcoma (OS) MG63, U2OS, and SAOS2 cell lines in a dose-dependent manner in vitro, and was associated with increased expression of p27/Kip1 and the pro-apoptotic factor Bax and decreased expression of AKT, glycogen synthase kinase 3 (GSK3)- $\beta$ (Ser9), and cyclin D1, indicating that matrine may be an effective anti-OS drug due to cell growth inhibitory effect possibly through modulation of the AKT signaling. Yu et al ${ }^{40}$ investigated the effects and molecular mechanisms of matrine, arsenic trioxide, and their combination on myeloma RPMI8226 and U266 cell lines, and demonstrated that matrine and arsenic trioxide significantly inhibited proliferation and promoted apoptosis of myeloma cells, and synergistic effects produced when the two were combined; mechanistically, by activating caspase3 and poly ADP-ribose polymerase (PARP), up-regulating the expression of Bim, down-regulating the expression of Bcl2 and survivin, and inhibiting p-AKT, matrine-mediated apoptosis was promoted.

Zhao et $\mathrm{al}^{41}$ and Li et $\mathrm{al}^{42}$ found that treatment of different subtypes of thyroid cancer cells with matrine inhibited cell proliferation, induced apoptosis and G1 phase cell cycle arrest, and downregulated miR-21 and p-AKT expression, but up-regulate PTEN expression, indicating that the miR-21/PTEN/AKT pathway may be one of the mechanisms of matrine-induced growth inhibition of thyroid cancer cells, and miR-21 is expected to be a potential target of matrine for the treatment of follicular thyroid carcinoma.

Matrine also has potential therapeutic effects on benign tumors. Li et al ${ }^{43}$ demonstrated that matrine inhibited the cell viability of pituitary tumor RC-4B/C cells and GH3 cells, decreased the levels of AKT and Foxo3a, increased the nuclear localization of Foxo3a and the expression of apoptosis-related gene Bcl-2, and inhibited the level of cytoplasmic Foxo3a, indicating that matrine inhibits the proliferation of pituitary tumor cells may be related to the AKT/Foxo3a signaling pathway.

In addition to anti-tumor activity, matrine exhibits protective effects in vascular injury, cardiopathy, immune system diseases, and the inflammatory reaction. $\mathrm{Xu}$ et $\mathrm{al}^{44}$ showed that matrine enhanced viability, inhibited apoptosis, and alleviated oxidative stress in $\mathrm{H}_{2} \mathrm{O}_{2}$-induced $\mathrm{H} 9 \mathrm{c} 2$ cardiomyocytes. They also confirmed that matrine modulated $\mathrm{H}_{2} \mathrm{O}_{2}$ induced myocardial oxidative stress repair through the HOX transcript antisense RNA (HOTAIR)/miR-106b-5p axis via the AKT and STAT3 signaling pathways, providing a potential therapeutic target for oxidative stress-associated heart diseases. Zhang et $\mathrm{al}^{45}$ demonstrated that matrine effectively improved lipid metabolism, inflammation, and vascular wall thickness in mice fed a high-fat diet, reduced the phosphorylation of nitric oxide synthase 3 (ENOS)-Thr497, and increased the phosphorylation of ENOS-S1177, thereby resulted in an increase in NO production, which is mediated by $\mathrm{PI} 3 \mathrm{~K} / \mathrm{AKT}$ and protein kinase C Alpha ( $\mathrm{PKC} \alpha$ ), revealing the molecular mechanism underlying the protective effect of matrine in high-fat diet-induced vascular disease. Ma et $\mathrm{al}^{46}$ pre-treated human coronary smooth muscle cells (HCSMCs) with matrine and then exposed them to advanced glycation end products (AGEs). They found that matrine pre-treatment significantly reduced collagen content, increased smooth muscle myosin heavy chain 11 (MYH11) and DNA polymerase delta interacting protein 2 (Poldip2) expression, decreased the expressions of collagen I, $\beta 1$-integrin, PI3K and nuclear p-p70S6k, and reduced the phosphorylation of AKT and mTOR in HCSMCs exposed to AGEs. These results indicate that matrine inhibits AGEs-induced contraction synthesis phenotypic transformation and the fibrosis response by regulating the Poldip2/mTOR signaling pathway. Liu et $\mathrm{al}^{47}$ showed that matrine pre-treatment partially alleviated subarachnoid hemorrhage (SAH)-induced early brain injury (EBI) in rats, inhibited apoptosis and reduced increased levels of the inflammatory cytokines tumor necrosis factor alpha (TNF- $\alpha$ ) and interleukin (IL)-1 $\beta$. This study also found

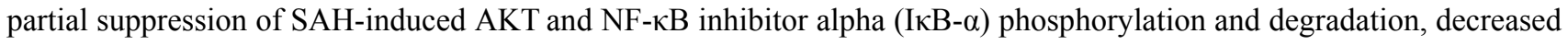


NF- $\mathrm{KB}$ p65 protein levels, and upregulated expression of Kelch like ECH associated protein 1 (Keap1), nuclear factor erythroid 2-related factor 2 (Nrf2), and Heme oxygenase 1 (HO-1). Mechanistically, matrine may alleviate EBI after experimental SAH in rats possibly via PI3K/AKT-mediated NF- $\mathrm{BB}$ inhibition and Keap1/Nrf2-dependent HO-1 induction.

Matrine has been approved for the prevention and therapy of cancer cachexia, such as skeletal muscle atrophy, which is associated with poor prognosis and suboptimal responses. Chen et $\mathrm{al}^{48}$ evaluated the mechanism of matrine on skeletal muscle atrophy and found that matrine increased muscle fiber size and muscle mass in a CT26 colon adenocarcinoma cachexia mouse model, and significantly improved the differentiation of $\mathrm{C} 2 \mathrm{C} 12$ myoblasts, reduced $\mathrm{C} 2 \mathrm{C} 12$ myotube atrophy and apoptosis, down-regulated the levels of specifically expressed E3 ubiquitin ligases muscle-specific ring finger protein 1 (MuRF1) and muscle atrophy F-box protein (MAFbx) in skeletal muscle, and increased the phosphorylation of AKT, mTOR and FoxO3 $\alpha$ in atrophic $\mathrm{C} 2 \mathrm{C} 12$ myotube, indicating that matrine may alleviate muscle atrophy and improve myoblast differentiation by inhibiting E3 ubiquitin ligases and activating the AKT/mTOR/FoxO3a signaling pathway.

Matrine has been reported to be beneficial in experimental autoimmune encephalomyelitis (EAE) mainly through its anti-inflammatory effect, but the underlying mechanism is unclear. Liu et $\mathrm{al}^{49}$ induced EAE in C57BL/6 mice and found that matrine treatment effectively inhibited the severity of EAE, increased the expression of protein lipoprotein, a marker protein of CNS myelin, significantly increased the number of mature oligodendrocytes, and activated the PI3K/AKT/ mTOR signaling pathway to promote oligodendrocyte differentiation and myelination, thereby protecting myelin from CNS inflammation-induced damage. Chen et $\mathrm{al}^{50}$ showed that matrine significantly prevented ovariectomy-induced bone loss and inhibited osteoclastogenesis in vivo with decreased serum levels of tartrate-resistant acid phosphatase 5 (TRAcp5b), TNF- $\alpha$, and IL-6, and significantly inhibited osteoclast differentiation in bone marrow monocytes and RAW264.7 cells. Mechanistically, matrine blocked receptor activator for NF- $\mathrm{kB}$ ligand (RANKL)-induced activation of NF- $\mathrm{KB}, \mathrm{AKT}$, and MAPK pathways, and inhibited the expression of osteoclastogenesis-related markers, including MMP9, nuclear factor of activated T cells 1 (NFATc1), tartrate-resistant acid phosphatase (TRAP), proto-oncogene tyrosineprotein kinase Src (c-Src), and cathepsin $\mathrm{K}$, suggesting that matrine inhibits osteoclastogenesis by regulating multiple signaling pathways and may serve as a promising agent for the treatment of osteoclast-related diseases such as osteoporosis.

In addition to the biological activities mentioned above, recent studies have also shown that matrine exhibits antidepressant effects. Wu et al ${ }^{51}$ found that matrine exhibited significant antidepressant effects in a mouse model of depression induced by forced swim test and tail suspension test, completely reversed the mild depression-like symptoms caused by chronic unpredictable stress. Further, they demonstrated that matrine treatment restored the attenuating effects of these stresses on $\mathrm{PI} 3 \mathrm{~K} / \mathrm{AKT} / \mathrm{mTOR}$ signaling pathway in the hippocampus, thereby exerting antidepressant-like effects. This study sheds light on the development of novel antidepressants with better efficacy and fewer side effects and further extends the understanding of the pharmacological effects of matrine.

Although natural matrine alkaloids have significant pharmacological activities, their shortcomings such as low bioavailability, poor activity, large dosage, and strong side effects restrict their wide application. Therefore, the structural modification of matrine alkaloids to develop derivative compounds with higher activity is a valuable research direction. For instance, Feng et $\mathrm{al}^{52}$ reported a more effective thio-derivative of matrine (MD-1) and showed that it more effectively inhibited the proliferation and migration of hepatic stellate cells (HSCs) -T6 cells and induced cell cycle G0/G1 phase arrest and apoptosis to a greater extent than matrine. Further, they found that MD-1 bound to the EGFR on the surface of HSC-T6 cells, further inhibiting the phosphorylation of EGFR and its downstream target AKT, resulting in decreased expression of cyclin D1 and eventual inhibition of the activation of HSC-T6 cells, thus exhibiting an anti-hepatic fibrosis role. Moreover, in rats with dimethylnitrosamine (DMN)-induced hepatic fibrosis, MD-1 delayed the development and progression of hepatic fibrosis, protected hepatic parenchymal cells, and improved hepatic functions, suggesting that it may serve as a potential anti-hepatic fibrosis drug. Sun et $\mathrm{al}^{53}$ obtained the novel derivative WM622 (C26H35ON3S2) after structural modification of matrine, which had better biological activity and a greater inhibitory effect on transplanted tumors in vivo than matrine. WM622 also significantly inhibited the proliferation and promoted apoptosis of HCC cells, induce G0/G1 cell cycle arrest, and dose-dependently decreased the phosphorylation levels of EGFR, AKT, PI3K, and 
GSK3 3 . These results indicate that WM622 can inhibit the proliferation of the HCC both in vivo and in vitro by inducing apoptosis, blocking cell cycle in the G0/G1 phase, and inhibiting the PI3K/AKT signal pathway.

Qian et $\mathrm{al}^{54}$ modified the structure of matrine and obtained a novel derivative WM130 (C30N4H40SO5F) with pharmacological activity superior to matrine. They found that WM130 significantly inhibited the proliferation, invasion and migration, induced apoptosis of HCC cells, and inhibited Huh-7 xenograft tumors growth in a dose-dependent manner. Furthermore, the expressions of p-EGFR, p-ERK, p-AKT, MMP-2, Ki67, and Bcl-2/Bax were down-regulated, while the expression of PTEN was up-regulated in HCC after WM130 treatment. It is concluded that WM130 inhibits HCC by suppressing EGFR/ERK/MMP-2 and PTEN/AKT signaling pathways. Zou et al ${ }^{55}$ evaluated the anticancer properties of MASM ([(6aS, 10S, 11aR, 11bR, 11cS) 210-Methylamino-dodecahydro-3a, 7a-diaza-benzo (de) anthracene-8-thione]), a potent matrine derivative, on A549 (non-small-cell lung cancer cell line), MCF-7 and MDA-MB-231 (breast cancer cell lines), and Hela (cervical cancer cell line), and found that MASM induced apoptosis and autophagy in all cancer lines and possessed higher pharmaceutical potency than matrine, but removal of ROS with N-acetylcysteine rescued tumor cells from apoptosis and autophagy. In addition, the inhibition of autophagy can further enhance MASMinduced apoptosis through ROS-mediated PI3K/AKT/mTOR, ERK and p38 signaling pathways, suggesting that modulating autophagy during MASM administration may further enhance its therapeutic effects. Wu et $\mathrm{al}^{56}$ found that matrine derivative 5I bearing benzo- $\alpha$-pyranone structure effectively inhibited the proliferation of lung cancer cells in vivo and in vitro without obvious side effects. In addition, compound 5I induced G1 cell cycle arrest and autophagy in lung cancer cells through up-regulating P27, down-regulating cyclin dependent kinase 4 (CDK4) and Cyclin D1 (CCND1) and attenuating PI3K/Akt/mTOR pathway, and suppression of autophagy significantly attenuated the inhibitory effect of 5I on cell proliferation; thus providing a potential paradigm for exploiting the anticancer properties of 5I.

Sophora flavescens alkaloid (SFA) gels, a compound Traditional Chinese Medicine, its effective ingredients mainly include matrine and oxymatrine. Zhou et $\mathrm{al}^{57}$ proved that SFA gels can inhibit the proliferation and metastasis of cervical cancer cells, induce cell cycle arrest in G2/M phase and apoptosis; further they showed that SFA gels may exert anticervical cancer effects by suppressing the AKT/mTOR signaling pathway. The results suggest that SFA gels may be a potential anti-tumor therapeutic agent for the treatment of cervical cancer.

Xie et $\mathrm{al}^{58}$ treated nasopharyngeal carcinoma cell lines (CNE1, CNE2, and HONE1) with 14-thienyl methylene matrine (YYJ18) and demonstrated that YYJ18 significantly inhibited proliferation and induced apoptosis of these three cell lines in a dose-dependent manner; further, YYJ18 treatment significantly suppressed the phosphorylation of p38, but upregulated the phosphorylation of ERK1/2 and AKT, activated the downstream signaling Bax, caspase-3, and inhibited the activity of Bcl-2, confirming that the inhibitory effect of YYJ18 on nasopharyngeal carcinoma cells may be related to the modulation of MAPK and PI3K/AKT signaling pathways.

Postmenopausal osteoporosis (POMP) is a metabolic bone disorder characterized by decreased bone density, microarchitectural deterioration of bone tissue, and over-activated osteoclastogenesis. Chen et al ${ }^{59}$ developed a novel matrine derivative MASM (M19) based on sophocarpine, which significantly inhibited RANKL/macrophage colony stimulating factor (M-CSF) induced osteoclastogenesis through suppressing NF- $\mathrm{KB}$, MAPKs, and PI3K/AKT pathways in vitro and ameliorated bone loss in ovariectomized mice in vivo, and confirmed that M19 targeted and stabilized ribosomal protein S5 (RPS5), while overexpressing of RPS5 synergized with M19 significantly inhibited osteoclastogenesis. These results indicated that RPS5 may be a potential candidate target for inhibiting osteoclastogenesis and treating osteoporosis, and M19 is a promising drug for the treatment of POMP. Xin et al ${ }^{60}$ found that M54, a bioactive derivative of matrine, can also target RPS5 and inhibit osteoclastogenesis through a mechanism similar to that of M19, which may also serve as a potential clinical drug for treating POMP. The above results suggest that matrine derivatives indeed have more efficient and less toxic biological activities, and are more likely to be valuable drug candidates for the therapy of various diseases.

We have summarized the relevant studies on the pharmacological effects of matrine through the PI $3 \mathrm{~K} / \mathrm{AKT} / \mathrm{mTOR}$ signaling pathway in Table 1 . 
Table I The Relevant Studies on the Pharmacological Effects of Matrine Through the PI3K/AKT/mTOR Signaling Pathway

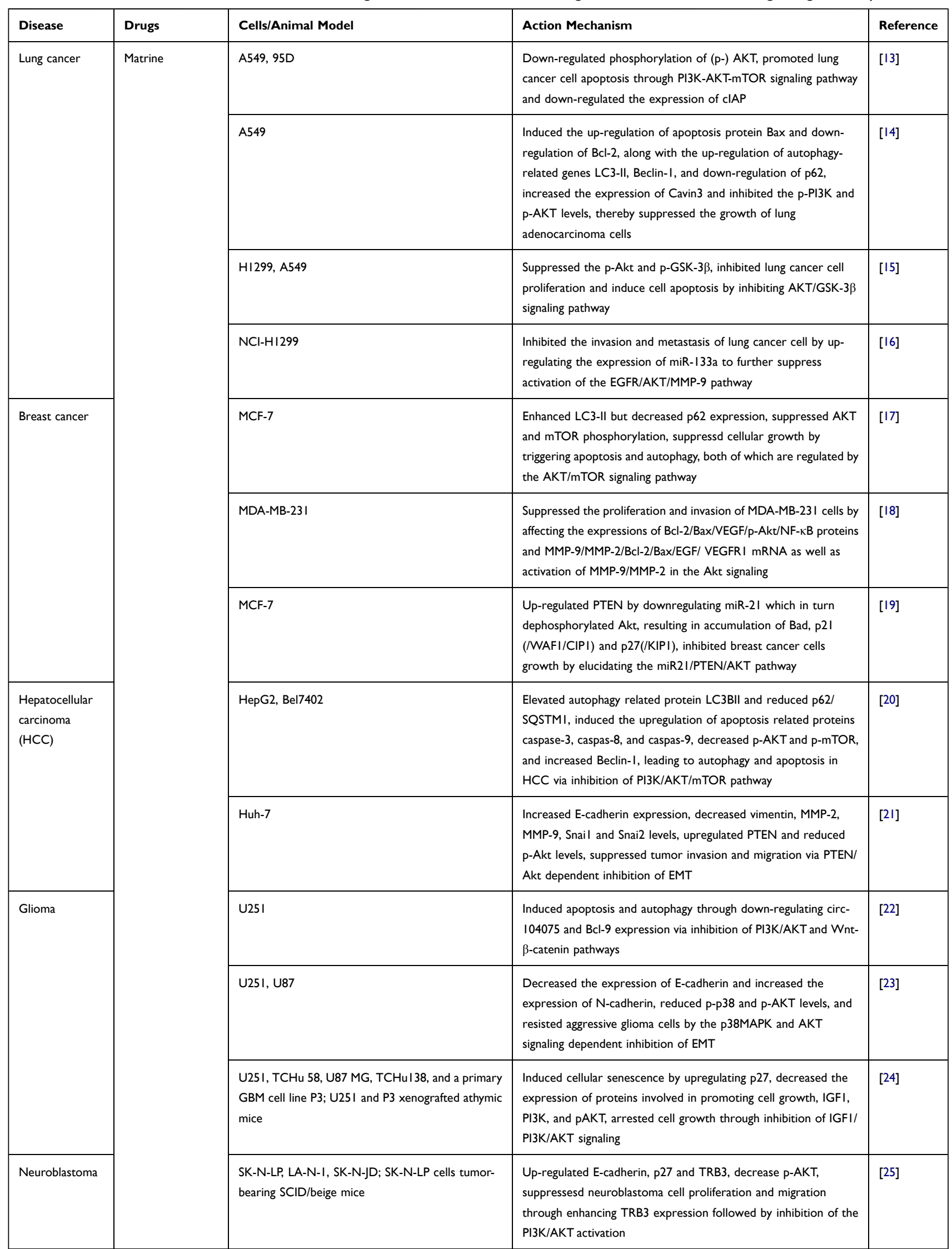


Table I (Continued).

\begin{tabular}{|c|c|c|c|c|}
\hline Disease & Drugs & Cells/Animal Model & Action Mechanism & Reference \\
\hline \multirow[t]{3}{*}{$\begin{array}{l}\text { Acute } \\
\text { Myelocytic } \\
\text { Leukaemia } \\
\text { (AML) }\end{array}$} & & $\begin{array}{l}\text { HL- } 60, \text { THP-I, CI } 498 \text { and primary AML cells; } \\
\text { CI } 498 \text { cell tumor-bearing C57BL/6 mice }\end{array}$ & $\begin{array}{l}\text { Up-regulated the levels of caspase-3, PARP, LC3-II, down- } \\
\text { regulated the levels of SQSTMI/p62, and inhibited the p-AKT, } \\
\text { p-mTOR and their downstream substrates p70S6K and 4EBPI, } \\
\text { leading to the occurrence of autophagy and exerting the anti- } \\
\text { tumor effect through the AKT/mTOR signaling pathway }\end{array}$ & [26] \\
\hline & & THP-I & $\begin{array}{l}\text { Reduced the expression of } \mathrm{p}-\mathrm{PI} 3 \mathrm{~K}, \mathrm{p}-\mathrm{AKT} \text { and } \mathrm{p}-\mathrm{mTOR} \text {, inhibited } \\
\text { the proliferation of leukemia cells and induce apoptosis through } \\
\text { the PI3K/AKT/mTOR signaling pathway }\end{array}$ & [27] \\
\hline & & $\begin{array}{l}\text { HL-60, U937, NB4 and primary human bone } \\
\text { marrow mononuclear cells; HL-60 xenografted } \\
\text { SCID mice }\end{array}$ & $\begin{array}{l}\text { Induced apoptosis by collapsing the mitochondrial membrane } \\
\text { potential, inducing cytochrome c release from mitochondria, } \\
\text { reducing the ratio of Bcl-2/Bax, increasing activation of caspase-3, } \\
\text { and decreasing the levels of p-Akt and p-ERKI/2 }\end{array}$ & [28] \\
\hline \multirow[t]{2}{*}{$\begin{array}{l}\text { Bladder cancer } \\
\text { (BC) }\end{array}$} & & T24 & $\begin{array}{l}\text { Downregulated the expression of } \mathrm{p}-\mathrm{P} 13 \mathrm{~K}, \mathrm{p}-\mathrm{AKT}, \mathrm{MMP}-2 \text { and } \\
\text { MMP-9, and upregulated the expression of } \mathrm{p} 16, \mathrm{p} 2 \mathrm{I} \text { and } \mathrm{p} 27 \text {, } \\
\text { regulated the expression of cell cycle and invasion-related genes } \\
\text { through the PI3K/AKT signaling pathway thus to inhibit bladder } \\
\text { cancer cell proliferation and invasion }\end{array}$ & [29] \\
\hline & & $\begin{array}{l}\text { T24/5637, SV-Huc-I; T24 cells xenograft BALB/c } \\
\text { nude mice }\end{array}$ & $\begin{array}{l}\text { Enhanced PDCD4 expression by up-regulating LINC00472, } \\
\text { elevated PTEN expression but decreased the ratio of p/t-PI3K/ } \\
\text { AKT, thereby restrained BC cells growth, invasion and migration } \\
\text { by up-regulating LINC00472/PDCD4 via restraining PTEN/PI3K/ } \\
\text { AKT pathways }\end{array}$ & [30] \\
\hline $\begin{array}{l}\text { Urothelial } \\
\text { bladder cancer }\end{array}$ & $\begin{array}{l}\text { Matrine combined } \\
\text { with cisplatin }\end{array}$ & EJ, T24 & $\begin{array}{l}\text { Up-regulated the expressions of E-cadherin, } \beta \text {-catenin, Bax, and } \\
\text { Caspase-3, down-regulated the expressions of Fibronectin, } \\
\text { Vimentin, Bcl-2, p-AKT, p-PI3K, VEGFR2, and VEGF, matrine } \\
\text { combined with cisplatin synergistically inhibited the proliferation } \\
\text { of urothelial bladder cancer cells via down-regulating the VEGF/ } \\
\text { PI3K/AKT signaling pathway }\end{array}$ & [3। $]$ \\
\hline \multirow[t]{2}{*}{ Gastric cancer } & \multirow[t]{5}{*}{ Matrine } & SGC790I & $\begin{array}{l}\text { Reduced uPA, p-PI3K, p-AKT, p-ERK proteins, inhibited the } \\
\text { proliferation and metastasis of gastric cancer cells through the } \\
\text { PI3K/AKT/uPA pathway }\end{array}$ & [32] \\
\hline & & SGC790I & $\begin{array}{l}\text { Does not inhibit p-AKT and its downstream effectors p-mTOR } \\
\text { and p-p70S6K, while the total level of AKT and mTOR is reduced. } \\
\text { AKT/mTOR/p70S6K signaling pathway may not participate in the } \\
\text { autophagy of SGC-790I cells }\end{array}$ & [33] \\
\hline \multirow[t]{2}{*}{ Prostate cancer } & & PC-3, RWPEI & $\begin{array}{l}\text { Decreased the levels of } \mathrm{p} \text {-FoxO3a, induced the increased } \\
\text { expression of downstream target proteins Bim and P27, down- } \\
\text { regulated p-AKT, increased levels of Bax and decreased levels of } \\
\text { Bcl-2, and participate in matrine-mediated prostate cancer } \\
\text { suppression by targeting the Akt/FoxO3a signaling pathway }\end{array}$ & [34] \\
\hline & & DUI45, PC3 & $\begin{array}{l}\text { Increased the expression levels of FOXOIA, FOXO3A, FOXO4 } \\
\text { and FOXO6, decreased the expression levels of PI3K, inhibitd the } \\
\text { proliferation, migration, as well as invasion of of prostate cancer } \\
\text { cells through the FOXO and PI3K-AKT signaling pathways }\end{array}$ & [35] \\
\hline Colon cancer & & LoVo & $\begin{array}{l}\text { Reduced the protein levels of p-Akt, and increased the protein } \\
\text { levels of other downstream factors, p-Bad and p-GSK- } 3 \beta \text {, } \\
\text { suppressed the colon cancer cells growth by inactivating the Akt } \\
\text { pathway }\end{array}$ & [36] \\
\hline
\end{tabular}

(Continued) 
Table I (Continued).

\begin{tabular}{|c|c|c|c|c|}
\hline Disease & Drugs & Cells/Animal Model & Action Mechanism & Reference \\
\hline Ovarian cancer & & $\begin{array}{l}\text { A2780, SKOV3, A2780/DDP; A2780 and A2780/ } \\
\text { DDP xenograft BALB/c nude mice model }\end{array}$ & $\begin{array}{l}\text { Retarded the cancer associated signaling transduction by } \\
\text { decreasing the phosphorylation levels of ERKI/2, MEKI/2, PI3K, } \\
\text { Akt, mTOR, FAK, RhOA, VEGFR2, and Tie2, showed excellent } \\
\text { antitumor effect }\end{array}$ & [37] \\
\hline Melanomas & & MCF-7, MDB-MA-23I, HCT-II6, M2I, A375 & $\begin{array}{l}\text { Upregulated the expression level of PTEN, leading to } \\
\text { downregulation of p-Akt and p-PI3K, and activated p2I and Bax, } \\
\text { induced growth inhibition and apoptosis in V600EBRAF harboring } \\
\text { melanoma cells }\end{array}$ & [38] \\
\hline Sarcoosteoma & & MG63, HOS, U2OS, SAOS2 & $\begin{array}{l}\text { Increased the expression of } \mathrm{p} 27 / \mathrm{Kipl} \text { and Bax, decreased } \mathrm{p}-\mathrm{AKT} \text {, } \\
\text { GSK3- } \beta \text { and cyclin DI, inhibited the proliferation and apoptosis of } \\
\text { sarcoma cells by inactivating the Akt pathway }\end{array}$ & [39] \\
\hline Myeloma & $\begin{array}{l}\text { Matrine and } \\
\text { arsenic trioxide }\end{array}$ & RPMI8226, U266 & $\begin{array}{l}\text { Induced apoptosis via the activation of caspase- } 3 \text { and PARP, } \\
\text { upregulation of Bim, downregulation of Bcl- } 2 \text { and survivin, and } \\
\text { inhibition of p-AKT, and combined with arsenic trioxide enhanced } \\
\text { the anticancer effects }\end{array}$ & [40] \\
\hline \multirow[t]{2}{*}{ Thyroid cancer } & \multirow[t]{8}{*}{ Matrine } & TPC-1 & $\begin{array}{l}\text { Downregulated the expression of miR-2I, increased levels of the } \\
\text { miR-2I target PTEN and decreased the levels of p-Akt, inhibited } \\
\text { thyroid cancer cells through miR-2I/PTEN/Akt pathway }\end{array}$ & 4I] \\
\hline & & FTC-133 & $\begin{array}{l}\text { Downregulated the expression of miR-2I is, upregulated the } \\
\text { expression of PTEN and decreased p-AKT levels, suppressed the } \\
\text { growth and induced apoptosis of FTC-133 cells via the miR-2I/ } \\
\text { PTEN/Akt signaling pathway. }\end{array}$ & [42] \\
\hline Pituitary tumor & & RC-4B/C, GH3, AtT 20 & $\begin{array}{l}\text { Decreased the p-AKT and p-Foxo3a, increased the nuclear } \\
\text { localization of Foxo3a and the expression of proapoptotic genes, } \\
\text { and inhibited the levels of cytoplasmic Foxo3a, promoted cell } \\
\text { death of pituitary cancer cells via Akt/Foxo3a signaling pathway }\end{array}$ & [43] \\
\hline $\begin{array}{l}\text { Oxidative stress } \\
\text { in heart disease }\end{array}$ & & $\mathrm{H} 9 \mathrm{C} 2$ & $\begin{array}{l}\text { Up-regulated the expression of HOTAIR, decreased the direct } \\
\text { target of HOTAIR, miR-106b-5p expression, promoted the } \\
\text { expression of p-AKT and pSTAT3/STAT3 ratio, alleviated cardiac } \\
\text { myocytes oxidative stress damage through HOTAIR/miR-106b-5p } \\
\text { network via AKT and STAT3 pathway in H2O2-induced cell model }\end{array}$ & [44] \\
\hline $\begin{array}{l}\text { Cardiovascular } \\
\text { disease }\end{array}$ & & HUVECs; High-fat diet mouse model & $\begin{array}{l}\text { Alleviated ox-LDL-stimulated dysfunction of HUVECs, decreased } \\
\text { ROS generation and increased p-AKT, p-eNOS-Ser I I77, but } \\
\text { down-regulated p-eNOS-Thr495, influenced eNOS/NO via PKC } \alpha \\
\text { inhibition, played a protective role in high-fat diet-induced vascular } \\
\text { diseases by mediating the PI3K/AKT pathway }\end{array}$ & [45] \\
\hline $\begin{array}{l}\text { Atherosclerotic } \\
\text { vascular disease }\end{array}$ & & HCSMCs & $\begin{array}{l}\text { Reduced collagen content, increased smooth muscle MYHII and } \\
\text { Poldip2 expression, decreased expressions of collagen I, } \beta \mathrm{I}- \\
\text { integrin, PI3K and nuclear p-p70S6k, and reduced p-Akt and } \\
\text { p-mTOR levels, suppressed AGEs-induced fibrosis of HCSMC by } \\
\text { regulating the Poldip2/mTOR signaling pathway }\end{array}$ & [46] \\
\hline $\begin{array}{l}\text { Subarachnoid } \\
\text { hemorrhage } \\
(\mathrm{SAH})\end{array}$ & & SAH SD rat model & $\begin{array}{l}\text { Alleviated SAH-induced neural cell apoptosis, reduced the } \\
\text { increased levels of inflammatory cytokines TNF- } \alpha \text { and IL-I } \beta \text {, } \\
\text { suppressed p-Akt, p-lkB- } \alpha \text { and NF-kB P65 protein levels, enhanced } \\
\text { the expression of KeapI, Nrf2, and HO-I proteins, alleviated early } \\
\text { brain injury after SAH via PI3K/Akt-mediated NF-kB inhibition and } \\
\text { Keap I/Nrf2-dependent HO-I induction }\end{array}$ & [47] \\
\hline Muscle atrophy & & $\begin{array}{l}\mathrm{C} 2 \mathrm{Cl} 2 \text {, } \mathrm{CT} 26 \text {; } \mathrm{CT} 26 \text { cell tumor-bearing mouse } \\
\text { model }\end{array}$ & $\begin{array}{l}\text { Downregulated MAFbx and MuRFI proteins, increased p-AKT, } \\
\text { p-mTOR and p-FOXO3 } \alpha \text {, activated the AKT/mTor/FOXO3 } \alpha \\
\text { signaling pathway by inhibiting E3 ubiquitin ligase, thus alleviated } \\
\text { muscle atrophy and improved myoblast differentiation }\end{array}$ & [48] \\
\hline
\end{tabular}


Table I (Continued).

\begin{tabular}{|c|c|c|c|c|}
\hline Disease & Drugs & Cells/Animal Model & Action Mechanism & Reference \\
\hline $\begin{array}{l}\text { Multiple } \\
\text { sclerosis }\end{array}$ & & EAE C57BL/6 mice model & $\begin{array}{l}\text { Increased the expression of proteolipid protein, up-regulated } \\
\mathrm{p}-\mathrm{PI} 3 \mathrm{~K} \text {, p-MTOR, and p-p } 70 \text { S6K expression, and play a beneficial } \\
\text { effect on oligodendrocyte differentiation and myelination by } \\
\text { activating the PI3K/AKT/mTOR signaling pathway }\end{array}$ & [49] \\
\hline Osteoporosis & & $\begin{array}{l}\text { Bone marrow mononuclear cells (BMMS), } \\
\text { AW264.7; Ovariectomized C57BL/6 mice }\end{array}$ & $\begin{array}{l}\text { Inhibited osteoclast differentiation induced by receptor activator } \\
\text { for NF- } \mathrm{B} \text { B ligand (RANKL) and M-CSF, abrogated RANKL-induced } \\
\text { activation of NF- } \mathrm{B} B, A K T \text {, and MAPK pathways and suppressed } \\
\text { osteoclastogenesis-related marker expression, inhibited } \\
\text { osteoclastogenesis through modulation of multiple pathways }\end{array}$ & {$[50]$} \\
\hline Depression & & $\begin{array}{l}\text { Forced swimming test (FST), tail suspension test } \\
\text { (TST), and chronic unpredictable mild stress } \\
\text { (CUMS) model of depression in C57BL/6] mice }\end{array}$ & $\begin{array}{l}\text { Reversed the decreased p-AKT, p-mTOR, p-4E-BP-I, and } \\
\text { p-p70S6K expression in hippocampus, exerted antidepressant } \\
\text { effect through promoting the PI3K/AKT/mTOR signaling pathway }\end{array}$ & {$[51]$} \\
\hline Hepatic fibrosis & $\begin{array}{l}\text { Matrine } \\
\text { thioderivative } \\
\text { MD-I }\end{array}$ & HSC-T6; SD rat hepatic fibrosis mode & $\begin{array}{l}\text { Binded the EGFR, and further inhibited the p-EGFR and its } \\
\text { downstream p-Akt, decreased the expression of cyclin DI and } \\
\text { eventual inhibited the activation of HSC-T6 cells, exerted the anti- } \\
\text { hepatic fibrosis functions via blocking the EGFR-related } \\
\text { downstream signaling pathways }\end{array}$ & {$[52]$} \\
\hline \multirow[t]{2}{*}{$\mathrm{HCC}$} & $\begin{array}{l}\text { Matrine derivative } \\
\text { WM622 }\end{array}$ & $\begin{array}{l}\text { LM3, Hep3B, WRL-68; LM3 tumor xenograft Balb/c } \\
\text { nude mice model }\end{array}$ & $\begin{array}{l}\text { Reduced p-EGFR, p-AKT, p-PI3K and p-GSK3 } 3 \text {, and suppressed } \\
\text { the proliferation of liver cancer cells by inhibiting the PI3K/AKT } \\
\text { signaling pathway }\end{array}$ & [53] \\
\hline & $\begin{array}{l}\text { Matrine derivative } \\
\text { WMI } 30\end{array}$ & Huh-7; Huh-7 cell tumor-bearing BALB/c nude mice & $\begin{array}{l}\text { Down-regulated the expression of p-EGFR, p-ERK, p-AKT, MMP- } \\
2, \mathrm{Ki} 67 \text { and the ratio of Bcl-2/Bax, up-regulated the expression of } \\
\text { PTEN, inhibited the growth of liver cancer by inhibiting EGFR/ } \\
\text { ERK/MMP-2 and PTEN/AKT signaling pathways }\end{array}$ & [54] \\
\hline $\begin{array}{l}\text { Multiple } \\
\text { Cancers }\end{array}$ & $\begin{array}{l}\text { MASM, an } \\
\text { effective } \\
\text { derivative of } \\
\text { matrine }\end{array}$ & A549, MDA-MB-23I, MCF-7 & $\begin{array}{l}\text { Down-regulated the expression of ERK, p } 38 \text { and p-AKT, and } \\
\text { played the anti-tumor effect by inhibiting the AKT signaling } \\
\text { pathway and activating the autophagy induced by the Erk and P38 } \\
\text { signaling pathways }\end{array}$ & {$[55]$} \\
\hline Lung cancer & $\begin{array}{l}\text { Matrine derivative } \\
51 \text { with benzo- } \alpha- \\
\text { pyranone } \\
\text { structure }\end{array}$ & $\begin{array}{l}\text { A549, H460, HI975; A549-luciferase cells tumor- } \\
\text { bearing SCID/beige mice }\end{array}$ & $\begin{array}{l}\text { Up-regulated P27, down-regulated CDK4, CyclinDI and } \\
\text { attenuated the PI3K/Akt/mTOR pathway, induced cell cycle arrest } \\
\text { and autophagy in lung cancer cells }\end{array}$ & [56] \\
\hline Cervical cancer & $\begin{array}{l}\text { Sophora } \\
\text { Flavescens } \\
\text { Alkaloid gel (SFA) }\end{array}$ & $\mathrm{SiHa}, \mathrm{C} 33 \mathrm{~A}, \mathrm{HK}-2$ & $\begin{array}{l}\text { Increased Bax, E-cadherin, decreased Bcl-2, MMP2, supppressed } \\
\text { the p-AKTand p-mTOR, inhibited cervical cancer cells } \\
\text { proliferation and migration via the suppression of AKT/mTOR } \\
\text { signaling pathway }\end{array}$ & 57] \\
\hline $\begin{array}{l}\text { Nasopharyngeal } \\
\text { carcinoma }\end{array}$ & $\begin{array}{l}\text { I4-Thienyl } \\
\text { Methylene } \\
\text { Matrine (YYJ|8) }\end{array}$ & CNEI, CNE2, HONEI & $\begin{array}{l}\text { Suppressed p-p38, but upregulated p-ERKI/2 and p-Akt, then } \\
\text { altered the downstream signaling, including activation of Bax, } \\
\text { caspase- } 3 \text { and inactivation of Bcl-2, inhibited nasopharyngeal } \\
\text { carcinoma cells by regulating the MAPK and PI3K/Akt signaling } \\
\text { pathways }\end{array}$ & {$[58]$} \\
\hline \multirow[t]{2}{*}{ Osteoporosis } & MASM (MI9) & \multirow[t]{2}{*}{$\begin{array}{l}\text { BMMs, RAW264.7; Ovariectomy C57BL/6 mice } \\
\text { model }\end{array}$} & $\begin{array}{l}\text { By targeting and stablizing RPS5, MI9 acted on the RPS5 and } \\
\text { blocked the NF-kB, MAPKs and PI3K/Akt pathways and } \\
\text { subsequently reduced the expression of nuclear transcription } \\
\text { factor NFATcl, thus to inhibit ANKL/M-CSF induced } \\
\text { osteoclastogenesis and bone loss in ovariectomized mice }\end{array}$ & [59] \\
\hline & $\begin{array}{l}\text { Matrine derivative } \\
\text { M54 }\end{array}$ & & $\begin{array}{l}\text { M54 also targeted to RPS5, exhibiting significant inhibitory effects } \\
\text { on osteoclastogenesis amd bone loss by suppressing RANKL } \\
\text { induced NF- } \mathrm{KB}, \mathrm{PI} 3 \mathrm{~K} / \mathrm{AKT} \text {, and MAPK pathways activation and the } \\
\text { expression of NFATcl }\end{array}$ & [60] \\
\hline
\end{tabular}




\section{Matrine Exerts Pharmacological Effects Through the TGF- $\beta$ Signaling Pathway}

TGF- $\beta$ belongs to a group of newly discovered superfamilies that regulate cell growth and differentiation. TGF- $\beta$ and other members of the family are evolutionally conserved secreted proteins that contain many different polypeptide morphogenesis factors and are involved in many cellular processes in both mature organisms and developing embryos. ${ }^{61}$

The TGF- $\beta$ superfamily in mammals mainly includes three subtypes: TGF- $\beta 1$, TGF- $\beta 2$, and TGF- $\beta 3$. TGF- $\beta 1$ is mainly expressed in endothelial cells, hematopoietic cells, and connective tissues, TGF- $\beta 2$ is mainly expressed in epithelial cells and nerve cells, and TGF- $\beta 3$ is mainly expressed in mesenchymal cells. ${ }^{62}$ They bind to the TGF- $\beta$ receptor (TGFBR) 2 and have similar biological activities, regulating cell proliferation, migration, differentiation, apoptosis, and exerting significant effects in the regulation of embryonic growth and development, inflammation and repair (including angiogenesis), and host resistance mechanisms. ${ }^{63,64}$ The TGF- $\beta$ signaling pathway is considered to play a key role in the process of fibrosis, exerting its biological functions by activating the downstream Smad pathway. TGF$\beta 1 / \mathrm{Smad} 3$ is the most important regulatory signaling pathway involved in tissue fibrosis in many diseases.

Zhang et $\mathrm{al}^{65}$ investigated the anti-fibrosis-associated cardioprotective effects of matrine on diabetic cardiomyopathy $(\mathrm{DbCM})$. They administered matrine orally to rats with experimental $\mathrm{DbCM}$ and found that matrine inhibited the expression of TGF- $\beta$ and the phosphorylation of R Smad (Smad2/3) and blocked the activation of TGF- $\beta 1 / \mathrm{R}$ Smad signal transduction to repress collagen production and deposition, leading to a marked recovery in left ventricular function and heart compliance. These results indicated that matrine has therapeutic effects against cardiac fibrosis by affecting TGF- $\beta 1 /$ Smad signaling and exerting cardioprotective effects in DbCM. Hou et al ${ }^{66}$ found that matrine treatment significantly decreased the level of non-fasting blood glucose, improved the hemodynamic parameters of DbCM model rats, inhibited the expression levels of the inflammatory cytokines TNF- $\alpha$ and IL- 6 , and decreased ROS generation, MDA, TGF- $\beta$ levels, and peroxisome proliferator activator receptor $\beta$ (PPAR $\beta$ ) and PPAR $\gamma 1$ activity. Matrine administration also significantly inhibited p-ERK expression, and endogenic expression of p-ERK counteracted matrineinduced apoptosis of myocardial cells. These results suggested that matrine may serve as a potential anti-inflammatory and anti-apoptotic agent in the pathological process of DbCM by downregulating the TGF- $\beta$ induced $p$-ERK signaling pathway. Ma et $\mathrm{al}^{67}$ demonstrated that matrine treatment resulted in reduced rates of atrial fibrillation (AF) inducibility and shorter AF duration in myocardial infarction (MI) rats. They also observed improved left atrial conduction velocity and homogeneity and decreased fibrosis positive areas and protein levels of type I collagen and type III collagen in the left atrium. In vitro, matrine inhibited cardiac fibroblast proliferation, migration, secretion, and differentiation to myofibroblasts, as well as the expression of TGF $\beta-1$ and MMP-9. These data indicated that matrine may reduce atrial fibrosis through the TGF- $\beta$ signaling pathway and thus decrease susceptibility to AF after MI.

$\mathrm{Yu}$ et $\mathrm{al}^{68}$ found that treating liver fibrosis model rats with matrine significantly reduced the expression of TGF- $\beta 1$, enhanced the activity of hepatocyte growth factor (HGF), and alleviated liver tissue damage, cell necrosis and connective tissue hyperplasia in collect abbacy, and there is a trend of obvious improvement, which clearly indicates its inhibitory effect on liver fibrosis in rats. Li et al ${ }^{69}$ designed and synthesized a series of matrine derivatives, among which compound 3F displayed the strongest anti-fibrotic activity, significantly inhibited the fibroblast-to-myofibroblast transition and extracellular matrix (ECM) production of the human embryonic lung fibroblast (HELF) MRC-5 cell lines, as well as the fibroblasts migration induced by TGF- $\beta 1$; while the cytoplasm-to-nuclear translocation of Smad2/3 and TGF- $\beta 1$ induced upregulation of TGF $\beta \mathrm{R} 1$ were also inhibited by $3 \mathrm{~F}$. These data suggested that $3 \mathrm{~F}$ may be a potential drug to treat idiopathic pulmonary fibrosis (PF) by inhibiting the TGF $/$ Smad signaling pathway. Zhang et al ${ }^{70}$ construct a PF model of HELF induced by TGF- $\beta 1$, and characterized the effect of ginkgo biloba leaf extract (GBLE), shenmai (S), and matrine on PF. The results showed that all three preparations significantly inhibited the proliferation and induced apoptosis of lung fibroblasts, suppressed the synthesis and secretion of collagen-I/III and $\alpha$-smooth muscle actin $(\alpha$ SMA), but promoted superoxide dismutase 3 (ECSOD) synthesis and secretion. Among them, matrine exhibited the strongest activity in reducing collagens synthesis, possibly by inhibiting the expression of collagen genes. These data indicated that GBLE, S, and matrine inhibited the pro-fibrotic effects of TGF- $\beta 1$ by targeting different steps in TGF- $\beta 1$ mediated fibrosis. Liu et $\mathrm{al}^{71}$ treated the pancreatic fibrosis model rats with matrine and found that the expression of 
TGF- $\beta 1, \alpha$-SMA, collagen I, Smad2, TGF $\beta$ R1, and TGF $\beta R 2$ was significantly reduced in the matrine treatment group, suggesting that matrine inhibited pancreatic fibrosis by modulating the TGF- $\beta /$ Smad signaling pathway. Overall, these findings provided useful information for the further development of matrine-based anti-fibrotic agents.

Heterotopic ossification (HO) is a debilitating disease characterized by ectopic bone formation within extraskeletal tissues, and active TGF- $\beta$ contributes to trauma-induced HO. Mao et $\mathrm{al}^{72}$ found that matrine significantly inhibited TGF$\beta$-induced mesenchymal stem cells (MSCs) migration, alkaline phosphatase (ALP) activity and osteogenic differentiation, reduced ossification in achilles tendon puncture mice, and inhibited HO progression. Mechanistically, matrine inhibited TGF- $\beta$ induced Smad2/3 phosphorylation and the transcription of RUNX family transcription factor 2 (Runx2), ALP, and osteocalcin (Ocn) after osteoinduction, indicating that matrine can inhibit the activation of TGF- $\beta / \mathrm{Smad} 2 / 3$ signaling pathway in $\mathrm{HO}$, and is expected to be a candidate for $\mathrm{HO}$ treatment.

Moreover, matrine has been proven to be an effective medication for the treatment of eczema, but the under mechanism remains unclear. Zhang et $\mathrm{al}^{73}$ used a matrine derivative, oxymatrine to treat eczema guinea pigs, and showed that oxymatrine treatment alleviated the symptoms of eczema, inhibited the expression of pro-inflammatory factor proteins, increased Th1 and CD4+TGF $\beta+$ levels, and regulated the expression levels of interferon gamma (IFN- $\gamma$ ) and TGF- $\beta$, indicating that matrine can mediate the Th1/Th2 balance to treat eczema by upregulating IFN- $\gamma$ and downregulating TGF- $\beta$ levels.

We have summarized the relevant studies on the pharmacological effects of matrine through the TGF- $\beta$ signaling pathway in Table 2.

\section{Matrine Exerts Pharmacological Effects Through the NF-kB Signaling Pathway}

$\mathrm{NF}-\kappa \mathrm{B}$ is a family of key nuclear transcription factor proteins that includes C-REL, RELB, RelA/p65, NF- $\mathrm{B} 1$ (p50/

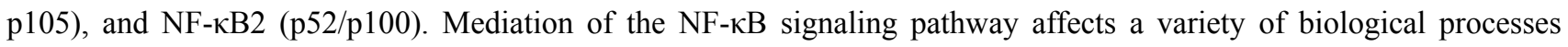
including innate and adaptive immunity, inflammation, the stress response, differentiation, apoptosis, and tumorigenesis. $^{74}$

When unstimulated, NF- $\mathrm{kB}$ binds to its inhibitor, IкB, forms a complex in the form of homo- or heterodimers, and remains inactive in the cytoplasm of almost all cell types. ${ }^{75}$ Only when the cell is stimulated or under stress, upstream

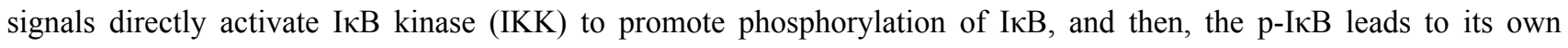
ubiquitination and is rapidly degraded and released by proteases, thereby releasing the inhibitory effect of IкB and

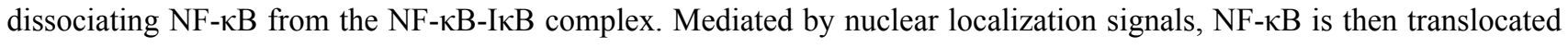
into the nucleus to bind to specific DNA sequences in the promoter regions of genes and promotes downstream target genes transcription and protein synthesis, participating in various pathophysiological reactions such as infection, inflammation, and the immune response. ${ }^{74,75}$

Zhang et $\mathrm{al}^{76}$ investigated the effect of matrine on lipopolysaccharide (LPS)-induced lung injury, and found that matrine significantly reduced the mortality of mice with LPS administration, improved LPS-induced lung histopathologic changes, alleviated pulmonary edema and lung vascular leakage, inhibited MPO and MDA activity, and reduced the production of inflammatory mediators such as TNF- $\alpha$, IL-6, and high mobility group box 1 (HMGB1). In vitro, matrine reduced the production of ROS and inflammatory factors, which may be related to the inhibition of NF- $\mathrm{kB}$. These data demonstrated that matrine exerts a protective effect against LPS-induced acute lung injury by inhibiting the inflammatory response, which may involve the suppression of ROS and tissue oxidative stress-mediated by the NF- $\mathrm{kB}$ signaling pathway.

Shao et $\mathrm{al}^{77}$ observed that matrine effectively inhibited the proliferation of three breast cancer cell lines: estrogen receptor (ER)-positive MCF7 cells, HER2-positive BT-474 cells, and highly metastatic MDA-MB-231 cells, and significantly reduced the expression of $\operatorname{IKK} \beta$, suggesting that matrine may be an effective candidate drug for the treatment of breast cancer by inhibiting NF- $\mathrm{KB}$ signaling pathway. 
Table 2 The Relevant Studies on the Pharmacological Effects of Matrine Through the TGF- $\beta$ Signaling Pathway

\begin{tabular}{|c|c|c|c|c|}
\hline Disease & Drugs & Cell Line/Animal Model & Action Mechanism & Reference \\
\hline \multirow[t]{2}{*}{$\begin{array}{l}\text { Diabetic } \\
\text { cardiomyopathy } \\
\text { (DbCM) }\end{array}$} & \multirow[t]{4}{*}{ Matrine } & $\begin{array}{l}\text { Cardiac fibroblasts (CFs); } \\
\text { Streptozotocin induced } \mathrm{DbCM} \text { rat } \\
\text { model }\end{array}$ & $\begin{array}{l}\text { Inhibited the expression of TGF- } \beta \text { and } p-R \text { Smad } \\
(\text { Smad } 2 / 3) \text {, without affecting I Smad, blocked the } \\
\text { activation of TGF } \beta I / R \text { Smad signaling transduction to } \\
\text { repress collagen production and depositionand }\end{array}$ & {$[65]$} \\
\hline & & $\begin{array}{l}\text { Myocardial cells; Streptozotocin } \\
\text { induced DbCM rat model }\end{array}$ & $\begin{array}{l}\text { Inhibited the expression levels of TNF- } \alpha \text { and IL- } 6 \text {, } \\
\text { decreased ROS production, MDA and TGF- } \beta \text { levels, } \\
\text { and PPAR } \beta \text { and PPAR } \gamma \text { I activity, also significantly } \\
\text { inhibited PERK expression, exerting anti-inflammatory } \\
\text { and anti-apoptotic effects by down-regulating the } \\
\text { TGF- } \beta \text { induced PERK signaling pathway }\end{array}$ & [66] \\
\hline Atrial fibrillation & & $\begin{array}{l}\text { CFs; Myocardial infarction rat } \\
\text { model }\end{array}$ & $\begin{array}{l}\text { Decreased the protein levels of type I collagen and } \\
\text { type III collagen, inhibited CFs differentiation to } \\
\text { myofibroblasts and the expression of TGF- } \beta \text { I and } \\
\text { MMP 9, reduced atrial fibrosis through the TGF- } \beta \\
\text { signaling pathway }\end{array}$ & [67] \\
\hline Liver fibrosis & & $\begin{array}{l}\text { Rat liver fibrosis model using } \\
\text { composite modulus method with } \\
\text { carbon tetrachloride (CCL4) }\end{array}$ & $\begin{array}{l}\text { Reduce the expression of TGF- } \beta \text { I and enhance the } \\
\text { activity of HGF, thereby achieving the inhibitory effect } \\
\text { on rat liver fibrosis }\end{array}$ & [68] \\
\hline \multirow[t]{2}{*}{$\begin{array}{l}\text { Idiopathic } \\
\text { pulmonary } \\
\text { fibrosis (IPF) }\end{array}$} & $\begin{array}{l}\text { Matrine } \\
\text { derivative } 3 \mathrm{~F}\end{array}$ & MRC-5 & $\begin{array}{l}\text { Inhibited the fibroblast-to-myofibroblast transition and } \\
\text { extracellular matrix production, inhibited cytoplasm- } \\
\text { to-nuclear translocation of Smad } 2 / 3 \text { and suppressed } \\
\text { TGF- } \beta \text { I-induced upregulation of TGF- } \beta \text { receptor type } \\
\text { I (TGF } \beta \text { RI) }\end{array}$ & [69] \\
\hline & $\begin{array}{l}\text { Ginkgo biloba } \\
\text { leaf extract, } \\
\text { shenmai, and } \\
\text { matrine }\end{array}$ & TGF- $\beta$ I-induced HELFs PF model & $\begin{array}{l}\text { Inhibited the proliferation and induced the apoptosis } \\
\text { of lung fibroblasts, inhibited the synthesis and } \\
\text { secretion of COL-I, COL-III and } \alpha \text {-SMA, and } \\
\text { promoted the synthesis and secretion of extracellular } \\
\text { superoxide dismutase (ECSOD), inhibited the pro- } \\
\text { fibrotic role of TGF- } \beta \text { I by targeting different steps in } \\
\text { TGF- } \beta \text { I-mediated fibrosis }\end{array}$ & {$[70]$} \\
\hline $\begin{array}{l}\text { Pancreatic } \\
\text { Fibrosis }\end{array}$ & \multirow[t]{2}{*}{ Matrine } & $\begin{array}{l}\text { Sprague Dawley (SD) rat model } \\
\text { with pancreatic fibrosis }\end{array}$ & $\begin{array}{l}\text { Reduced the expression of Smad } 2 \text { by downregulating } \\
\text { the expression of } \alpha \text {-SMA, TGF- } \beta \text { I, and collagen, } \\
\text { exerted the anti-pancreatic fibrosis effect by inhibiting } \\
\text { the TGF- } \beta / \text { Smad signal pathway }\end{array}$ & {$[7 I]$} \\
\hline $\begin{array}{l}\text { Heterotopic } \\
\text { ossification } \\
\text { (HO) }\end{array}$ & & $\begin{array}{l}\text { Mesenchymal stromal cells } \\
\text { (MSCs); HO mouse model } \\
\text { established by achilles tendon } \\
\text { puncture }\end{array}$ & $\begin{array}{l}\text { Inhibited TGF- } \beta \text { induced Smad } 2 / 3 \text { phosphorylation and } \\
\text { transcription of Runx2, Alp, and Ocn after } \\
\text { osteoinduction, inhibited HO by suppressing the } \\
\text { migration and osteogenic differentiation of TGF- } \beta \text { - } \\
\text { induced-MSCs in mice }\end{array}$ & {$[72]$} \\
\hline Eczema & $\begin{array}{l}\text { Oxymatrine, a } \\
\text { derivative of } \\
\text { matrine }\end{array}$ & Guinea pigs with eczema & $\begin{array}{l}\text { Increased ThI and CD4+TGF } \beta+\text { levels, improved the } \\
\text { expression of pro-inflammatory factor genes, and } \\
\text { exerted treating eczema effect by up-regulating IFN- } \gamma \\
\text { and down-regulating TGF- } \beta \text { levels to regulate the ThI/ } \\
\text { Th2 balance }\end{array}$ & [73] \\
\hline
\end{tabular}


Yu et $\mathrm{a}^{78}$ demonstrated that matrine effectively inhibited the invasion of HCC SMMC-7721 cells and the expression of MMP-9 and NF- $\mathrm{kB}$, and the use of NF- $\mathrm{kB}$ inhibitor significantly reduced MMP-9 expression, suggesting that matrine may downregulate MMP-9 by regulating the NF-kB signaling pathway, thereby inhibiting the invasion of HCC.

Studies by Huang et $\mathrm{al}^{79}$ showed that matrine significantly inhibited the migration and invasion ability of pancreatic cancer PAN-1 cells, decreased intracellular ROS levels, upregulated E-cadherin expression, and downregulated N-cadherin, Vimentin, MMP-2, and MMP-9 expression, as well as the levels of p-p65 and p-IкB $\alpha$. These data indicated that matrine may inhibit the invasion and epithelial-to-mesenchymal transition (EMT) of pancreatic cancer cells through the ROS/NF- $\mathrm{BB} / \mathrm{MMPs}$ pathway, further validating the anti-metastasis effect of matrine. Jung et al ${ }^{80}$ also evaluated the potential of matrine to affect tumor metastasis and found that matrine downregulated the phosphorylation and nuclear translocation of NF-kB-p65 in lung cancer (A549), prostate cancer (DU145), and pancreatic cancer (MIAPACA-2) cells, and effectively inhibited the cellular invasion and metastasis through significantly affecting the expression levels of C-X$\mathrm{C}$ motif chemokine receptor 4 (CXCR4), MMP-2, MMP-9, and NF- $\mathrm{BB}$, and may considered as a potential candidate for anti-tumor metastasis.

To date, the therapeutic efficacy of matrine on prostate cancer remains poorly understood. Li et $\mathrm{al}^{81}$ treated prostate cancer DU-145 and PC-3 cells with matrine, and found that cell proliferation, migration and invasion were significantly inhibited in a dose- and time-dependent manner, the levels of $\mathrm{p} 65$, IKK- $\alpha / \beta$, I $\mathrm{KB}-\alpha$ and corresponding phosphorylation were all decreased, suggesting matrine may exert an anti-tumor effect by regulating the NF- $\mathrm{KB}$ signaling pathway, and is expected to be a promising supplement for androgen-dependent prostate cancer drug. Huang et al ${ }^{82}$ explored the antimetastatic effects of matrine on castration-resistant prostate cancer (CRPC) and found that matrine inhibited the growth of DU145 and PC3 cells time- and dose-dependently both in vitro and in vivo, and suppressed cell migration and invasive ability. In addition, the expression levels of MMP-2, MMP-9, NF- $\mathrm{B}$ subunit p65 and p-p65 in both cell lines were significantly down-regulated, and it was finally demonstrated that matrine inhibited the migration and invasion of CRPC by downregulating MMP-2/9 through the NF- $\mathrm{KB}$ pathway. These data reveal a potential novel application of matrine in anti- CRPC metastatic therapy.

Luo et $\mathrm{al}^{83}$ investigated the anti-GC activity of matrine and found that matrine dose-dependently inhibited the GC cell line MNK45, the expression of NF-kB, X-linked inhibitor of apoptosis (XIAP), cellular inhibitor of apoptosis 1 (CIAP), and p-ERK were also markedly reduced under the action of matrine, indicating the matrine's anti-tumor effect is achieved by modulation of these proteins, which may serve as an effective potential anti-GC agent.

Multidrug resistance is currently the major obstacle to cancer chemotherapy. Chen et al ${ }^{84}$ evaluated the reversal effect of matrine on chemoresistant leukemia K562/ADR cells and found that matrine enhanced the cytotoxicity of cancer medicines on K562/ADR cells and apoptotic rate induced by doxorubicin, and inhibited the expression of drug-exporting factor ATP binding cassette subfamily B member 1 (ABCB1) and the phosphorylation of NF- $\mathrm{KB}$. These results indicated that matrine can downregulate the expression of $\mathrm{ABCB} 1$ by inhibiting NF- $\mathrm{KB}$, thereby reducing drug transport and promoting the endogenous apoptosis pathway, which may be an effective sensitizer for anti-tumor drug resistance.

Yi et $\mathrm{al}^{85}$ evaluated the anti-metastatic effect of matrine on osteosarcoma and showed that matrine inhibited proliferation of osteosarcoma cells in vivo and in vitro, inhibited tumor cell metastasis in vitro, downregulated the expression of MMP-2 and MMP-9, and reduced nuclear translocation of p50 and p65, as well as phosphorylation of IкB$\beta$ and ERK $1 / 2$. The results showed that matrine inhibited the invasion and proliferation of human osteosarcoma cells by downregulating the NF- $\mathrm{KB}$ signaling pathway.

Matrine has been used in anti-inflammatory and anticancer treatments for a long time. Jiang et al ${ }^{86}$ explored the potential application of matrine in the treatment of spinal cord injury (SCI) and found that matrine pretreatment partially attenuated LPS-induced loss of viability, apoptotic stimulation, and release of pro-inflammatory factors (IL-1 $\beta$, IL-6, and TNF- $\alpha$ ) in neuron-like PC12 cells, reversed LPS-reduced miR-9 levels. In addition, matrine also inhibited the activation of c-Jun-n-terminal kinase (JNK) and NF-кB pathways under LPS conditions, and miR-9 silencing attenuated the effects of matrine on these signal transductions. This study suggested that matrine can protect nerve cells from LPS-induced inflammatory damage by regulating miR-9 expression and activating JNK and NF- $\mathrm{kB}$ signaling pathways.

The signaling pathways induced by inflammatory mediator HMGB1 have been reported to play important roles in the pathogenesis of multiple sclerosis (MS). Matrine has the capacity to effectively inhibit MS animal model with 
experimental autoimmune encephalomyelitis (EAE), but its effect on HMGB1-induced signaling remains unclear. Chu et $\mathrm{al}^{87}$ showed that matrine treatment alleviated the severity of EAE, decreased inflammatory infiltration and demyelination, as well as the production of inflammatory factors in the CNS, including TNF- $\alpha$, IL-6, and IL-1 $\beta$, significantly reduced the expression of HMGB1 and toll like receptor 4 (TLR4) in the spinal cord, especially in astrocytes and microglia/infiltrating macrophages, but increased the level of IкB- $\alpha$, confirming the direct inhibitory effect of matrine on HMGB1/TLR4/NF- $\kappa B$ signaling in macrophages. These findings demonstrated that matrine treatment alleviated the inflammatory demyelination and activation of astrocytes and microglia/macrophages in the CNS of EAE rats, and the mechanism may be closely related to the modulation of HMGB1/TLR4/NF- $\mathrm{KB}$ signaling pathway.

Previous studies have demonstrated that matrine can alleviate brain edema induced by focal cerebral ischemia. $\mathrm{Xu}$ et $\mathrm{al}^{88}$ found that matrine reduced infarction volume and improved neurological deficit in a dose-dependent manner in the model of permanent middle cerebral artery occlusion (pMCAO), and further observed that matrine increased the level of $\mathrm{I} \kappa \mathrm{B} \alpha$ protein, blocked the translocation of NF- $\mathrm{BB}$ p65 from the cytoplasm to nucleus in ischemic cortex and injured neurons and astrocytes induced by oxygen-glucose deprivation (OGD) in vitro, and downregulated NF- $\mathrm{kB}$ p65 downstream pro-apoptotic genes p53 and/or c-Myc (MYC proto-oncogene, bHLH transcription factor). These results suggested that matrine directly protected neurons and astrocytes from focal cerebral ischemia injury by inhibiting the NF- $\mathrm{KB}$ signaling pathway.

Porcine circovirus associated diseases (PCVAD) is a multifactorial disease that is quite common in the world swine industry. Porcine reproductive respiratory syndrome virus (PRRSV) and porcine circovirus type 2 (PCV2) are the most common pathogens of PCVAD, there is currently no effective treatment. A previous study by Sun et al ${ }^{89}$ showed that matrine treatment inhibited PRRSV and PCV2 infection, significantly downregulated the expression of TLR3, TLR4, and TNF- $\alpha$, and suppressed the expression of $\mathrm{p}$-I $\kappa \mathrm{B} \alpha$ to a certain extent, indicating that the antiviral efficacy of matrine may be partly mediated by regulating the TLR3, 4/NF- $\mathrm{KB} / \mathrm{TNF}-\alpha$ signaling pathway. Although matrine is known to have dual effects of antiviral and anti-inflammatory, the specific molecular mechanism remains unclear. Sun et $\mathrm{al}^{90}$ established an inflammatory model by co-stimulating porcine alveolar macrophages (PAMs) with PRRSV 5'UTR RNA and LPS to study the specific anti-inflammatory mechanism of matrine, and found that matrine treatment strongly inhibited the expression and secretion of IL-1 $\beta$, IL-6, IL-8, and TNF- $\alpha$, inhibited the expression of MYD88 innate immune signal transduction adaptor (MyD88), NLR family pyrin domain containing 3 (NLRP3) and caspase-1 and the phosphorylation of $\mathrm{I} \kappa \mathrm{B} \alpha$, inhibited the speck formation of apoptosis-associated speck-like protein (ASC), and interfered the translocation of NF- $\mathrm{kB}$ from the cytoplasm to the nucleus. These results suggested that matrine played an important role in inflammatory response by affecting NF- $\mathrm{KB}$ and the NLRP3 inflammasome, and laid a foundation for exploring the clinical application of matrine in PRRSV disease.

Wang et al $^{91}$ investigated the effect of matrine on n-methyl-N'-nitro-n-nitrosoguanidine (MNNG) induced gastric mucosal injury in rats, and found that matrine treatment increased the body weight, drinking water, and diet, significantly reduced the expression levels of VEGF-C, VEGFR3, BAX, caspase-3, TLR4, MyD88, and NF-אB p65, but increased the protein level of Bcl-2 in the gastric mucosa tissues, suggesting that matrine may reduce MNNG- induced gastric mucosa injury in rats by downregulating VEGF-C/VEGFR3 and NF-KB/TLR4 signaling pathways.

Elevated suppressor of cytokine signaling 3 (SOCS3) has been demonstrated to correlate with the severity of asthma. Sun et $\mathrm{al}^{92}$ studied the effect of matrine on the expression of SOCS3 in airway inflammation and found that in ovalbumin (OVA)-induced asthmatic mice, matrine treatment significantly inhibited aryl hydrocarbon receptor (AHR), inflammatory cells infiltration, goblet cell differentiation, and mucogenesis. Further, mechanistic studies showed that matrine downregulated SOCS3, IL-6 and adhesion molecules, abrogated the levels of IL-4 and IL-13, but increase the expression of IFN- $\gamma$ by inhibiting NF- $\kappa B$ signaling in asthmatic mice and TNF- $\alpha$-stimulated airway epithelial cells, thereby inhibiting airway inflammation.

RA is a chronic and highly prevalent autoimmune disease characterized by synovial joint hyperplasia and inflammation. Niu et al ${ }^{93}$ established a rat model of RA and found that matrine treatment significantly mitigated the inflammation and severity of RA. Mechanistically, matrine may reduce the level of Th1 cytokines (IFN- $\gamma$, TNF- $\alpha$, IL-1 $1 \beta$ ) but increase the level of Th2 cytokines (IL-4 and IL-10) by inhibiting the NF-кB signaling pathway in T cells, thereby modulated the imbalance of Th1 and Th2 cytokine responses in RA rats, suggesting that matrine may be a promising drug for RA 
intervention. $\mathrm{Pu}$ et $\mathrm{al}^{94}$ investigated the anti-arthritic effect of matrine on type II collagen-induced arthritis (CIA) in rats and found that matrine significantly suppressed inflammatory response and the destruction of synovial tissue, and inhibited the paw swelling, arthritis indices, and weight loss. In addition, matrine reduced the levels of TNF- $\alpha$, IL-1 $\beta$, IL-6, IL-8, IL-17A, MMP-2, MMP-3, and MMP-9, downregulated the expression of p-IкB, cytochrome c oxidase II (Cox-2), and nitric oxide synthase (iNOS), but upregulated the expression of $\mathrm{I} \kappa \mathrm{B}$ in the synovial tissues of CIA rats. These results suggested matrine possessed an anti-arthritic effect on CIA rats by inhibiting the release of pro-inflammatory cytokines and proteins that promote the NF- $\kappa B$ pathway. Zou et al ${ }^{95}$ explored the therapeutic efficacy of matrine derivative MASM on RA in CIA mice and on fibroblast-like synoviocytes (FLS) cells, and found that MASM significantly reduced the severity of arthritis in CIA mice. Additionally, MASM induced RA-FLS apoptosis and inhibited the expression of pro-inflammatory cytokines and matrix metalloproteinases (MMP-1, MMP-3, and MMP-13) by inhibiting the phosphorylation of MAPKs and the activation of NF- $\kappa$, suggesting that MASM may at least exert therapeutic effects on CIA by blocking the phosphorylation of MAPKs and the activation of NF- $\kappa \mathrm{B}$, and may serve as a potent drug for the treatment of RA.

IL-1 $\beta$ plays an important role in promoting osteoarthritis (OA) lesions, but the underlying anti-inflammatory mechanism of matrine in this process remains unclear. Lu et al $^{96}$ found that matrine significantly inhibited IL-1 $\beta$-induced chondrocytes apoptosis and the release of MMP-3 and MMP-13, increased the production of TIMP metallopeptidase inhibitor 1 (TIMP-1), and inhibited the phosphorylation of p38, ERK, JNK and the degradation of I $\mathrm{B} \alpha$ in chondrocytes. These results indicated that matrine played a therapeutic role in OA by inhibiting the activation of MAPK and NF- $\kappa B$ signaling pathways in human chondrocytes, thereby inhibiting IL-1 $\beta$-induced matrix metalloproteinases.

Jiang et $\mathrm{al}^{97}$ investigated the protective effect of matrine on Staphylococcus aureus lipoteichoic acid (LTA)-induced endometritis, and found that matrine significantly relieved uterine injury in mice with endometritis, and dose-dependently reduced the expression of pro-inflammatory cytokines (TNF $\alpha$ and IL-1 $\beta$ ). Besides, matrine inhibited the expression of TLR2 and the activation of its downstream NF- $\kappa B$ in LTA-stimulated bovine endometrial epithelial cells (bEECs). These findings suggested that the favorable effect of matrine on LTA-induced endometritis may be through the negative regulation of $\mathrm{NF}-\kappa \mathrm{B}$ signaling pathway mediated by TLR2, which may act as a potential anti-inflammatory agent.

Atherosclerosis is a chronic inflammatory disease associated with increased expression of adhesion molecules in vascular smooth muscle cells (VSMCs). Liu et $\mathrm{al}^{98}$ found that matrine inhibited the expression of vascular cell adhesion molecule-1 (VCAM 1) and intercellular adhesion molecule-1 (ICAM 1) in TNF- $\alpha$ stimulated human aortic smooth muscle cells (HASMCs), significantly inhibited the expression of NF- $\kappa$ B p65 and the activation of MAPKs, and matrine also suppressed the production of intracellular ROS. This study demonstrated that matrine inhibited the expression of VCAM 1 and ICAM 1 in TNF- $\alpha$ stimulated HASMCs by inhibiting the production of ROS and the activation of NF- $\kappa B$ and MAPK pathways, which may be used to prevent the progression of atherosclerotic lesions.

We have summarized the relevant studies on the pharmacological effects of matrine through the NF- $\kappa \mathrm{B}$ signaling pathway in Table 3 .

\section{Matrine Exerts Pharmacological Effects Through the Wnt/B-Catenin Signaling Pathway}

The Wnt signaling pathway is a complex network of protein interactions that is highly conserved during species evolution. The Wnt gene was first cloned in mouse breast cancer cells and was named Integration 1 (Int1). Later studies found that the mouse Int1 gene was homologous to the Drosophila wingless gene WG, and the two were collectively named Wnt. Further studies showed that $\beta$-catenin is the key effector of the Wnt protein, controlling the classical Wnt/ $\beta$ -Catenin signaling pathway. ${ }^{99}$

In mammalian cells, the Wnt/ $\beta$-catenin signaling pathway interacts with a series of cell surface-specific receptors through the ligand-protein Wnt, resulting in the phosphorylation of downstream protein kinases that inhibit the degradation of $\beta$-catenin. This results in the accumulation of stable $\beta$-catenin in the cytoplasm, which then enters the nucleus and combines with T-cell factor/lymphoid enhancing factor (TCF/LEF) family transcription factors to transmit growth-stimulating signals and initiate the transcription of downstream target genes. The Wnt/ $\beta$-catenin signaling 
Table 3 The Relevant Studies on the Pharmacological Effects of Matrine Through the NF-kB Signaling Pathway

\begin{tabular}{|c|c|c|c|c|}
\hline Disease & Drugs & Cell Line/Animal Model & Action Mechnism & Reference \\
\hline Acute lung injury & \multirow[t]{7}{*}{ Matrine } & $\begin{array}{l}\text { NR8383; LPS-induced lung injury mouse } \\
\text { model }\end{array}$ & $\begin{array}{l}\text { Inhibited the NF- } \mathrm{KB} \text { inflammatory cascade, } \\
\text { down-regulating the inflam-mation mediator } \\
\text { TNF- } \alpha \text {, IL- } 6 \text { and HMGBI, and suppressed MPO } \\
\text { and MDA activity, thereby attenuated ROS and } \\
\text { tissue oxidative stress }\end{array}$ & [76] \\
\hline Breast cancer & & MCF-7, BT-474, MDA-MB-23I & $\begin{array}{l}\text { Reduced the expression of IKK } \beta \text {, play an anti- } \\
\text { tumor effect on breast cancer cells through NF- } \\
\kappa B \text { signaling pathway }\end{array}$ & [77] \\
\hline $\mathrm{HCC}$ & & SMMC-772I & $\begin{array}{l}\text { Suppressed the expression of MMP-9 and NF- } \\
\kappa B \text {, inhibited } \mathrm{HCC} \text { cells invasion by } \\
\text { downregulation the NF- } \mathrm{KB} \text { signaling pathway }\end{array}$ & [78] \\
\hline Pancreatic cancer & & PANC-I & 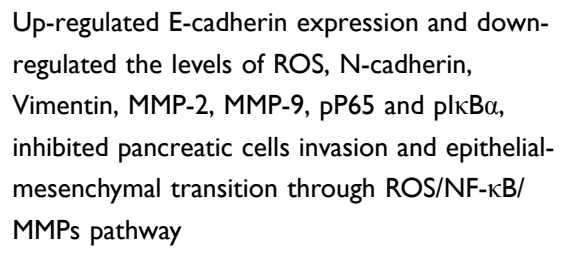 & [79] \\
\hline Cancers & & A549, DUI45, MIAPaca-2 & $\begin{array}{l}\text { Negatively regulated HER2 and CXCLI2- } \\
\text { induced CXCR4 expression, down-regulated } \\
\text { expression of MMP- } 9 / 2 \text { and NF-KB, blocking the } \\
\text { cancer metastasis through the negative } \\
\text { regulation of CXCR4 and MMP-9/2 }\end{array}$ & [80] \\
\hline \multirow[t]{2}{*}{ Prostate cancer } & & DU-I45, PC-3 & $\begin{array}{l}\text { Decreased the expression levels of } \mathrm{p} 65, \mathrm{p}-\mathrm{p} 65 \text {, } \\
\mathrm{ikk}-\alpha / \beta, \mathrm{p}-\mathrm{ikk}-\alpha / \beta, \mathrm{K} B-\alpha \text { and } \mathrm{p}-\mathrm{iKB}-\alpha \text {, indicating } \\
\text { the NF- } \mathrm{KB} \text { signaling pathway was involved in the } \\
\text { inhibition of prostate cancer }\end{array}$ & {$[8 \mathrm{I}]$} \\
\hline & & $\begin{array}{l}\text { DUI45, PC3; DUI } 45 \text { and PC-3 xenograft } \\
\text { tumor model in BALB/c nude mice }\end{array}$ & $\begin{array}{l}\text { Reduced the expression levels of MMP-9, MMP- } \\
2 \text { and p-p65, inhibited invasion of castration- } \\
\text { resistant prostate cancer (CRPC) by } \\
\text { downregulating MMP- } 2 / 9 \text { through NF-KB } \\
\text { pathway }\end{array}$ & [82] \\
\hline Gastric cancer & & MNK45 & $\begin{array}{l}\text { Inhibited gastric cancer cell growth via } \\
\text { controlling NF- } \mathrm{kB} \text { subunit proteins, CIAP, XIAP, } \\
\text { and p-ERK }\end{array}$ & [83] \\
\hline Leukemia & & K562, K562/ADR & $\begin{array}{l}\text { Increased caspase- } 9 \text { activity, reduced the } \\
\text { expression of } \mathrm{p}-\mathrm{NF}-\mathrm{\kappa} B \text {, Survivin, and } \mathrm{Bcl}-\mathrm{xl} \text {, } \\
\text { suppressed } \mathrm{ABCB} \text { Irug transport and } \\
\text { facilitated the intrinsic apoptosis pathway } \\
\text { through inhibiting NF- } \mathrm{K} B \text {, enhanced the effect of } \\
\text { anticancer drugs on K562/ADR cells }\end{array}$ & [84] \\
\hline Osteosarcoma & & $\begin{array}{l}\text { SaOS-2, U2OS, MG-63; U2OS xenograft } \\
\text { tumor model in BALB/c nude mice }\end{array}$ & $\begin{array}{l}\text { Decrease the expression of MMP- } 2 \text { and } 9 \text {, } \\
\text { reduce the nuclear translocation of } \mathrm{p} 50 \text { and } \\
\mathrm{p} 65 \text {, and the phosphorylation level of IKB- } \beta \text { and } \\
\text { ERK I/2, and act by down-regulating the NF- } \mathrm{kB} \\
\text { signaling pathway }\end{array}$ & [85] \\
\hline
\end{tabular}

(Continued) 
Table 3 (Continued).

\begin{tabular}{|c|c|c|c|c|}
\hline Disease & Drugs & Cell Line/Animal Model & Action Mechnism & Reference \\
\hline Spinal cord injury & & $\mathrm{PCl} 2$ & $\begin{array}{l}\text { Reversed LPS-decreased miR-9 level to } \\
\text { attenuate the loss of viability, stimulation of } \\
\text { apoptosis, and release of pro-inflammatory } \\
\text { cytokines (IL-I } \beta, \text { IL- } 6 \text {, and TNF- } \alpha \text { ), inhibited } \\
\text { LPS-evoked JNK and NF- KB pathways via a miR- } \\
\text { 9-dependent way }\end{array}$ & {$[86]$} \\
\hline Multiple sclerosis & & Encephalomyelitisl Wistar rat model & 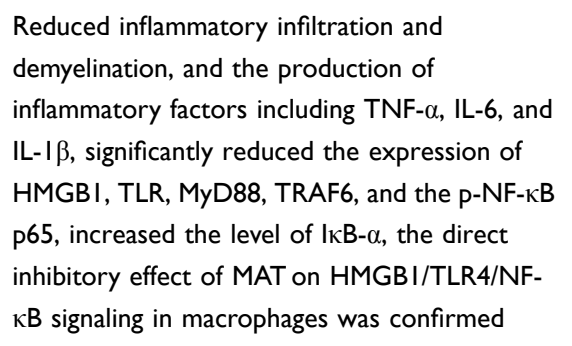 & {$[87]$} \\
\hline Acute ischemic stroke & & $\begin{array}{l}\text { Permanent middle cerebral artery occlusion } \\
\text { SD rat model }\end{array}$ & 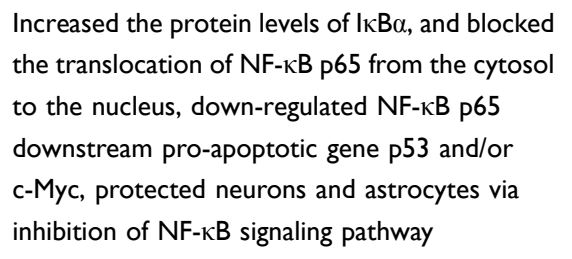 & {$[88]$} \\
\hline $\begin{array}{l}\text { Porcine circovirus } \\
\text { associated diseases }\end{array}$ & & $\begin{array}{l}\text { Porcine alveolar macrophages (PAMs) cells } \\
\text { model co-infected with PRRSV/PCV2 }\end{array}$ & 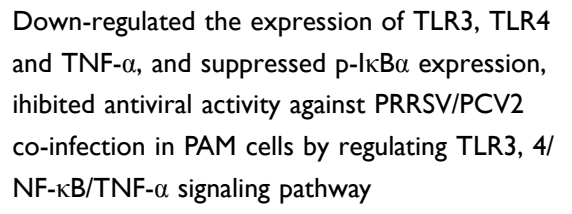 & [89] \\
\hline $\begin{array}{l}\text { Porcine reproductive } \\
\text { and respiratory } \\
\text { syndrome virus } \\
\text { (PRRSV) disease }\end{array}$ & & $\begin{array}{l}\text { Inflammatory model of PAMs by transfecting } \\
\text { PRRSV 5'UTR RNA and LPS }\end{array}$ & 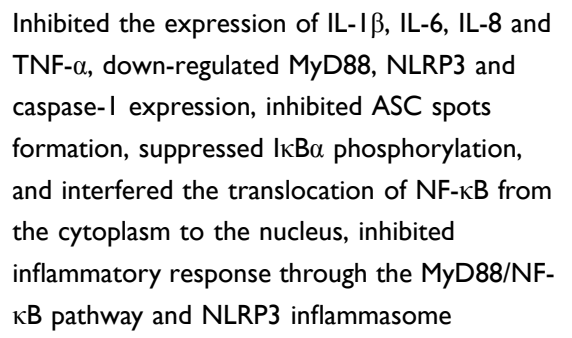 & [90] \\
\hline $\begin{array}{l}\text { Gastric mucosal } \\
\text { injury }\end{array}$ & & $\begin{array}{l}\text { Gastric mucosal injury induced by } \\
\text { N-methyl-N'-nitro-N-nitrosoguanidine } \\
\text { (MNNG) in rats }\end{array}$ & 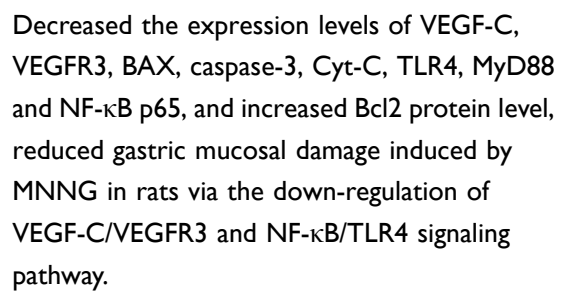 & [9I] \\
\hline Asthma & & $\begin{array}{l}\text { BEAS-2B, MLE- } 12 \text {; allergic airway } \\
\text { inflammation BALB/C mice model }\end{array}$ & $\begin{array}{l}\text { Abrogated the level of IL- } 4 \text { and IL-I } 3 \text { but } \\
\text { enhanced IFN- } \gamma \text { expression, impeded TNF- } \alpha- \\
\text { induced expression of IL- } 6 \text { and adhesion } \\
\text { molecules, suppressed airway inflammation by } \\
\text { downregulating SOCS3 expression via inhibiting } \\
\text { NF- } \mathrm{kB} \text { signaling }\end{array}$ & [92] \\
\hline
\end{tabular}


Table 3 (Continued).

\begin{tabular}{|c|c|c|c|c|}
\hline Disease & Drugs & Cell Line/Animal Model & Action Mechnism & Reference \\
\hline \multirow[t]{3}{*}{ Rheumatoid arthritis } & & Rat model of rheumatoid arthritis (RA) & $\begin{array}{l}\text { Modulated the imbalance of ThI and Th2 } \\
\text { cytokine responses in rats with RA by reducing } \\
\text { the levels of ThI cytokines (IFN- } \gamma \text {, TNF- } \alpha \text {, IL- } \\
\text { I } \beta \text { ), but increasing Th2 cytokine (IL- } 4 \text { and IL- I0) } \\
\text { through attenuating the NF- } \mathrm{B} \text { s signaling in T } \\
\text { cells }\end{array}$ & [93] \\
\hline & & $\begin{array}{l}\text { Type II collagen-induced arthritis (CIA) in } \\
\text { rats }\end{array}$ & 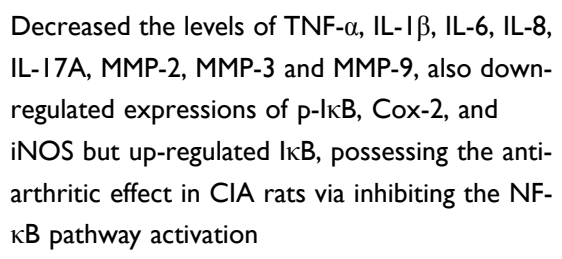 & [94] \\
\hline & MASM & $\begin{array}{l}\text { DBA/I mice with collagen-induced arthritis } \\
\text { (CIA) and fibroblast-like synoviocytes } \\
\text { derived from rheumatoid arthritis patients } \\
\text { (RA-FLS) }\end{array}$ & $\begin{array}{l}\text { Suppressed the expression of inflammatory } \\
\text { mediators pro-inflammatory cytokines (TNF- } \alpha \text {, } \\
\text { IL-6, IL-8) and matrix metalloproteinases (MMP- } \\
\text { I, MMP-3 and MMP-I3) by inhibiting both the } \\
\text { MAPK and NF-KB pathways and inducing } \\
\text { apoptosis of RA-FLS }\end{array}$ & [95] \\
\hline Osteoarthritis & \multirow[t]{3}{*}{ Matrine } & Human articular cartilage chondrocytes & $\begin{array}{l}\text { Inhibited the IL-I } \beta \text {-induced release of MMP-3 } \\
\text { and MMP-I3, and increased the production of } \\
\text { TIMP-I, inhibited the } \mathrm{P}-\mathrm{P} 38, \mathrm{P}-\mathrm{ERK}, \mathrm{P}-\mathrm{C}-\mathrm{JNK} \\
\text { and } \mathrm{p}-\mathrm{I} \mathrm{K} \alpha \text { degradation in chondrocytes, thus } \\
\text { exerted anti-inflammatory effects by } \\
\text { suppressing the activation of MAPK and NF- } \mathrm{KB} \\
\text { signaling pathways }\end{array}$ & [96] \\
\hline Endometritis & & $\begin{array}{l}\text { Bovine endometrial epithelial cells BEND } \\
\text { cells; Staphylococcus aureus lipoteichoic } \\
\text { acid (LTA)-induced endometritis in BALB/c } \\
\text { mice }\end{array}$ & $\begin{array}{l}\text { Reduced the expression of pro-inflammatory } \\
\text { cytokines (TNF- } \alpha \text { and IL-I } \beta \text { ), suppressed TLR2 } \\
\text { expression and its downstream nuclear factor } \\
\text { (NF)- } \mathrm{B} \text { activation, alleviating LTA-induced } \\
\text { endometritis through negative regulation of } \\
\text { TLR2-mediated NF- } \kappa B \text { pathway }\end{array}$ & [97] \\
\hline Atherosclerosis & & HASMCs & $\begin{array}{l}\text { Inhibited the expression of VCAM I and ICAM } \\
I \text { in TNF } \alpha \text { stimulated HASMCs via the } \\
\text { suppression of ROS production as well as NF } \kappa B \\
\text { and MAPK pathway activation }\end{array}$ & [98] \\
\hline
\end{tabular}

pathway plays an important role in development, stem cell differentiation, and homeostasis, but abnormal activation or interruption of this signaling is closely related to the occurrence of various types of diseases. ${ }^{100}$ Currently, the Wnt $/ \beta$ catenin pathway has become one of the major targets for drug discovery and development.

Dai et $\mathrm{al}^{101}$ explored the effect of matrine on HCC cell proliferation and stemness, and found that matrine inhibited the proliferation and colony formation of HEPG2 and Huh7 cells in a time-concentration-dependent manner, and the mechanism may be to inhibit the activation of Wnt/ $\beta$-catenin signaling pathway, and then interfere with the expression of tumor stem cell markers epithelial cell adhesion molecule (EPCAM), CD90 and CD133, thereby weakening the malignant biological characteristics such as infinite proliferation and differentiation of HCC cells, and playing an anti-tumor effect.

Eradication of cancer stem cell-like cells (CSCs) is of great significance for the treatment and prevention of cancer. $\mathrm{Li}$ et $\mathrm{al}^{102}$ focused on the possible roles of matrine on the self-renewal capacity of non-small cell lung cancer (NSCLC) CSCs and demonstrated that matrine inhibited the properties of CSCs, increased MicroRNA let-7b (Let-7b) levels in a 
Dicer1-dependent manner, and revealed that Let-7b directly targeted and reduced the expression of CCND1, thereby inactivating the CCND1/Wnt signaling pathway and inhibiting EMT. In addition, matrine enhanced the sensitivity of CSCs to 5-FU and inhibited the accumulation of CCND1 in 5-FU-induced tumor tissues. These results illustrated the role of matrine in inhibiting the properties of NSCLC CSCs and improving the therapeutic effect of 5-FU on NSCLC, and provided new insight for the molecular mechanism of matrine or combined 5-FU in interventing in the expansion of NSCLC CSCs, which is helpful to fulfill the anti-NSCLC effect of matrine. Another study by them ${ }^{103}$ explored the potential mechanism of matrine in regulating human breast cancer stem cells (BrCSCs) and found that matrine inhibited the differentiation and self-renewal of BrCSCs by down-regulating the expression of Lin-28 homolog A (Lin28A), a well-characterized suppressor of Let-7b, thereby inactivating the Wnt pathway in a Let-7b-dependent manner. Furthermore, matrine increased the sensitivity of BrCSCs to cisplatin inhibition of tumor expansion in vitro and in vivo. These data revealed a novel mechanism by which matrine induced breast cancer regression and chemosensitivity.

Xiao et $\mathrm{al}^{104}$ studied the effect of matrine on breast cancer and found that matrine inhibited the viability of breast cancer 4T1 and MCF-7 cells and induced apoptosis in a dose- and time-dependent manner. In addition, matrine suppressed the growth of 4T1 tumors, promoted apoptosis, inhibited vascular endothelial growth factor expression, and down-regulated the levels of major proteins of the $\mathrm{Wnt} / \beta$-catenin signaling pathway in vivo, suggesting that matrine can effectively inhibit breast cancer growth by downregulating the Wnt/ $\beta$-catenin signaling pathway, and may be a potential treatment for breast cancer.

Liu et $\mathrm{al}^{105}$ used matrine to stimulate colon cancer SW480 and SW620 cells and found that matrine upregulated the expression of miR-22, thereby obstructing Wnt/ $\beta$-catenin and MEK/ERK pathways, significantly inhibiting cell viability, and inducing apoptosis and cell cycle arrest at G0/G1 phase, while suppression of miR-22 reversed the effect of matrine on colon cancer cell behaviors, revealing the antitumor activity of matrine in colon cancer cells.

Ma et $\mathrm{al}^{106}$ explored the mechanism of matrine inhibiting the migration and invasion of human pancreatic cancer cell, and demonstrated that matrine inhibited the proliferation of human pancreatic cancer HPAC and Capan-1 cells in a doseeffect manner within a certain concentration range, and markedly inhibited the cell migration and invasion. Moreover, the expression of matrix metallopeptidase 14 (MT1-MMP), MMP-2, MMP-9, Wnt, and $\beta$-Catenin significantly decreased upon matrine treatment. Analysis of MT1-MMP transcriptional activity revealed that matrine mediated downregulation of MT1-MMP expression through the Wnt signaling pathway. These findings indicated that matrine inhibited the migration and invasion of HPAC cells by downregulating the Wnt/ $\beta$-Catenin signaling pathway.

Survivin has been reported to be overexpressed in HCC and promote the malignant progression of HCC. Yin et al ${ }^{107}$ established a Survivin-targeted drug screening platform, screened and identified a matrine derivative bearing a benzo- $\alpha-$ pyrone structure, WM-127, which was demonstrated to be a strong Survivin inhibitor that inhibited cell proliferation, induced cell cycle arrest and apoptosis of HCC cells, and showed low cytotoxicity in normal cells. Besides, WM-127 also suppressed the growth of HCC xenografted tumors in nude mice. Mechanistically, WM-127 may exert its anti-tumor effect by inhibiting the activity of the Survivin/ $\beta$-catenin pathway and upregulating Bax expression. These data implied that WM-127 may be a promising chemotherapeutic drug for HCC with favorable safety profile.

Ni et $\mathrm{al}^{108}$ evaluated the effect of a novel matrine derivative WM130 on HCC CSCs, and demonstrated that WM130 significantly and preferentially inhibited hepatic CSCs, while inhibiting the expression of some stemness-related genes and HCC xenografts growth in vivo. Moreover, they indicated that WM130 in combination with Doxorubicin (DOX) exhibits a better inhibitory efficacy. Further mechanistic studies revealed that WM130 administration notably reduced GSK3 $\beta$ (Ser9) phosphorylation and decreased the expression level of $\beta$-catenin and its target gene CCND1, as well as the expression of hepatic stem cell biomarker EPCAM, suggesting that the inhibitory effect of WM130 on hepatic CSCs was mediated, at least partly, by inhibiting the Wnt/ $\beta$-catenin signaling pathway. These findings prompted that WM130 may serve as a novel therapeutic candidate for HCC.

We have summarized the relevant studies on the pharmacological effects of matrine through the Wnt/ $\beta$-catenin signaling pathway in Table 4. 
Table 4 The Relevant Studies on the Pharmacological Effects of Matrine Through the Wnt/B-Catenin Signaling Pathway

\begin{tabular}{|c|c|c|c|c|}
\hline Disease & Drugs & Cell Line/Animal Model & Action Mechanism & Reference \\
\hline NSCLC & Matrine & $\begin{array}{l}\text { A549, H460; A549 xenograft tumor model } \\
\text { in BALB/c nude mice }\end{array}$ & $\begin{array}{l}\text { Increased Let-7b levels, reduced the expression of } \\
\text { CCNDI, inactivated the CCNDI/Wnt signaling pathway } \\
\text { and inhibited EMT, thus inhibited cancer stem-like cell } \\
\text { (CSC) properties }\end{array}$ & {$[102]$} \\
\hline \multirow[t]{2}{*}{$\begin{array}{l}\text { Breast } \\
\text { cancer }\end{array}$} & & $\begin{array}{l}\text { MCF-7, T47D; T47D xenograft tumor } \\
\text { model in SCID/beige mice }\end{array}$ & $\begin{array}{l}\text { Decreased BrCSCs markers (CDI33 and KLF4) and Wnt/ } \\
\text { CCNDI signaling, increased Let-7b level in LIN28A } \\
\text { dependent manner, suppressed the BrCSCs differentiation } \\
\text { and self-renewal through downregulating the expression of } \\
\text { Lin28A, inhibited BrCSCs via Let-7b/CCNDI/Wnt } \\
\text { pathway }\end{array}$ & {$[103]$} \\
\hline & & $\begin{array}{l}\text { 4TI, MCF-7; } 4 \text { TI xenograft tumor model in } \\
\text { BALB/C mice }\end{array}$ & $\begin{array}{l}\text { Reduced the expression of VEGF, Wnt I, } \beta \text {-catenin, cyclin } \\
\text { DI and c-Myc, effectively inhibited breast cancer growth by } \\
\text { downregulating the } W n t / \beta \text {-catenin signaling pathway }\end{array}$ & {$[104]$} \\
\hline $\begin{array}{l}\text { Colon } \\
\text { cancer }\end{array}$ & & SW480, SW620 & $\begin{array}{l}\text { Enhanced the expression of miR-22, abated } \beta \text {-catenin, } \\
\text { p-MEK and p-ERK levels, thereby blocking } W n t / \beta \text {-catenin } \\
\text { and MEK/ERK pathways }\end{array}$ & {$[105]$} \\
\hline $\begin{array}{l}\text { Pancreatic } \\
\text { cancer }\end{array}$ & & HPAC, CAPAN-I & $\begin{array}{l}\text { Reduced the expression of MTI-MMP, MMP2, MMP9, Wnt } \\
\text { and } \beta \text {-catenin, inhibited HPAC cellular migration and } \\
\text { invasion via the Wnt signaling pathway. }\end{array}$ & {$[106]$} \\
\hline \multirow[t]{2}{*}{$\mathrm{HCC}$} & $\begin{array}{l}\text { WM- } \\
127\end{array}$ & $\begin{array}{l}\text { HepG2, Hep3B, Huh-7, LM3, SMMC-772I, } \\
\text { and WRL-68; HuH-7 xenograft tumor } \\
\text { model in BALB/c nude mice }\end{array}$ & $\begin{array}{l}\text { Suppressed the activity of Survivin/ } \beta \text {-catenin pathway and } \\
\text { the expression of Bax to induce cell cycle arrest and } \\
\text { apoptosis }\end{array}$ & {$[107]$} \\
\hline & WMI30 & $\begin{array}{l}\text { Hep3B, MHCC-LM3, and MHCC-97H; } \\
\text { MHCC-LM3 xenograft tumor model }\end{array}$ & $\begin{array}{l}\text { Decreased the p-GSK3 } 3 \text { (Ser9), } \beta \text {-catenin and its target } \\
\text { genes Cyclin DI and EpCAM, remarkably inhibited hepatic } \\
\text { CSCs via the inhibition of GSK3 } 3 / \beta \text {-catenin signaling } \\
\text { pathway }\end{array}$ & {$[108]$} \\
\hline
\end{tabular}

\section{Matrine Exerts Pharmacological Effects Through the MAPK Signaling Pathways}

MAPK belongs to a large family of conserved serine-threonine protein kinases that mediate the cascade of important signal transduction pathways from extracellular signals to intracellular reactions in eukaryotic cells. For example, MAPK is phosphorylated and activated by MAPK kinase (MAPKK), MAPKK is phosphorylated and activated by MAPKK kinase (MAPKKK), and MAPKKK is activated by interacting with small GTPase and/or other proteases, thereby linking MAPK with cell surface receptors and extracellular signals to jointly regulate various physiological and pathological processes, such as cell proliferation, differentiation, apoptosis, and the stress response. ${ }^{109}$

Four MAPK cascade signal transduction pathways have been identified in eukaryotic cells: extracellular signalregulated protein kinase 1/2 (ERK1/2), JNK/stress-activated protein kinase (SAPK), p38 MAPK, and ERK5 signal transduction pathway. Erk1/2 was the earliest discovered classical Ras-Raf-MAPK signal transduction pathway, which participates in the signal transduction of various growth factors, cytokines, mitogens, and hormone receptors after activation and plays an important regulatory role in cell proliferation, growth, and differentiation. The JNK/SAPK and p38 MAPK signaling pathways are mainly responsible for signal transduction of various stress responses (such as UV, heat shock, and hypertonic pressure), chemotherapy drugs, and stimulation of inflammatory factors, and are involved in the regulation of apoptosis. ${ }^{110}$ Studies have shown that abnormal or excessive activation of the MAPK signaling pathway plays a significant role in the malignant transformation and evolution of cells. 
Tan et $\mathrm{al}^{111}$ investigated the inhibitory effect of matrine on lung cancer cells and confirmed that matrine inhibited NSCLC cell proliferation and induced apoptosis by inhibiting Bcl-2 and activating caspase- 3 and PARP. Additionally, matrine significantly increased the phosphorylation of $\mathrm{p} 38$, and inhibition of the p38 pathway partially prevented matrine-induced apoptosis. Furthermore, matrine stimulated ROS generation in a dose- and time-dependent manner. These findings indicated that matrine may be a promising NSCLC drug by activating the p38 pathway, inducing ROS production in non-small cell lung cancer cells, and leading to caspase-dependent apoptosis.

Yang et al ${ }^{112}$ explored the anticancer effect of matrine on human lymphoma cell line (U937) and found that matrine significantly suppressed the proliferation of U937 cell and induced apoptosis in vitro, inhibited the activity of ERK but increased the activities of $\mathrm{p} 38$ and JNK, suggesting matrine may promote apoptosis through the MAPK signaling pathway, and further provide experimental evidence for lymphoma chemotherapy and combination therapy.

Studies have shown that the MAPK pathway, a downstream signaling pathway abnormally activated by BCR/ABL tyrosine kinase, plays an important role in the occurrence and development of chronic myelogenous leukemia (CML). Ma et $\mathrm{al}^{113}$ studied the underlying molecular mechanism of the effect of matrine on CML K562 and HL-60 cells and demonstrated that matrine treatment significantly inhibited the expression of BCR/ABL in CML cells, downregulated the phosphorylation levels of MEK1, ERK1/2, and their upstream adaptor molecules Src homology 2 domain (SPH2) and Src homology 2 domain containing protein $\mathrm{C}$ (Shc), as well as the expression levels of BCL2-like 1 (Bcl-xL), CCND1, and c-Myc. Moreover, matrine significantly reduced the mortality of human leukemia cells-bearing mice. These results indicated that matrine inhibited the growth of CML cells by inhibiting the ERK/MAPK signaling pathway mediated by $\mathrm{BCR} / \mathrm{ABL}$, suggesting that matrine has a certain anti-leukemia activity.

MAPK/ERK has been found to be a crucial signaling pathway promoting endothelial cell proliferation, differentiation and survival. Lu et $\mathrm{al}^{114}$ studied the potential mechanism of matrine against lung cancer angiogenesis and found that matrine significantly inhibited the proliferation, migration, and p-ERK expression of HUVECs induced by conditioned medium of A549 human lung cancer cells, implying that suppressed MAPK/ERK signaling pathway is involved in the mechanism of matrine against angiogenesis in lung carcinoma, providing an experimental basis for the clinical application of matrine in the treatment of lung carcinoma.

A study by Ren et $\mathrm{al}^{115}$ explored the anti-metastatic effect of matrine on colorectal cancer (CRC) and found that matrine inhibited the proliferation, migration and invasion of CRC cells in vitro and in vivo. Additionally, matrine treatment significantly reduced the expression levels and proteinase activities of MMP-2 and MMP-9 in a dose-dependent manner, and decreased the phosphorylation level of p38. It was also found that the combination of $\mathrm{p} 38$ inhibitor SB203580 and matrine synergistically reduced CRC cell invasion and MMP-2/9 expression. These findings suggested that matrine may be involved in the inhibition of CRC cell migration and invasion by reducing the expression of MMP-2/ 9 through the p38 signaling pathway, and may serve as a potential CRC therapeutic drug.

Xin et $\mathrm{al}^{116}$ found that matrine significantly inhibited the viability, migration and invasion of ovarian cancer cells, and induced apoptosis. In addition, matrine treatment significantly upregulated the expression levels of p38MAPK, p-ERK/ ERK, and p-JNK/JNK, while p38MAPK knockdown significantly downregulated the expression levels of p-ERK/ERK and $\mathrm{p}-\mathrm{JNK} / \mathrm{JNK}$, promoting the viability, migration and invasion of ovarian cancer cells. Moreover, they also demonstrated that p38MAPK was involved in matrine-induced apoptosis of ovarian cancer cells by upregulating the expression of Fas cell surface death receptor (Fas) and caspase-8. This study showed that matrine significantly inhibited cell viability, migration and invasion, and induced apoptosis by up-regulating the p38 MAPK-mediated ERK/JNK signaling pathway, and in vivo experiments further verified these findings, which may provide a basis for evaluating the efficacy of matrine in the treatment of ovarian cancer.

Hai et $\mathrm{al}^{117}$ further studied the therapeutic potential of matrine on prostate cancer based on the cancer genome atlas (TCGA) database, and identified growth arrest and DNA damage inducible beta (GADD45B) as one of the major target genes of matrine. GADD45B is a tumor-suppressive gene involved in the regulation of cell cycle, DNA damage repair, cell survival, senescence, apoptosis, and other cellular processes. They found that matrine promoted the expression of GADD45B through the p38/JNK and ROS-GADD45B-p38 signaling pathways, and the higher level of GADD45B indicate the better survival of prostate cancer patients. These findings suggested that matrine can be used to treat prostate cancer patients and improve their survival. 
A research by $\mathrm{Ma}$ et $\mathrm{al}^{118}$ investigated the effect of matrine against human osteosarcoma MG-63 cells through autophagy, and found that matrine significantly inhibited cell proliferation and induced cell apoptosis, and upregulated the expression of pro-apoptosis-related proteins Bax, LC3II, and p-ERK, and downregulated the expression of antiapoptotic protein Bcl-2 in a time-dependent manner. Furthermore, matrine induced protective autophagy in MG-63 cells, and demonstrated for the first time that matrine-induced autophagy attenuated apoptosis through the ERK1/2 signaling pathway. This study indicated that matrine combined with autophagy inhibitors (including CHQ) or ERK signaling pathway inhibitors (including U0126) may be a promising therapeutic strategy for osteosarcoma.

Zhou et $\mathrm{al}^{119}$ studied the anti-inflammatory effect of matrine on oxidized low-density lipoprotein (ox-LDL)-exposed macrophages, and found that matrine significantly inhibited the inflammatory response of ox-LDL-induced macrophages, reduced the intracellular ROS levels. In addition, matrine reduced the relative phosphorylation of MAP Kinase Kinase (MKK) 3, MKK6, and p38 MAPK. These results suggested that matrine may inhibit ox-LDL-induced inflammation by inhibiting the activation of MKKs/p38 MAPK signaling pathway, providing evidence and clues for the potential application of matrine in the clinical treatment of atherosclerotic diseases.

AGEs have been reported to mediate diabetic vascular complications, trigger ROS overproduction, and induce apoptosis in aortic endothelium cells both in vitro and in vivo. Liu et al ${ }^{120}$ indicated that administration of matrinetype alkaloids (ie, matrine, oxymatrine and sophocarpine) suppressed intracellular ROS levels and endothelial cell apoptosis by restoring the phosphorylation of MKK3/6 and the activation of $\mathrm{p} 38 \mathrm{MAPK} / \mathrm{Nrf2} /$ antioxidant response element (ARE) in vitro and in vivo. These findings proved that matrine-type alkaloids have endothelial protective effects on ROS-mediated AGEs-induced apoptosis of aortic endothelial cells by targeting MKK3 and p38MAPK signaling, and provide clues for the potential clinical application of matrine-type alkaloids in the therapy of diabetic vascular complications.

Zhang et $\mathrm{al}^{121}$ explored the effect of matrine on cardiac fibrosis and found that matrine significantly reduced fibrosis reconstruction and cardiac dysfunction induced by aortic banding (AB) operation or continuous injection of isoproterenol (ISO) in mice, and significantly inhibited the proliferation, migration, collagen production and phenotypic transdifferentiation of cardiac fibroblasts. Mechanistically, matrine inhibited the activation of p38 both in vitro and in vivo, but overexpression of $\mathrm{p} 38$ eliminated the protective effect of matrine. It was also confirmed that the upregulation of RPS5 was associated with matrine-mediated p38 inhibition and fibrogenesis. What's more, matrine can improve preexisting cardiac fibrosis in mice. From these results, it can be seen that matrine treatment attenuated cardiac fibrosis in mice by regulating the RPS5/p38 signaling pathway, and may be an effective drug for the treatment of pathological cardiac fibrosis.

Wu et al ${ }^{122}$ evaluated the anti-tumor effect of matrine in cervical cancer and found that matrine significantly inhibited the growth of cervical cancer cells by inducing apoptosis, and suppressed the invasion and migration ability of cervical cancer cells in a concentration-dependent manner in vitro, while in vivo by intraperitoneal (i.p.) injection of matrine significantly reduced the growth of xenograft tumor. Mechanistically, matrine reduced the expression and activity of the ECM factors, MMP-2 and MMP-9 by inhibiting the p38 signaling pathway. These findings suggested that matrine may suppress the growth and metastasis of cervical cancer by downregulating the p38 signaling pathway, providing a potential drug candidate for the treatment of cervical cancer.

MASM, a matrine derivative, has been reported to inhibit the activation of macrophages, dendritic cells, and hepatic stellate cells, and bind to RPS5. Xu et al ${ }^{123}$ evaluate the effect of MASM on murine-established lethal sepsis and found that MASM markedly attenuated LPS-induced release and expression of TNF $\alpha, \mathrm{IL}-6$, and NO/iNOS in murine peritoneal macrophages and RAW264.7 cells. Meanwhile, MASM inhibited LPS-induced activation of NF-kB and MAPK pathways. They also found that RPS5, a cellular target of MASM, inhibited LPS-induced inflammatory response, at least partially mediating the anti-inflammatory effects of MASM in vitro. Furthermore, MASM significantly improved overall survival in mice model of sepsis. The mechanism of action of MASM observed in this study may be related to the RPS5mediated suppression of NF- $\mathrm{KB}$ and MAPK activation and the decrease in the expression of proinflammatory mediators, indicating that MASM may be further used in the treatment of sepsis. Li et al ${ }^{124}$ found a protective effect of MASM against rats with lethal total body irradiation (TBI), and that MASM pretreatment reduced the symptoms of radiation sickness and increased the survival of rats before or after lethal TBI, which may be mainly or partly by modulating 
multiple MAPK pathways. These results suggested that MASM has the potential to serve as an effective therapeutic or radioprotective agent to minimize radiation damages and improve the efficacy of combined oncology radiotherapy.

The maturation of dendritic cells (DCs) is a crucial step in the development of T-cell immune responses and immune tolerance. $\mathrm{Xu}$ et al ${ }^{125}$ investigated the inhibitory effect of MASM on LPS-induced maturation of mouse bone marrowderived DCs and found that MASM suppressed the maturation of phenotypic and functional DCs, which was associated with the downregulation of NF-KB, MAPKs, and PI3K/AKT signaling pathways. These findings may provide new insight into the immunosuppressive effects of MASM.

We have summarized the relevant studies on the pharmacological effects of matrine through the MAPKs signaling pathway in Table 5.

Table 5 The Relevant Studies on the Pharmacological Effects of Matrine Through the MAPK Signaling Pathway

\begin{tabular}{|c|c|c|c|c|}
\hline Disease & Drugs & Cell Line/Animal Model & Action Mechanism & Reference \\
\hline NSCLC & Matrine & A549, $\mathrm{NCl}-\mathrm{H} 358$ & $\begin{array}{l}\text { Increased the p-p38, inhibited } \mathrm{BCl} 2 \text { and activated caspase- } 3 \text { and } \\
\text { PARP, caused NSCLC apoptosis via induction of ROS generation } \\
\text { and subsequent activation of MAPK/p38 signaling pathway }\end{array}$ & {$[111]$} \\
\hline Lymphoma & & U937 & $\begin{array}{l}\text { Inhibited the activity of ERK and increased the activities of p } 38 \\
\text { and JNK, promoted cell apoptosis through MAPK signaling } \\
\text { pathway }\end{array}$ & [112] \\
\hline CML & & $\begin{array}{l}\text { K562, HL-60; K562 cells xenograft tumor model in } \\
\text { NOD/SCID mice }\end{array}$ & $\begin{array}{l}\text { Down-regulated the p-MEKI, p-ERKI/2, and their upstream } \\
\text { adaptor molecules Shc and SHP2, reduced the expression of } \\
B C R / A B L, B c l-x L, \text { Cyclin DI, and c-Myc, increased the expression } \\
\text { of p27, inhibited cell growth by inhibiting the BCR/ABL-mediated } \\
\text { ERK/MAPK signaling pathway }\end{array}$ & {$[113]$} \\
\hline Lung cancer & & A549, HUVECs & $\begin{array}{l}\text { Decreased expression of } \mathrm{p}-\mathrm{ERK} \text {, resisted lung cacinoma } \\
\text { angiogenesis by suppressing the MAPK/ERK signal transduction }\end{array}$ & 114] \\
\hline $\begin{array}{l}\text { Colorectal } \\
\text { cancer }\end{array}$ & & $\begin{array}{l}\mathrm{HT29} \text {, DLDI; HT29 xenograft BALB/c nude mice } \\
\text { and lung metastasis model }\end{array}$ & $\begin{array}{l}\text { Reduced the expression levels and proteinase activity of MMP-2 } \\
\text { and MMP-9, as well as the phosphorylation level of p } 38 \text {, inhibited } \\
\text { the proliferation and invasion of colorectal cancer cells via } \\
\text { reducing the activity of p } 38 \text { signaling pathway }\end{array}$ & {$[115]$} \\
\hline Ovarian cancer & & CAOV-3; CAOV-3-derived xenograft mice model & $\begin{array}{l}\text { Upregulated caspase } 8 \text { and Fas expression, downregulated Bcl2, } \\
\text { Bcl xl, ATIP3a, HMGA2, MTA-I and FN expression levels, and } \\
\text { increased p38MAPK, p-ERK/ERK and pJNK/JNK expression levels, } \\
\text { suppressed ovarian cancer cell viability, migration and invasion via } \\
\text { the p38MAPK-mediated ERK/JNK signaling pathway }\end{array}$ & {$[116]$} \\
\hline Prostate cancer & & DUI45, PC3 & $\begin{array}{l}\text { Promoted the expression of tumor suppressor gene GADD } 45 B \\
\text { through } \mathrm{p} 38 / \mathrm{JNK} \text {, ROS-GADD } 45 \mathrm{~B}-\mathrm{p} 38 \text {, or other signal pathways } \\
\text { to inhibit tumor invasion and improve patient survivals }\end{array}$ & [117] \\
\hline Osteosarcoma & & MG-63 & $\begin{array}{l}\text { Up-regulated the expression of Bax, LC3II and phosphorylated } \\
\text { ERK, down-regulated Bcl-2, induced autophagy thus attenuated } \\
\text { cell apoptosis via the ERKI/2 pathway }\end{array}$ & [118] \\
\hline Atherosclerosis & & THP-I & $\begin{array}{l}\text { Reduced intracellular ROS level and supernatant ILI8 and TNF } \alpha \\
\text { concentrations and increased TAC, reduced p-MKK6, p-MKK3, } \\
\text { and p-p38 MAPK, as well as the expression levels of ILI8 and } \\
\text { TNFalpha, suppressed ox-LDL-induced inflammation by inhibiting } \\
\text { the activation of MKKs/P38 MAPK signaling pathway }\end{array}$ & [119] \\
\hline
\end{tabular}

(Continued) 
Table 5 (Continued).

\begin{tabular}{|c|c|c|c|c|}
\hline Disease & Drugs & Cell Line/Animal Model & Action Mechanism & Reference \\
\hline & & $\begin{array}{l}\text { Rat aortic endothelial cells (RAECs); AGEs-induced } \\
\text { oxidative stress SD rat model }\end{array}$ & $\begin{array}{l}\text { Recovered p-MKK3/6 and p-p38 MAPK, Nrf2 nuclear } \\
\text { translocation, and antioxidant response element binding activity, } \\
\text { as well as the expression levels of } \mathrm{HOI} \text { and NQOI, increased } \\
\text { antioxidant ability of RAECs to inhibit ROS-mediated apoptosis by } \\
\text { regulating the p38 MAPK/Nrf2/ARE pathway }\end{array}$ & [120] \\
\hline $\begin{array}{l}\text { Pathological } \\
\text { cardiac fibrosis }\end{array}$ & & $\begin{array}{l}\text { Neonatal rat cardiac fibroblasts; aortic banding ( } \mathrm{AB}) \\
\text { operation or isoprenaline (ISO) induced pathological } \\
\text { cardiac fibrosis mice model }\end{array}$ & $\begin{array}{l}\text { Suppressed p } 38 \text { activation, upregulated RPS5, and ameliorated } \\
\text { preexisting cardiac fibrosis in mice, which may attenuate cardiac } \\
\text { fibrosis by regulating RPS5/p38 signaling pathway }\end{array}$ & {$[|2|]$} \\
\hline Cervical cancer & & $\begin{array}{l}\text { HeLa, C33A; HeLa cells subcutaneous xenograft } \\
\text { nude mice model }\end{array}$ & $\begin{array}{l}\text { Decreased the expression and activity of the extracellular MMP-2 } \\
\text { and MMP-9 via the suppression of } p 38 \text { signaling pathway, thereby } \\
\text { inhibited the growth and metastasis of cervical cancer }\end{array}$ & [122] \\
\hline Sepsis & MASM & $\begin{array}{l}\text { Primary macrophages, RAW264.7; LPS-induced } \\
\text { endotoxemia and Cecal Ligation and Puncture } \\
\text { (CLP)-induced sepsis }\end{array}$ & $\begin{array}{l}\text { Attenuated release and mRNA expression of TNF } \alpha \text {, IL6, and NO/ } \\
\text { inducible NO synthase, inhibited RPS5-mediated activation of } \\
\text { NFKB and MAPK pathways }\end{array}$ & [123] \\
\hline $\begin{array}{l}\text { Radiation } \\
\text { sickness }\end{array}$ & & Total-body irradiation Wistar rat & $\begin{array}{l}\text { Prevented differential expression of } 53 \% \text { ( } 765 \text { genes) of } 1445 \\
\text { differentially expressed genes induced by TBI, providing the } \\
\text { protective effects on lethal TBI mainly or partially through the } \\
\text { modulation of pathways, such as metabolic pathways, pathways in } \\
\text { cancer, and MAPK pathways }\end{array}$ & [124] \\
\hline $\begin{array}{l}\text { Autoimmune } \\
\text { diseases }\end{array}$ & & Primary dendritic cells & $\begin{array}{l}\text { Inhibited LPS-induced expression of costimulatory molecules } \\
\text { CD80 and CD86, attenuated IL-12p70, TNF- } \alpha \text {, IL- } 6 \text { and NO } \\
\text { release of DCs, suppressed the phenotypic and functional } \\
\text { maturation of murine DC by down-regulation of NF-KB, MAPKs } \\
\text { and PI3K/Akt signaling pathways }\end{array}$ & {$[125]$} \\
\hline
\end{tabular}

\section{Matrine Exerts Pharmacological Effects Through the Notch Signaling Pathway}

The Notch gene was originally identified by Thomas H. Morgan et al in mutant fruit flies and is so named based on its dominant wing notching phenotype. The Notch signaling pathway is an evolutionarily highly conserved transduction system, but unlike TGF- $\beta$, Wnt, Hedgehog, and other signaling pathways, activation of canonical Notch signaling is generally initiated by a ligand-binding process to the Notch receptor between two adjacent cells. ${ }^{126}$

To date, four Notch receptors (Notches 1-4) expressed on the surface of cell membranes and five transmembrane ligands, including delta-like ligand (DLL) 1, 3, and 4, and jagged canonical Notch ligand 1 and 2 (Jagged 1/2), have been described in mammals. After activation, Notch receptors are proteolytically cleaved by two proteases, a disintegrin and metalloprotease (ADAM) and gamma-secretase (GS), followed by cytoplasmic release and nuclear translocation of the notch intracellular domain (NICD), and further binds to the transcription factor CSL and participates in the transcriptional modulation of downstream target genes. ${ }^{127}$ The Notch signaling pathway governs many cellular core processes including cell fate and plays a crucial regulatory role in diverse biological processes such as the development, differentiation, survival, and functions of many immune cell populations.

Contractile-synthetic phenotypic conversion of VSMCs results in the formation of atherosclerotic plaque through abnormal synthesis, secretion, and deposition of ECM. Liu et al ${ }^{128}$ investigated the effect and underlying mechanism of matrine on AGE-induced VSMC contractile-synthetic phenotypic conversion. They found that matrine restored AGEinduced contractile-synthetic phenotypic conversion by increasing intracellular MYH11 and smooth muscle $\alpha$-actin (ACTA2) in HCSMCs, reduced AGE-mediated activation of Notch signaling, and downregulated the expression levels of NICD1, Hes family basic helix-loop-helix (bHLH) transcription factor 1 (HES1), collagen I, as well as collagen VIII 
and collagen secretion. Moreover, matrine treatment inhibited the expression of Dll4 without affecting other Notch ligands in HCSMCs exposed to AGEs. These results indicated that matrine blocked AGE-induced HCSMC phenotypic conversion by suppressing the activation of the Dll4-Notch signaling pathway. Zhao et al ${ }^{129}$ also carried out relevant studies and confirmed that matrine inhibited AGE-induced phenotypic transformation of HCSMCs in a concentrationdependent manner and reduced the expression levels of glucose-regulated protein 78 (GRP78), D114, NICD1, and HES1 and the phosphorylation level of protein kinase RNA-like ER kinase (PERK). This suggested that matrine suppressed AGE-induced HCSMC phenotypic conversion by attenuating endoplasmic reticulum stress PERK signaling-dependent Dll4-Notch signaling pathway activation. These studies provide a theoretical basis for the clinical application of matrine in the treatment of arteriosclerosis.

In vivo administration of matrine was observed to promote oval cell-mediated liver regeneration in rats, suggesting that matrine may affect the differentiation of hepatic progenitor cells. To further investigate the effect of matrine on the differentiation of rat hepatic progenitor WB-F344 cells, Yang et a ${ }^{130}$ collected rat serum after administering matrine and co-cultured WB-F344 cells with rat serum. Matrine serum was found to inhibit the proliferation of WB-F344 cells, downregulate Jagged1 and HES1, upregulate albumin (ALB), induce WB-F344 cells differentiation; and also found that Notch signaling pathway activator reversed the effects of matrine serum. These findings indicated that matrine may induce differentiation of hepatic progenitor cells by inhibiting the Notch/Jagged1/HES1 signaling pathway.

Shi et $\mathrm{al}^{131}$ found in HCC patients, the hyperactive Notch pathway was closely related to poor liver function, and confirmed that the Notch pathway could maintain stem cell properties of hepatic oval cells (HOCs). In addition, matrine inhibited the stem cell properties of HOCs, inhibited Notch1, Jagged1, HES1, and the HOC markers Alpha-fetoprotein (AFP), cytokeratin19 (CK-19), and C-Kit (KIT proto-oncogene, receptor tyrosine kinase) expression, but increased ALB secretion in mature hepatocytes. In the rat Solt-Farber precancerous lesion model, prophylactic matrine attenuated liver injury, downregulated the Notch pathway and the expression of HOC markers, and dose-dependently upregulated ALB. These suggested that matrine can induce HOCs to differentiate into hepatocytes by inhibiting the Notch signaling pathway and alleviate liver injury, providing a novel strategy for the treatment of severe liver damage and the prevention of HCC.

Shi et $\mathrm{al}^{132}$ established a rat model of drug-resistant hepatocyte and further explored the effect of matrine on the early changes of liver carcinogenesis. They indicated that matrine treatment significantly inhibited the development of precancerous lesions, including restoration of hepatic cord structure, reduction of hepatic edema and degeneration, and changes in AFP and ALB expression. In addition, the activation of Notch signaling pathway was detected in the model, while the application of high-dose matrine significantly reduced the expression levels of Notch pathway components Notch1 and HES1, indicating that matrine may prevent the early development of HCC-like lesions by suppressing the activation of Notch signaling pathway, and may be an effective chemopreventive agent for HCC.

We have summarized the relevant studies on the pharmacological effects of matrine through the Notch signaling pathway in Table 6.

\section{Matrine Exerts Pharmacological Effects Through the JAK/STAT Signaling Pathway}

The JAK/STAT signaling pathway is an evolutionarily conserved signaling cascade that is essential for numerous developmental and homeostatic processes. The pathway communicates information from extracellular chemical signals to receptors that permit their associated intracellular JAKs to phosphorylate one another. Trans-p-JAKs then phosphorylate and activate downstream STATs, which are transported into the nucleus, bind as dimers or as more complex oligomers to specific enhancer sequences in target genes, and regulate their transcription. ${ }^{133}$ There are three key parts of JAK/STAT signaling: JAKs, STATs, and tyrosine kinase-related receptors (which bind the chemical signals). These signaling pathways are involved in cell proliferation, differentiation, apoptosis, immune regulation, and hematopoiesis, as well as other cellular processes. ${ }^{134}$ Disrupted JAK/STAT signaling may lead to a variety of diseases, such as skin conditions, cancers, and disorders affecting the immune system. 
Table 6 The Relevant Studies on the Pharmacological Effects of Matrine Through the Notch Signaling Pathway

\begin{tabular}{|c|c|c|c|c|}
\hline Disease & Drugs & $\begin{array}{l}\text { Cell Line/Animal } \\
\text { Model }\end{array}$ & Action Mechanism & Reference \\
\hline \multirow[t]{2}{*}{ Atherosclerosis } & \multirow[t]{5}{*}{ Matrine } & \multirow[t]{2}{*}{ HCSMCs } & $\begin{array}{l}\text { Reduced AGEs-mediated activation of Notch signaling, inhibited Notch } \\
\text { ligand DII4 expression, down-regulated expression of NICDI, HESI, } \\
\text { collagen I and collagen VIII and collagen secretion contents, blocked the } \\
\text { contractile-synthetic phenotypic conversion by suppressing DII4-Notch } \\
\text { signaling pathway activation }\end{array}$ & [128] \\
\hline & & & $\begin{array}{l}\text { Reduced expression level of GRP78, DII4, NICDI, HESI and the } \\
\text { phosphrylation level of PERK, and suppressed AGE-BSA-induced phenotypic } \\
\text { conversion of HCSMCs via attenuating ER stress PERK signaling-dependent } \\
\text { DIl4-Notch pathway activation. }\end{array}$ & [129] \\
\hline $\begin{array}{l}\text { Liver } \\
\text { regeneration }\end{array}$ & & WB-F344 & $\begin{array}{l}\text { Inhbited the expression of the Notch signaling ligands, JaggedI and HESI, } \\
\text { and upregulated the expression of ALB, induced hepatic progenitor cells } \\
\text { differentiation by inhibiting Notch/Jagge I/HESI signaling pathway }\end{array}$ & {$[130]$} \\
\hline \multirow[t]{2}{*}{$\mathrm{HCC}$} & & $\begin{array}{l}\text { WB-F344; rat Solt- } \\
\text { Farber precancerous } \\
\text { model }\end{array}$ & $\begin{array}{l}\text { Inhibited stem cell characteristics of HOCs, the expression of Notch-I, } \\
\text { Jagge-I, Hes-I and HOC markers AFP, CK-19, C-Kit, but upregulated ALB, } \\
\text { and induced HOCs to differentiate into hepatocytes by inhibiting the Notch } \\
\text { signaling pathway to reduce liver damage }\end{array}$ & {$[13 \mid]$} \\
\hline & & $\begin{array}{l}\text { Rat model of drug- } \\
\text { resistant hepatocytes }\end{array}$ & $\begin{array}{l}\text { Decreased the expression of AFP, increased the expression of ALB, and } \\
\text { reduced the expression levels of Notch pathway components Notch I and } \\
\text { HesI, and prevented the early development of HCC-like lesions by } \\
\text { inhibiting the activation of Notch pathway }\end{array}$ & [132] \\
\hline
\end{tabular}

Ma et $\mathrm{al}^{135}$ instilled bleomycin intratracheally in C57BL/6 mice to establish a PF model and then administered matrine intragastrically. They found that matrine treatment significantly relieved the severity of alveolitis and PF, inhibited the growth of pulmonary fibrocytes, and downregulated the abnormal expression of JAK, STAT1, and STAT3, showing that matrine exerts its anti-fibrotic effect by inhibiting the JAK-STAT signal transduction pathway, which may provide a new target for PF treatment.

Ma et $\mathrm{al}^{136}$ investigated the growth inhibitory effect of matrine on CML K562 cells and found that matrine significantly inhibited the phosphorylation levels of STAT3 and JAK2, inhibited the transcription and protein expression of downstream regulatory genes Bcl-xL, CCND1 and c-Myc of STAT3, and inhibited the IL-6 expression and secretion. Furthermore, matrine treatment decreased the upregulation of STAT3, JAK2, p-STAT3, and p-JAK2 protein in K562 cells after IL-6 pretreatment. These findings suggested that matrine exerts its anti-leukemia effect by interfering with the JAK/ STAT3 signaling pathway, and inhibiting the expression of IL-6 may be the initial mechanism of matrine regulated JAK/ STAT3 signaling. Lu et al, ${ }^{137}$ who belong to the same group as Ma et al, showed that matrine induced the expression of an killer cell lectin like receptor K1 (NKG2D) ligand UL16 binding protein 2 (ULBP2) in CML K562 cells and enhanced natural killer (NK) cell cytotoxicity, which is related to the inhibition of IL-6 expression, which in turn suppressed the activation of IL-6 receptor-mediated JAK/STAT3 signaling pathway. These studies provided useful evidence for further elucidating the underlying mechanism of matrine in the treatment of leukemia, as well as its clinical application.

Resistance to EGFR inhibitors is a major threat to patients with EGFR-mutant NSCLC. Chen et $\mathrm{a}^{138}$ demonstrated that matrine treatment reduced the expression of IL-6, inhibited the activation of JAK1/STAT3 signaling pathway, and restrained the growth of T790M EGFR-mutated NSCLC H1975 cells, while afatinib and matrine combination strengthened the inhibitory effects of afatinib, indicating that matrine enhanced the toxicity of afatinib toward H1975 cells by suppressing the activation of the IL-6/JAK1/STAT3 signaling pathway. Combination of matrine and afatinib in patients with T790M EGFR-mutant NSCLC may be a successful treatment strategy. 
Excessive proliferation of FLS and intrinsic resistance to apoptosis are significant mechanisms for the occurrence of RA. Nevertheless, the effect of matrine on FLS in RA is unclear. Yang et $\mathrm{al}^{139}$ explored the effect of matrine in the CIA rat model and found that matrine significantly reduced the arthritis index (AI) and improved ankle pathology, inhibited the proliferation of FLS in CIA rats, induced G0/G1 cell cycle arrest and apoptosis. In addition, matrine treatment also suppressed the phosphorylation of JAK2, STAT1, and STAT3. It is suggested that matrine exerted anti-proliferative and pro-apoptotic effects on FLS by inhibiting the activation of JAK/STAT signaling pathway, and may serve as a novel RA therapeutic agent.

We have summarized the relevant studies on the pharmacological effects of matrine through the JAK/STAT signaling pathway in Table 7.

\section{Matrine Exerts Pharmacological Effects Through Other Signaling Pathways}

The AMP-activated protein kinase (AMPK) signaling pathway is a fuel sensor and regulator that promotes ATPproduction and inhibits ATP-consuming pathways in various tissues, and also plays an important role in the regulation of cellular energy homeostasis. ${ }^{140,141}$ It is therefore a potential target in the development of new treatments for obesity, type II diabetes, metabolic syndrome, and cancer. ${ }^{142} \mathrm{Lu}$ et al ${ }^{143}$ explored the cardioprotective effect of matrine on cardiomyocyte damage under hypoxia/reoxygenation and found that matrine significantly increased cardiomyocyte viability and inhibited apoptosis after hypoxia/reoxygenation. In addition, matrine administration upregulated Sirtuin 3 (Sirt3) and AMPK expression and activity in the presence of hypoxia/reoxygenation, where inhibition of the Sirt3/AMPK pathway abolished the cardioprotective effect of matrine in cardiomyocytes. These findings demonstrated that matrine reduced hypoxia/reoxygenation-mediated cardiomyocyte death by activating the Sirt3/AMPK pathway, which may provide novel insight into the treatment of myocardial ischemia-reperfusion injury. Xie et al ${ }^{144}$ found that matrine inhibited proliferation and induced apoptosis in hepatoma cells and stimulated autophagy in HCC HepG2 cells in an mTOR-independent manner. Further studies showed that autophagy induced by matrine was regulated by p53 inactivation through AMPK signal transduction, and inhibition of AMPK converted autophagy to apoptosis. These results

Table 7 The Relevant Studies on the Pharmacological Effects of Matrine Through the JAK-STAT Signaling Pathway

\begin{tabular}{|c|c|c|c|c|}
\hline Disease & Drugs & Cell Line/Animal Model & Action Mechanism & Reference \\
\hline $\begin{array}{l}\text { Pulmonary } \\
\text { fibrosis (PF) }\end{array}$ & Matrine & $\begin{array}{l}\text { MRC5; Bleomycin (BLM)- } \\
\text { induced PF C57BL/6 mice } \\
\text { model }\end{array}$ & $\begin{array}{l}\text { Down-regulated the abnormal expression of JAK, STATI and } \\
\text { STAT3, and play an anti-fibrotic effect by inhibiting the JAK-STAT } \\
\text { signal transduction pathway }\end{array}$ & [135] \\
\hline \multirow[t]{2}{*}{ Leukemia } & & K562 & $\begin{array}{l}\text { Down-regulated the p-STAT3 and p-JAK2 expression, decreased } \\
\text { the Bcl-xL, Cyclin DI, and IL-6 levels, play anti-leukemia effects } \\
\text { by interfering with JAK/STAT3 signaling pathway }\end{array}$ & [136] \\
\hline & & K562, NK92 & $\begin{array}{l}\text { Induced the expression of the NKG2D ligand ULBP2, enhanced } \\
\text { the cytotoxicity of NK cells, inhibited IL- } 6 \text { expression and the } \\
\text { protein levels of P-STAT3 and p-JAK2, and suppressed the } \\
\text { activation of the IL- } 6 \text { receptor-mediated JAK/STAT3 signaling } \\
\text { pathway }\end{array}$ & [137] \\
\hline NSCLC & $\begin{array}{l}\text { Matrine or } \\
\text { combination } \\
\text { with afatinib }\end{array}$ & HI975 & $\begin{array}{l}\text { Decreased IL } 6 \text { expression, inhibited activation of the JAKI/ } \\
\text { STAT3 signaling pathway, reduced the expression levels of Bcl } 2 \\
\text { and inhibits cell growth; increased the inhibitory effects of } \\
\text { afatinib on HI975 cells with the T790M EGFR mutation }\end{array}$ & [138] \\
\hline $\begin{array}{l}\text { Rheumatoid } \\
\text { arthritis }\end{array}$ & Matrine & $\begin{array}{l}\text { Fibroblast-like synoviocytes; } \\
\text { Collagen-induced arthritis SD } \\
\text { rat model }\end{array}$ & $\begin{array}{l}\text { Decreased Bcl-2 levels but increased Bax and caspase- } 3 \text { levels, } \\
\text { diminished the phosphorylation, and hence activation of JAK2, } \\
\text { STATI and STAT3, induced apoptosis by inhibiting the activation } \\
\text { of JAK/STAT signaling pathway }\end{array}$ & [139] \\
\hline
\end{tabular}


suggested that the p53/AMPK signaling pathway is involved in matrine-induced autophagy, and pharmacological regulation of autophagy may improve the therapeutic effect of matrine against HCC.

Mitochondrial homeostasis is closely related to the progression of HCC through multiple mechanisms and is a potential tumor suppressor target in clinical practice. Cao et $\mathrm{al}^{145}$ investigated the effect of matrine on mitochondrial homeostasis in HCC HepG2 cells and showed that matrine treatment activated mitochondrial fission, which promoted mitochondrial dysfunction and initiated apoptotic pathways to inhibit cell proliferation. Moreover, they verified that the macrophage stimulating 1 (MST1)/JNK signaling pathway was necessary for matrine-modulated mitochondrial fission and that matrine-mediated mitochondrial dysfunction can be reversed by inhibiting this pathway. These results suggested that matrine has an anti-HCC effect via activating the mitochondrial division mediated by the MST1/JNK pathway. Yang et $\mathrm{al}^{146}$ established a rat oval cell-mediated liver regeneration model and found that matrine accelerated the recovery of hepatic function and decreased the expression of the OV6 protein (oval cell marker), recombination signal sequencebinding protein $\mathrm{J} \kappa(\mathrm{RBP}-\mathrm{J} \kappa)$, and HES1, suggesting that matrine promoted oval cell-mediated liver regeneration through downregulation of the RBP-JK/HES1 signaling pathway. These findings highlight new strategies for potential targets and treatment of HCC.

$\mathrm{Lu}$ et $\mathrm{al}^{147}$ studied the effect of matrine on lung adenocarcinoma A549 cells and found that matrine inhibited the proliferation and migration ability of A549 cells, which may be associated with the induction of p53 and p21 overexpression and the reduction of the expression of proliferating cell nuclear antigen (PCNA) and eukaryotic translation initiation factor $4 \mathrm{E}$ (eIF4E), indicating the $\mathrm{p} 53 / \mathrm{p} 21 / \mathrm{PCNA} / \mathrm{eIF} 4 \mathrm{E}$ signaling pathway may be a new discovery in the treatment of lung adenocarcinoma with matrine. Abnormalities in the c-Myc gene make the clinical manifestations of diffuse large B-cell lymphoma (DLBCL) more aggressive. Gu et $\mathrm{al}^{148}$ found that the growth inhibitory effect of matrine on human B lymphoma SU-DHL-16 cells could be rescued by overexpression of c-Myc via recombinant adenovirus infection, the ectopic expression of c-Myc protein rescued the decreased expression of CDK6, and matrine treatment downregulated the phosphorylation of calcium/calmodulin dependent protein kinase II gamma (CaMKI $\gamma$ ), a critical protein kinase of c-Myc, confirming that matrine suppressed cell growth of DLBCL by inhibiting te CaMKII $\gamma / \mathrm{c}-\mathrm{Myc} /$ CDK6 signaling pathway. Studies suggest that the dysregulation of the JNK pathway and neurotrophic factors play a key role in the pathogenesis of neurobehavioral disorders (anxiety and depression). Khan et $\mathrm{al}^{149}$ observed that matrine treatment ameliorated anxiety- and depression-like emotional states in an acute burn injury mouse model by modulating JNK-mediated inflammation, oxidative stress, apoptosis, and brain-derived neurotrophic factor (BDNF)/VEGF signaling pathway, targeting the JNK and BDNF/VEGF signaling by matrine may represent a novel strategy for the treatment of neurobehavioral disorders.

We have summarized the relevant studies on the pharmacological effects of matrine through other signaling pathways in Table 8.

\section{Conclusions}

Researchers have carried out many beneficial studies on the roles and molecular mechanisms of matrine in the treatment of different pathological processes. Matrine acts on tissues and cells through multiple signaling pathways, exerting pharmacological functions such as anti-tumor, anti-inflammatory, and anti-fibrosis. Studies have reported that matrine has a strong inhibitory effect on various tumor cells, and its molecular mechanism lies in regulating cell cycle progression, promoting apoptosis, inhibiting tumor invasion and metastasis, inducing autophagy, reversing multidrug resistance in tumor cells, and regulating metabolism through mediating multiple cellular signaling pathways such as the PI3K/AKT/ mTOR, ${ }^{13-43}$ NF-kB,${ }^{77-85}$ Wnt/ $\beta$-catenin, ${ }^{101-108}$ MAPKs, ${ }^{111-118}$ Notch, ${ }^{131,132}$ and JAK-STAT ${ }^{136-138}$ pathways. Non-coding RNAs also play an important role in these events, ${ }^{16,19,22,41,42,102,103,105}$ indicating that the anti-tumor mechanisms of matrine involve multi-pathways, multi-targets, and multi-systems. In addition, matrine has anti-inflammatory effects in a variety of organ system diseases such as those of the cardiovascular, cerebrovascular, liver, kidney, and immune systems. Its mechanism of action may be related to blocking inflammatory signaling pathways induced by PI3K/AKT/ mTOR, ${ }^{44,47,49} \mathrm{NF}-\mathrm{\kappa B},{ }^{76,86,87,90,92-95,97,98}$ and $\mathrm{p} 38 / \mathrm{MAPKs},{ }^{119}$ ultimately inhibiting the release of inflammatory factors (IL-1 $\beta$, IL-6, IL-8, TNF- $\alpha$, etc.) and the expression of matrix metalloproteinases (MMP-1, MMP-2, MMP-3, MMP-9 and MMP-13, etc.), promoting the antioxidant-related Nrf2 signaling pathway to inhibit oxidative damage and improving the 
Table 8 The Relevant Studies on the Pharmacological Effects of Matrine Through Other Signaling Pathways

\begin{tabular}{|c|c|c|c|c|}
\hline Disease & Drugs & $\begin{array}{l}\text { Cell Linel } \\
\text { Animal } \\
\text { Model }\end{array}$ & Action Mechanism & References \\
\hline $\begin{array}{l}\text { Myocardial } \\
\text { Infarction }\end{array}$ & \multirow[t]{7}{*}{ Matrine } & $\mathrm{H} 9 \mathrm{C} 2$ & $\begin{array}{l}\text { Up-regulated Sirt3 and AMPK expression, reduced hypoxia/reoxygenation- } \\
\text { mediated cardiomyocyte death by activating the Sirt3/AMPK pathway in } \\
\text { cardiomyocytes }\end{array}$ & [143] \\
\hline \multirow[t]{2}{*}{$\mathrm{HCC}$} & & $\begin{array}{l}\text { HepG2, } \\
\text { SMMC-772I }\end{array}$ & $\begin{array}{l}\text { Increased p70S6K, AMPK and p53 levels, decreased Akt, ERK expression, the p53/ } \\
\text { AMPK signaling pathway is involved in matrine-promoted autophagy }\end{array}$ & [144] \\
\hline & & HepG2, Huh7 & $\begin{array}{l}\text { Increased Caspase3, PARP, Caspase9, Bax, Bad, Mstl, and JNK; decreased Cyclin } \\
\text { D, CDK4, Cytc, CyclinDI, and CyclinE, induced mitochondrial dysfunction and } \\
\text { amplified cell apoptosis via Mstl/JNK-mediated mitochondrial fission }\end{array}$ & [145] \\
\hline Liver damage & & $\begin{array}{l}\text { 2-AAF/PH rat } \\
\text { model }\end{array}$ & $\begin{array}{l}\text { Decreased OV6 protein, RBP-Jא and HESI mRNA expression, promoted oval cell- } \\
\text { mediated liver regeneration by down-regulating the RBP-JK-HESI signaling } \\
\text { pathway }\end{array}$ & [146] \\
\hline Lung cancer & & A549 & $\begin{array}{l}\text { Induced apoptosis and growth inhibition of lung cancer cells by overexpression of } \\
\text { p53 and p2I, and reduction of PCNA and elF4E, indicating the inhibitory effect of } \\
\text { matrine via the p53/p2I/PCNA/elF4E signal transduction pathway }\end{array}$ & [147] \\
\hline $\begin{array}{l}\text { Diffuse large } \\
\text { B-cell lymphom }\end{array}$ & & $\begin{array}{l}\text { SU-DHL-16, } \\
\text { OCI-LY3 }\end{array}$ & $\begin{array}{l}\text { Remarkably reduced the levels of p-c-Myc (Ser62) and p-CaMKIl } \gamma \text {, suppressed cell } \\
\text { growth of DLBCL by inhibiting CaMKIl } \gamma / \mathrm{c}-\mathrm{MyC} / \mathrm{CDK} 6 \text { signaling pathway }\end{array}$ & [148] \\
\hline $\begin{array}{l}\text { Neurobehavioral } \\
\text { disorders }\end{array}$ & & $\begin{array}{l}\text { Acute burn } \\
\text { injury mice }\end{array}$ & $\begin{array}{l}\text { Produced significant antianxiety and antidepressant effects through suppression of } \\
\text { JNK-mediated apoptotic/inflammatory signaling, oxidative stress, and reversed } \\
\text { burn-induced downregulation of BDNF/VEGF in the hippocampus }\end{array}$ & [149] \\
\hline
\end{tabular}

antioxidant capacity of the body. TGF- $\beta$ is an important factor driving fibrosis, and the dysregulation of the TGF- $\beta /$ Smad signaling pathway is the main pathogenesis of fibrosis in the liver, lung, kidney, and myocardium. ${ }^{63,64}$ The anti-fibrotic effect of matrine is mainly mediated through the inhibition of the TGF- $\beta$ /Smad signaling pathway, promoting the activity of cell growth factors, reducing apoptosis and collagen synthesis, and inhibiting fibrosis progression. ${ }^{65,67-71}$ Additionally, matrine can also exert anti-fibrotic effects by inhibiting the activation of p38 and the JAK-STAT signal transduction pathway, ${ }^{121,135}$ providing a basis for the development of anti-fibrotic drugs. By blocking multiple signaling pathways such as NF-KB, PI3K/AKT, and MAPK, matrine inhibited osteoclast formation and may therefore be a promising drug for the treatment of osteoporosis and other related diseases. ${ }^{50,72}$ The antiviral effects of matrine are related to NF- $\mathrm{kB}$ and other signaling pathways ${ }^{89}$ but its clinical antiviral activity still requires further exploration. Some studies have proved that matrine exerts antidepressant effects through different mechanisms, ${ }^{51,149}$ further expanding our understanding of the pharmacological actions of matrine.

Over the past few decades, matrine has attracted tremendous interest in the medical community due to its widespread biological activity and therapeutic effects. However, matrine has only moderate bioactivity and certain toxic and side effects, which limit its further application; but it is considered to be an ideal lead compound for further modification since its good solubility, intriguing structure and favorable safety. Recently, in order to ameliorate the bioactivity and extend its applicability, a series of matrine derivatives have been synthesized by focusing on the structural modifications such as the lactam ring alteration, D-ring variation and structural simplification, leading to the less toxic effects, better drug activity, and improved pharmacokinetic properties. ${ }^{150}$ Literature analysis found that these novel derivatives performed more significant effects in inhibiting tumor cell proliferation, invasion and metastasis, ${ }^{52-58,107}$ targeted killing tumor stem cells, ${ }^{108}$ treating osteoporosis, ${ }^{59,60}$ and anti-inflammatory, ${ }^{123}$ and the mechanisms may be related to the regulation of the $\mathrm{PI} 3 \mathrm{~K} / \mathrm{AKT} / \mathrm{mTOR}, \mathrm{NF}-\mathrm{\kappa B}$, and Survivin/ $\beta$-catenin signaling pathways. Overall, novel modificatory strategies of matrine 
should be developed to explore more potent bioactive derivatives and further reveal their molecular mechanisms of action in the future.

Matrine interferes with multiple intracellular signaling pathways and regulates multiple target genes systematically, thus achieving anti-tumor and other pharmacological effects. These effects fully embody the advantages of the systemic, omnidirectional, multi-angle, and multi-target mechanisms of the treatment of diseases by traditional Chinese medicine preparations. However, current studies on the pharmacological mechanisms of matrine tend to focus on linear and single signaling pathways, and exploratory studies on the interaction network of different targets and signaling pathways remain rare. With the in-depth development of network pharmacology and holistic pharmacology, and the active use of gene chips and proteomics technology, the pharmacological mechanisms of matrine will be further clarified, and its signal transduction regulatory networks and synergistic mechanisms will be revealed. This will provide more theoretical basis for the design of effective drug targets at the molecular level, as well as theoretical support for the further expansion of the clinical application of matrine.

\section{Acknowledgment}

We thank LetPub (www.letpub.com) for its linguistic assistance during the preparation of this manuscript.

\section{Funding}

This work was supported by the Natural Science Foundation of Jiangsu Province (BK20200936), the Natural Science Research Project of the Higher Educational Institutions of Jiangsu Province (20KJB320007), and the Yangzhou Science and Technology Planning Project (YZ2021082).

\section{Disclosure}

The authors report no conflicts of interest for this work.

\section{References}

1. Li X, Tang Z, Wen L, et al. Matrine: a review of its pharmacology, pharmacokinetics, toxicity, clinical application and preparation researches. $J$ Ethnopharmacol. 2021;269:113682. doi:10.1016/j.jep.2020.113682

2. Zhang H, Chen L, Sun X, et al. Matrine: a promising natural product with various pharmacological activities. Front Pharmacol. $2020 ; 11: 588$. doi:10.3389/fphar.2020.00588

3. Rashid HU, Xu Y, Muhammad Y, et al. Research advances on anticancer activities of matrine and its derivatives: an updated overview. Eur $J$ Med Chem. 2019;161:205-238. doi:10.1016/j.ejmech.2018.10.037

4. Vanhaesebroeck B, Stephens L, Hawkins P. PI3K signalling: the path to discovery and understanding. Nat Rev Mol Cell Biol. 2012;13(3):195203. doi: $10.1038 / \mathrm{nrm} 3290$

5. Fruman DA, Chiu H, Hopkins BD, et al. The PI3K pathway in human disease. Cell. 2017;170(4):605-635. doi:10.1016/j.cell.2017.07.029

6. Alessi DR, James SR, Downes CP, et al. Characterization of a 3-phosphoinositide-dependent protein kinase which phosphorylates and activates protein kinase Balpha. Curr Biol. 1997;7(4):261-269. doi:10.1016/S0960-9822(06)00122-9

7. Manning BD, Cantley LC. AKT/PKB signaling: navigating downstream. Cell. 2007;129(7):1261-1274. doi:10.1016/j.cell.2007.06.009

8. Fayard E, Xue G, Parcellier A, et al. Protein kinase B (PKB/Akt), a key mediator of the PI3K signaling pathway. Curr Top Microbiol Immunol. 2010;346:31-56. doi:10.1007/82_2010_58

9. Liu GY, Sabatini DM. mTOR at the nexus of nutrition, growth, ageing and disease. Nat Rev Mol Cell Biol. 2020;21(4):183-203. doi:10.1038/ s41580-019-0199-y

10. Porta C, Paglino C, Mosca A. Targeting PI3K/Akt/mTOR signaling in cancer. Front Oncol. 2014;4:64. doi:10.3389/fonc.2014.00064

11. LoRusso PM. Inhibition of the PI3K/AKT/mTOR pathway in solid tumors. J Clin Oncol. 2016;34(31):3803-3815. doi:10.1200/ JCO.2014.59.0018

12. Yang J, Nie J, Ma X, et al. Targeting PI3K in cancer: mechanisms and advances in clinical trials. Mol Cancer. 2019;18(1):26. doi:10.1186/ s12943-019-0954-x

13. Niu H, Zhang Y, Wu B, et al. Matrine induces the apoptosis of lung cancer cells through downregulation of inhibitor of apoptosis proteins and the Akt signaling pathway. Oncol Rep. 2014;32(3):1087-1093. doi:10.3892/or.2014.3273

14. Wan Q, Du Z, Fang Z, et al. Matrine induces apoptosis and autophagy in human lung adenocarcinoma cells via upregulation of Cavin3 and suppression of PI3K/AKT pathway. J BUON. 2020;25(3):1512-1516.

15. Xie W, Lu J, Lu Q, et al. Matrine inhibits the proliferation and migration of lung cancer cells through regulation of the protein kinase B/ glycogen synthase kinase-3 beta signaling pathways. Exp Ther Med. 2018;16(2):723-729. doi:10.3892/etm.2018.6266

16. Liao H, Zhao X, Qu J, et al. Matrine suppresses invasion and metastasis of NCI-H1299 cells by enhancing microRNA-133a expression. Int $J$ Clin Exp Med. 2015;8(7):10714-10722.

17. Du J, Li J, Song D, et al. Matrine exerts antibreast cancer activity by mediating apoptosis and protective autophagy via the AKT/mTOR pathway in MCF7 cells. Mol Med Rep. 2020;22(5):3659-3666. doi:10.3892/mmr.2020.11449 
18. Yu P, Liu Q, Liu K, et al. Matrine suppresses breast cancer cell proliferation and invasion via VEGF-Akt-NF- $\mathrm{BB}$ signaling. Cytotechnology. 2009;59(3):219-229. doi:10.1007/s10616-009-9225-9

19. Li LQ, Li XL, Wang L, et al. Matrine inhibits breast cancer growth via miR-21/PTEN/Akt pathway in MCF-7 cells. Cell Physiol Biochem. 2012;30(3):631-641. doi:10.1159/000341444

20. Wang L, Gao C, Yao S, et al. Blocking autophagic flux enhances matrine-induced apoptosis in human hepatoma cells. Int J Mol Sci. 2013; 14 (12):23212-23230. doi:10.3390/ijms141223212

21. Wang Y, Zhang S, Liu J, et al. Matrine inhibits the invasive and migratory properties of human hepatocellular carcinoma by regulating epithelial-mesenchymal transition. Mol Med Rep. 2018;18(1):911-919. doi:10.3892/mmr.2018.9023

22. Chi G, Xu D, Zhang B, et al. Matrine induces apoptosis and autophagy of glioma cell line U251 by regulation of circRNA-104075/BCL-9. Chem Biol Interact. 2019;308:198-205. doi:10.1016/j.cbi.2019.05.030

23. Wang Z, Wu Y, Wang Y, et al. Matrine inhibits the invasive properties of human glioma cells by regulating epithelial to mesenchymal transition. Mol Med Rep. 2015;11(5):3682-3686. doi:10.3892/mmr.2015.3167

24. Zhou W, Wang J, Qi Q, et al. Matrine induces senescence of human glioblastoma cells through suppression of the IGF1/PI3K/AKT/p27 signaling pathway. Cancer Med. 2018;7(9):4729-4743. doi:10.1002/cam4.1720

25. Shen X, Huang J, Liu G, et al. Matrine inhibits neuroblastoma cell proliferation and migration by enhancing tribbles 3 expression. Oncol Res 2018;26(7):1133-1142. doi:10.3727/096504018X15168461629558

26. Wu J, Hu G, Dong Y, et al. Matrine induces Akt/mTOR signalling inhibition-mediated autophagy and apoptosis in acute myeloid leukaemia cells. J Cell Mol Med. 2017;21(6):1171-1181. doi:10.1111/jcmm.13049

27. Hao Y, Zhang N, Wei N, et al. Matrine induces apoptosis in acute myeloid leukemia cells by inhibiting the PI3K/Akt/mTOR signaling pathway. Oncol Lett. 2019;18(3):2891-2896. doi:10.3892/ol.2019.10649

28. Zhang S, Zhang Y, Zhuang Y, et al. Matrine induces apoptosis in human acute myeloid leukemia cells via the mitochondrial pathway and Akt inactivation. PLoS One. 2012;7(10):e46853. doi:10.1371/journal.pone.0046853

29. Yang Y, Guo JX, Shao ZQ, et al. Matrine inhibits bladder cancer cell growth and invasion in vitro through PI3K/AKT signaling pathway: an experimental study. Asian Pac J Trop Med. 2017;10(5):515-519. doi:10.1016/j.apjtm.2017.05.009

30. Li L, Qi F, Wang K. Matrine restrains cell growth and metastasis by up-regulating LINC00472 in bladder carcinoma. Cancer Manag Res 2020;12:1241-1251. doi:10.2147/CMAR.S224701

31. Liao XZ, Tao LT, Liu JH, et al. Matrine combined with cisplatin synergistically inhibited urothelial bladder cancer cells via down-regulating VEGF/PI3K/Akt signaling pathway. Cancer Cell Int. 2017;17:124. doi:10.1186/s12935-017-0495-6

32. Peng X, Zhou D, Wang X, et al. Matrine suppresses proliferation and invasion of SGC7901 cells through inactivation of PI3K/Akt/uPA pathway. Ann Clin Lab Sci. 2016;46(5):457-462.

33. Li Y, Zhang J, Ma H, et al. Protective role of autophagy in matrineinduced gastric cancer cell death. Int J Oncol. 2013;42(4):1417-1426. doi:10.3892/ijo.2013.1817

34. Bai S, Chen T, Yu X, et al. The specific killing effect of matrine on castration-resistant prostate cancer cells by targeting the Akt/FoxO3a signaling pathway. Oncol Rep. 2017;37(5):2819-2828. doi:10.3892/or.2017.5510

35. Li Q, Huang H, He Z, et al. Regulatory effects of antitumor agent matrine on FOXO and PI3K-AKT pathway in castration-resistant prostate cancer cells. Sci China Life Sci. 2018;61(5):550-558. doi:10.1007/s11427-016-9050-6

36. Zhang S, Cheng B, Li H, et al. Matrine inhibits proliferation and induces apoptosis of human colon cancer LoVo cells by inactivating Akt pathway. Mol Biol Rep. 2014;41(4):2101-2108. doi:10.1007/s11033-014-3059-z

37. Zhang X, Hou G, Liu A, et al. Matrine inhibits the development and progression of ovarian cancer by repressing cancer associated phosphorylation signaling pathways. Cell Death Dis. 2019;10(10):770. doi:10.1038/s41419-019-2013-3

38. Jin H, Sun Y, Wang S, et al. Matrine activates PTEN to induce growth inhibition and apoptosis in V600EBRAF harboring melanoma cells. Int $J$ Mol Sci. 2013;14(8):16040-16057. doi:10.3390/ijms140816040

39. $\mathrm{Xu} \mathrm{GP,} \mathrm{Zhao} \mathrm{W,} \mathrm{Zhuang} \mathrm{JP,} \mathrm{et} \mathrm{al.} \mathrm{Matrine} \mathrm{inhibits} \mathrm{the} \mathrm{growth} \mathrm{and} \mathrm{induces} \mathrm{apoptosis} \mathrm{of} \mathrm{osteosarcoma} \mathrm{cells} \mathrm{in} \mathrm{vitro} \mathrm{by} \mathrm{inactivating} \mathrm{the} \mathrm{Akt}$ pathway. Tumour Biol. 2015;36(3):1653-1659. doi:10.1007/s13277-014-2764-5

40. Yu Q, Chen B, Zhang X, et al. Arsenic trioxide-enhanced, matrine-induced apoptosis in multiple myeloma cell lines. Planta Med. 2013;79 (9):775-781. doi:10.1055/s-0032-1328554

41. Zhao L, Zhang X, Cui S. Matrine inhibits TPC-1 human thyroid cancer cells via the miR-21/PTEN/Akt pathway. Oncol Lett. 2018;16(3):29652970. doi:10.3892/ol.2018.9006

42. Li Q, Zhang S, Wang M, et al. Downregulated miR-21 mediates matrine-induced apoptosis via the PTEN/Akt signaling pathway in FTC-133 human follicular thyroid cancer cells. Oncol Lett. 2019;18(4):3553-3560. doi:10.3892/ol.2019.10693

43. Li L, Chen S, Sun Y, et al. Matrine inhibits the proliferation of pituitary tumor cells by decreasing Foxo3a phosphorylation and promoting Foxo3a nuclear localization. Exp Ther Med. 2019;17(5):3775-3780. doi:10.3892/etm.2019.7365

44. $\mathrm{Xu} \mathrm{G}$, Zhang W, Wang Z, et al. Matrine regulates $\mathrm{H}_{2} \mathrm{O}_{2}$-induced oxidative stress through long non-coding RNA HOTAIR/miR-106b-5p axis via AKT and STAT3 pathways. Biosci Rep. 2020;40(5). doi:10.1042/BSR20192560

45. Zhang S, Guo S, Gao XB, et al. Matrine attenuates high-fat diet-induced in vivo and ox-LDL-induced in vitro vascular injury by regulating the PKC $\alpha /$ eNOS and PI3K/Akt/eNOS pathways. J Cell Mol Med. 2019;23(4):2731-2743. doi:10.1111/jcmm.14180

46. Ma W, Xu J, Zhang Y, et al. Matrine pre-treatment suppresses AGEs- induced HCSMCs fibrotic responses by regulating Poldip2/mTOR pathway. Eur J Pharmacol. 2019;865:172746. doi:10.1016/j.ejphar.2019.172746

47. Liu X, Zhang X, Ma K, et al. Matrine alleviates early brain injury after experimental subarachnoid hemorrhage in rats: possible involvement of PI3K/Akt-mediated NF-кB inhibition and Keap1/Nrf2-dependent HO-1 induction. Cell Mol Biol. 2016;62(11):38-44.

48. Chen L, Chen L, Wan L, et al. Matrine improves skeletal muscle atrophy by inhibiting E3 ubiquitin ligases and activating the Akt/mTOR/ FoxO3 $\alpha$ signaling pathway in C2C12 myotubes and mice. Oncol Rep. 2019;42(2):479-494. doi:10.3892/or.2019.7205

49. Liu SQ, Zhang ML, Zhang HJ, et al. Matrine promotes oligodendrocyte development in CNS autoimmunity through the PI3K/Akt signaling pathway. Life Sci. 2017;180:36-41. doi:10.1016/j.1fs.2017.05.010

50. Chen X, Zhi X, Pan P, et al. Matrine prevents bone loss in ovariectomized mice by inhibiting RANKL-induced osteoclastogenesis. FASEB J. 2017;31(11):4855-4865. doi:10.1096/fj.201700316R 
51. Wu Z, You Z, Chen P, et al. Matrine exerts antidepressant-like effects on mice: role of the hippocampal PI3K/Akt/mTOR signaling. Int $J$ Neuropsychopharmacol. 2018;21(8):764-776. doi:10.1093/ijnp/pyy028

52. Feng Y, Ying HY, Qu Y, et al. Novel matrine derivative MD-1 attenuates hepatic fibrosis by inhibiting EGFR activation of hepatic stellate cells. Protein Cell. 2016;7(9):662-672. doi:10.1007/s13238-016-0285-2

53. Sun X, Zhuo XB, Hu YP, et al. A novel matrine derivative WM622 inhibits hepatocellular carcinoma by inhibiting PI3K/AKT signaling pathways. Mol Cell Biochem. 2018;449(1-2):47-54. doi:10.1007/s11010-018-3341-9

54. Qian L, Liu Y, Xu Y, et al. Matrine derivative WM130 inhibits hepatocellular carcinoma by suppressing EGFR/ERK/MMP-2 and PTEN/AKT signaling pathways. Cancer Lett. 2015;368(1):126-134. doi:10.1016/j.canlet.2015.07.035

55. Zou Y, Sarem M, Xiang S, et al. Autophagy inhibition enhances Matrine derivative MASM induced apoptosis in cancer cells via a mechanism involving reactive oxygen species-mediated PI3K/Akt/mTOR and Erk/p38 signaling. BMC Cancer. 2019;19(1):949. doi:10.1186/s12885-0196199-7

56. Wu L, Wang G, Liu S, et al. Synthesis and biological evaluation of matrine derivatives containing benzo- $\alpha$-pyrone structure as potent anti-lung cancer agents. Sci Rep. 2016;6:35918. doi:10.1038/srep35918

57. Zhou YJ, Guo YJ, Yang XL, et al. Anti-cervical cancer role of matrine, oxymatrine and sophora flavescens alkaloid gels and its mechanism. $J$ Cancer. 2018;9(8):1357-1364. doi:10.7150/jca.22427

58. Xie M, Yi X, Wang R, et al. 14-Thienyl methylene matrine (YYJ18), the derivative from matrine, induces apoptosis of human nasopharyngeal carcinoma cells by targeting MAPK and PI3K/Akt pathways in vitro. Cell Physiol Biochem. 2014;33(5):1475-1483. doi:10.1159/000358712

59. Chen X, Zhi X, Cao L, et al. Matrine derivate MASM uncovers a novel function for ribosomal protein S5 in osteoclastogenesis and postmenopausal osteoporosis. Cell Death Dis. 2017;8(9):e3037. doi:10.1038/cddis.2017.394

60. Xin Z, Jin C, Chao L, et al. A matrine derivative M54 suppresses osteoclastogenesis and prevents ovariectomy-induced bone loss by targeting ribosomal protein S5. Front Pharmacol. 2018;9:22. doi:10.3389/fphar.2018.00022

61. Zhang Y, Alexander PB, Wang XF. TGF- $\beta$ family signaling in the control of cell proliferation and survival. Cold Spring Harb Perspect Biol. 2017;9(4):a022145. doi:10.1101/cshperspect.a022145

62. Hu HH, Chen DQ, Wang YN, et al. New insights into TGF- $\beta /$ Smad signaling in tissue fibrosis. Chem Biol Interact. 2018;292:76-83. doi:10.1016/j.cbi.2018.07.008

63. Vander Ark A, Cao J, Li X. TGF- $\beta$ receptors: in and beyond TGF- $\beta$ signaling. Cell Signal. 2018;52:112-120. doi:10.1016/j.cellsig.2018.09.002

64. Clark DA, Coker R. Transforming growth factor-beta (TGF-beta). Int J Biochem Cell Biol. 1998;30(3):293-298. doi:10.1016/S1357-2725(97) 00128-3

65. Zhang Y, Cui L, Guan G, et al. Matrine suppresses cardiac fibrosis by inhibiting the TGF- $\beta /$ Smad pathway in experimental diabetic cardiomyopathy. Mol Med Rep. 2018;17(1):1775-1781. doi:10.3892/mmr.2017.8054

66. Hou H, Zhang Q, Dong H, et al. Matrine improves diabetic cardiomyopathy through TGF- $\beta$-induced protein kinase RNA-like endoplasmic reticulum kinase signaling pathway. J Cell Biochem. 2019;120(8):13573-13582. doi:10.1002/jcb.28632

67. Ma J, Ma S, Yin $\mathrm{C}$, et al. Matrine reduces susceptibility to postinfarct atrial fibrillation in rats due to antifibrotic properties. $J$ Cardiovasc Electrophysiol. 2018;29(4):616-627. doi:10.1111/jce.13448

68. Yu J-L, Li J-H, Chengz R-G, et al. Effect of matrine on transforming growth factor $\beta 1$ and hepatocyte growth factor in rat liver fibrosis model. Asian Pac J Trop Med. 2014;7(5):390-393. doi:10.1016/S1995-7645(14)60062-6

69. Li L, Ma L, Wang D, et al. Design and synthesis of matrine derivatives as novel anti-pulmonary fibrotic agents via repression of the TGF- $\beta /$ Smad pathway. Molecules. 2019;24(6):1108.

70. Zhang X, Cai Y. Effects of Ginkgo biloba leaf extract, shenmai and matrine on a human embryonic lung fibroblast fibrosis model. Exp Ther Med. 2018;16(5):4289-4295. doi:10.3892/etm.2018.6698

71. Liu P, Zhu L, Zou G, et al. Matrine suppresses pancreatic fibrosis by regulating TGF- $\beta$ /Smad signaling in rats. Yonsei Med J. 2019 ;60(1):79-87. doi:10.3349/ymj.2019.60.1.79

72. Mao D, Pan X, Rui Y, et al. Matrine attenuates heterotopic ossification by suppressing TGF- $\beta$ induced mesenchymal stromal cell migration and osteogenic differentiation. Biomed Pharmacother. 2020;127:110152. doi:10.1016/j.biopha.2020.110152

73. Zhang L, Lin S, Zheng Y, et al. Matrine regulates Th1/Th2 balance to treat eczema by upregulating interferon- $\gamma$. J Nanosci Nanotechnol. 2020;20(6):3378-3386. doi:10.1166/jnn.2020.17417

74. Zhang Q, Lenardo MJ, Baltimore D. 30 years of NF-kB: a blossoming of relevance to human pathobiology. Cell. 2017;168(1-2):37-57. doi:10.1016/j.cell.2016.12.012

75. Sacks D, Baxter B, Campbell BCV. Multisociety consensus quality improvement revised consensus statement for endovascular therapy of acute ischemic stroke. Int J Stroke. 2018;13(6):612-632. doi:10.1177/1747493018778713

76. Zhang B, Liu ZY, Li YY, et al. Antiinflammatory effects of matrine in LPS-induced acute lung injury in mice. Eur J Pharm Sci. 2011;44 (5):573-579. doi:10.1016/j.ejps.2011.09.020

77. Shao H, Yang B, Hu R, et al. Matrine effectively inhibits the proliferation of breast cancer cells through a mechanism related to the NF- $\mathrm{kB}$ signaling pathway. Oncol Lett. 2013;6(2):517-520. doi:10.3892/o1.2013.1399

78. Yu HB, Zhang HF, Li DY, et al. Matrine inhibits matrix metalloproteinase-9 expression and invasion of human hepatocellular carcinoma cells. $J$ Asian Nat Prod Res. 2011;13(3):242-250. doi:10.1080/10286020.2010.551641

79. Huang M, Xin W. Matrine inhibiting pancreatic cells epithelial-mesenchymal transition and invasion through ROS/NF-kB/MMPs pathway. Life Sci. 2018;192:55-61. doi:10.1016/j.lfs.2017.11.024

80. Jung YY, Um JY, Narula AS, et al. Identification of matrine as a novel regulator of the CXCR4 signaling axis in tumor cells. Int J Mol Sci. 2020;21(13):4731. doi:10.3390/ijms21134731

81. Li Q, Lai Y, Wang C, et al. Matrine inhibits the proliferation, invasion and migration of castration-resistant prostate cancer cells through regulation of the NF-kB signaling pathway. Oncol Rep. 2016;35(1):375-381. doi:10.3892/or.2015.4341

82. Huang H, Du T, Xu G, et al. Matrine suppresses invasion of castration-resistant prostate cancer cells by downregulating MMP-2/9 via NF- $\mathrm{kB}$ signaling pathway. Int J Oncol. 2017;50(2):640-648. doi:10.3892/ijo.2016.3805

83. Luo C, Zhong HJ, Zhu LM, et al. Inhibition of matrine against gastric cancer cell line MNK45 growth and its anti-tumor mechanism. Mol Biol Rep. 2012;39(5):5459-5464. doi:10.1007/s11033-011-1346-5 
84. Chen Z, Nishimura N, Okamoto T, et al. Molecular mechanism of matrine from sophora alopecuroides in the reversing effect of multianticancer drug resistance in K562/ADR cells. Biomed Res Int. 2019;2019:1269532. doi:10.1155/2019/1269532

85. Li Y, Zhang ZN, Zhao HM, et al. Matrine inhibits the invasive properties of human osteosarcoma cells by downregulating the ERK-NF- $\mathrm{KB}$ pathway. Anticancer Drugs. 2014;25(9):1035-1043. doi:10.1097/CAD.0000000000000136

86. Jiang J, Wang G. Matrine protects PC12 cells from lipopolysaccharide-evoked inflammatory injury via upregulation of miR-9. Pharm Biol. 2020;58(1):314-320. doi:10.1080/13880209.2020.1719165

87. Chu Y, Jing Y, Zhao X, et al. Modulation of the HMGB1/TLR4/NF- $\kappa B$ signaling pathway in the CNS by matrine in experimental autoimmune encephalomyelitis. $J$ Neuroimmunol. 2021;352:577480. doi:10.1016/j.jneuroim.2021.577480

88. Xu M, Yang L, Hong LZ, et al. Direct protection of neurons and astrocytes by matrine via inhibition of the NF- $\mathrm{KB}$ signaling pathway contributes to neuroprotection against focal cerebral ischemia. Brain Res. 2012;1454:48-64. doi:10.1016/j.brainres.2012.03.020

89. Sun N, Sun P, Lv H, et al. Matrine displayed antiviral activity in porcine alveolar macrophages co-infected by porcine reproductive and respiratory syndrome virus and porcine circovirus type 2. Sci Rep. 2016;6:24401. doi:10.1038/srep24401

90. Sun P, Sun N, Yin W, et al. Matrine inhibits IL-1 $\beta$ secretion in primary porcine alveolar macrophages through the MyD88/NF- $\mathrm{BB}$ pathway and NLRP3 inflammasome. Vet Res. 2019;50(1):53. doi:10.1186/s13567-019-0671-x

91. Wang J, Liu Z, Li W, et al. Matrine alleviates N-methyl-N'-nitro-N-nitrosoguanidine (MNNG)-induced gastric mucosal damage in rats and its mechanism. Xi Bao Yu Fen Zi Mian Yi Xue Za Zhi. 2020;36(2):157-163.

92. Sun D, Wang J, Yang N, et al. Matrine suppresses airway inflammation by downregulating SOCS3 expression via inhibition of NF- $\mathrm{kB}$ signaling in airway epithelial cells and asthmatic mice. Biochem Biophys Res Commun. 2016;477(1):83-90. doi:10.1016/j.bbrc.2016.06.024

93. Niu Y, Dong Q, Li R. Matrine regulates Th1/Th2 cytokine responses in rheumatoid arthritis by attenuating the NF- $\mathrm{kB}$ signaling. Cell Biol Int. 2017;41(6):611-621. doi:10.1002/cbin.10763

94. Pu J, Fang FF, Li XQ, et al. Matrine exerts a strong anti-arthritic effect on type II collagen-induced arthritis in rats by inhibiting inflammatory responses. Int J Mol Sci. 2016;17(9):1410. doi:10.3390/ijms17091410

95. Zou Y, Li Q, Liu D, et al. Therapeutic effects of matrine derivate MASM in mice with collagen-induced arthritis and on fibroblast-like synoviocytes. Sci Rep. 2017;7(1):2454. doi:10.1038/s41598-017-02423-7

96. Lu S, Xiao X, Cheng M. Matrine inhibits IL-1 $\beta$-induced expression of matrix metalloproteinases by suppressing the activation of MAPK and NF- $\mathrm{kB}$ in human chondrocytes in vitro. Int J Clin Exp Pathol. 2015;8(5):4764-4772.

97. Jiang K, Guo S, Yang J, et al. Matrine alleviates Staphylococcus aureus lipoteichoic acid-induced endometritis via suppression of TLR2mediated NF-kB activation. Int Immunopharmacol. 2019;70:201-207. doi:10.1016/j.intimp.2019.02.033

98. Liu J, Zhang L, Ren Y, et al. Matrine inhibits the expression of adhesion molecules in activated vascular smooth muscle cells. Mol Med Rep. 2016;13(3):2313-2319. doi:10.3892/mmr.2016.4767

99. Dannheisig DP, Bachle J, Tasic J, et al. The Wnt/B-catenin pathway is activated as a novel nucleolar stress response. $J$ Mol Biol. 2021;433 (2):166719. doi:10.1016/j.jmb.2020.11.018

100. Astudillo P. Extracellular matrix stiffness and Wnt//-catenin signaling in physiology and disease. Biochem Soc Trans. 2020;48(3):1187-1198. doi:10.1042/BST20200026

101. Dai M, Cai Z, Chen N, et al. Matrine suppresses stemness of hepatocellular carcinoma cells by regulating $\beta$-catenin signaling pathway. Nan Fang Yi Ke Da Xue Xue Bao. 2019;39(10):1239-1245. doi:10.12122/j.issn.1673-4254.2019.10.17

102. Li X, Wang M, Du N, et al. Matrine inhibitory effect on self-renewal and re-sensitization of 5-FU resistant NSCLC stem cells were through Let7b dependent downregulation of CCND1. Cell Cycle. 2020;19(23):3249-3259. doi:10.1080/15384101.2020.1838791

103. Li X, Liang T, Chen SS, et al. Matrine suppression of self-renewal was dependent on regulation of LIN28A/Let-7 pathway in breast cancer stem cells. J Cell Biochem. 2020;121(3):2139-2149. doi:10.1002/jcb.29396

104. Xiao X, Ao M, Xu F, et al. Effect of matrine against breast cancer by downregulating the vascular endothelial growth factor via the Wnt/ $\beta$ catenin pathway. Oncol Lett. 2018;15(2):1691-1697. doi:10.3892/ol.2017.7519

105. Liu J, Guo Y, Cao J. Matrine triggers colon cancer cell apoptosis and G0/G1 cell cycle arrest via mediation of microRNA-22. Phytother Res. 2020;34(7):1619-1628. doi:10.1002/ptr.6626

106. Ma Y, Zou F, Xiong J, et al. Effect of Matrine on HPAC cell migration by down-regulating the expression of MT1-MMP via Wnt signaling. Cancer Cell Int. 2015;15:59. doi:10.1186/s12935-015-0210-4

107. Yin H, Que R, Liu C, et al. Survivin-targeted drug screening platform identifies a matrine derivative WM-127 as a potential therapeutics against hepatocellular carcinoma. Cancer Lett. 2018;425:54-64. doi:10.1016/j.canlet.2018.03.044

108. Ni CX, Qi Y, Zhang J, et al. WM130 preferentially inhibits hepatic cancer stem-like cells by suppressing AKT/GSK3 $\beta / \beta$-catenin signaling pathway. Oncotarget. 2016;7(48):79544-79556. doi:10.18632/oncotarget.12822

109. Kim EK, Choi EJ. Pathological roles of MAPK signaling pathways in human diseases. Biochim Biophys Acta. 2010;1802(4):396-405. doi:10.1016/j.bbadis.2009.12.009

110. Wagner EF, Nebreda AR. Signal integration by JNK and p38 MAPK pathways in cancer development. Nat Rev Cancer. 2009;9(8):537-549. doi: $10.1038 / \mathrm{nrc} 2694$

111. Tan C, Qian X, Jia R, et al. Matrine induction of reactive oxygen species activates p38 leading to caspase-dependent cell apoptosis in non-small cell lung cancer cells. Oncol Rep. 2013;30(5):2529-2535. doi:10.3892/or.2013.2727

112. Yang Z, Mu J, Chen J, et al. Apoptosis of U937 cell line promoted by matrine through MAPK signal transduction pathway. Zhongguo Zhong Yao Za Zhi. 2009;34(12):1553-1556.

113. Ma L, Xu Z, Wang J, et al. Matrine inhibits BCR/ABL mediated ERK/MAPK pathway in human leukemia cells. Oncotarget. 2017;8 (65):108880-108889. doi:10.18632/oncotarget.22353

114. Lu J, Luo Q, Cheng P, et al. The role of matrine and mitogen-ativated protein kinase/extracellular signal-regulated kinase signal transduction in the inhibition of the proliferation and migration of human umbilical veins endothelial cells induced by lung cancer cells. Zhongguo Fei Ai Za Zhi. 2009;12(7):747-752. doi:10.3779/j.issn.1009-3419.2009.07.002

115. Ren H, Zhang S, Ma H, et al. Matrine reduces the proliferation and invasion of colorectal cancer cells via reducing the activity of $\mathrm{p} 38$ signaling pathway. Acta Biochim Biophys Sin (Shanghai). 2014;46(12):1049-1055. doi:10.1093/abbs/gmu101 
116. Liang X, Ju J. Matrine inhibits ovarian cancer cell viability and promotes apoptosis by regulating the ERK/JNK signaling pathway via p38MAPK. Oncol Rep. 2021;45(5). doi:10.3892/or.2021.8033

117. Huang H, Wang Q, Du T, et al. Matrine inhibits the progression of prostate cancer by promoting expression of GADD45B. Prostate. 2018;78 (5):327-335. doi:10.1002/pros.23469

118. Ma K, Huang MY, Guo YX, et al. Matrine-induced autophagy counteracts cell apoptosis via the ERK signaling pathway in osteosarcoma cells. Oncol Lett. 2016;12(3):1854-1860. doi:10.3892/o1.2016.4848

119. Zhou J, Ma W, Wang X, et al. Matrine suppresses reactive oxygen species (ROS)-mediated MKKs/p38-induced inflammation in oxidized lowdensity lipoprotein (ox-LDL)-stimulated macrophages. Med Sci Monit. 2019;25:4130-4136. doi:10.12659/MSM.917151

120. Liu Z, Lv Y, Zhang Y, et al. Matrine-type alkaloids inhibit advanced glycation end products induced reactive oxygen species-mediated apoptosis of aortic endothelial cells in vivo and in vitro by targeting MKK3 and p38MAPK signaling. J Am Heart Assoc. 2017;6(12). doi:10.1161/ JAHA.117.007441

121. Zhang X, Hu C, Zhang N, et al. Matrine attenuates pathological cardiac fibrosis via RPS5/p38 in mice. Acta Pharmacol Sin. 2021;42(4):573584. doi:10.1038/s41401-020-0473-8

122. Wu X, Zhou J, Cai D, et al. Matrine inhibits the metastatic properties of human cervical cancer cells via downregulating the p38 signaling pathway. Oncol Rep. 2017;38(2):1312-1320. doi:10.3892/or.2017.5787

123. Xu J, Wang KQ, Xu WH, et al. The matrine derivate MASM prolongs survival, attenuates inflammation, and reduces organ injury in murine established lethal sepsis. J Infect Dis. 2016;214(11):1762-1772. doi:10.1093/infdis/jiw445

124. Li J, Xu J, Lu Y, et al. MASM, a matrine derivative, offers radioprotection by modulating lethal total-body irradiation-induced multiple signaling pathways in wistar rats. Molecules. 2016;21(5):649.

125. Xu J, Qi Y, Xu WH, et al. Matrine derivate MASM suppresses LPS-induced phenotypic and functional maturation of murine bone marrowderived dendritic cells. Int Immunopharmacol. 2016;36:59-66. doi:10.1016/j.intimp.2016.04.022

126. Siebel C, Lendahl U. Notch signaling in development, tissue homeostasis, and disease. Physiol Rev. 2017;97(4):1235-1294. doi:10.1152/ physrev.00005.2017

127. Borggrefe T, Oswald F. The Notch signaling pathway: transcriptional regulation at Notch target genes. Cell Mol Life Sci. 2009;66(10):16311646. doi:10.1007/s00018-009-8668-7

128. Liu Z, Wang Y, Zhu H, et al. Matrine blocks AGEs- induced HCSMCs phenotypic conversion via suppressing Dll4-Notch pathway. Eur $J$ Pharmacol. 2018;835:126-131. doi:10.1016/j.ejphar.2018.07.051

129. Zhao L, Cai H, Tang Z, et al. Matrine suppresses advanced glycation end products-induced human coronary smooth muscle cells phenotype conversion by regulating endoplasmic reticulum stress-dependent Notch signaling. Eur J Pharmacol. 2020;882:173257. doi:10.1016/j. ejphar.2020.173257

130. Yang Z, Wang L, Wang X. Matrine induces the hepatic differentiation of WB-F344 rat hepatic progenitor cells and inhibits Jagged 1/HES1 signaling. Mol Med Rep. 2016;14(4):3841-3847. doi:10.3892/mmr.2016.5668

131. Shi J, Han G, Wang J, et al. Matrine promotes hepatic oval cells differentiation into hepatocytes and alleviates liver injury by suppression of Notch signalling pathway. Life Sci. 2020;261:118354. doi:10.1016/j.1fs.2020.118354

132. Shi J, Han X, Wang J, et al. Matrine prevents the early development of hepatocellular carcinoma like lesions in rat liver. Exp Ther Med. 2019. doi:10.3892/etm.2019.7875

133. Harrison DA. The Jak/STAT pathway. Cold Spring Harb Perspect Biol. 2012;4(3):a011205-a011205. doi:10.1101/cshperspect.a011205

134. Muller P, Kuttenkeuler D, Gesellchen V, et al. Identification of JAK/STAT signalling components by genome-wide RNA interference. Nature. 2005;436(7052):871-875. doi:10.1038/nature03869

135. Ma X, Chen R, Liu X, et al. Effects of matrine on JAK-STAT signaling transduction pathways in bleomycin-induced pulmonary fibrosis. Afr $J$ Tradit Complement Altern Med. 2013;10(3):442-448. doi:10.4314/ajtcam.v10i3.10

136. Ma L, Zhu Z, Sun X, et al. Growth inhibition effect of matrine on K562 cells mediated by IL-6/JAK/STAT3 signaling pathway. Zhonghua Xue Ye Xue Za Zhi. 2015;36(5):422-426. doi:10.3760/cma.j.issn.0253-2727.2015.05.015

137. Lu X, Zhu Z, Jiang L, et al. Matrine increases NKG2D ligand ULBP2 in K562 cells via inhibiting JAK/STAT3 pathway: a potential mechanism underlying the immunotherapy of matrine in leukemia. Am J Transl Res. 2015;7(10):1838-1849.

138. Chen SF, Zhang ZY, Zhang JL. Matrine increases the inhibitory effects of Afatinib on H1975 cells via the IL6/JAK1/STAT3 signaling pathway. Mol Med Rep. 2017;16(3):2733-2739. doi:10.3892/mmr.2017.6865

139. Yang Y, Dong Q, Li R. Matrine induces the apoptosis of fibroblast-like synoviocytes derived from rats with collagen-induced arthritis by suppressing the activation of the JAK/STAT signaling pathway. Int J Mol Med. 2017;39(2):307-316. doi:10.3892/ijmm.2016.2843

140. Tamargo-Gomez I, Marino G. AMPK: regulation of metabolic dynamics in the context of autophagy. Int J Mol Sci. $2018 ; 19(12): 3812$. doi:10.3390/ijms 19123812

141. Lin SC, Hardie DG. AMPK: sensing glucose as well as cellular energy status. Cell Metab. 2018;27(2):299-313. doi:10.1016/j.cmet.2017.10.009

142. Li Y, Chen Y. AMPK and autophagy. Adv Exp Med Biol. 2019;1206:85-108.

143. Lu Q, Lin X, Wu J, et al. Matrine attenuates cardiomyocyte ischemia-reperfusion injury through activating AMPK/Sirt3 signaling pathway. $J$ Recept Signal Transduct Res. 2020;1-6. doi:10.1080/10799893.2020.1863987

144. Xie SB, He XX, Yao SK. Matrine-induced autophagy regulated by 553 through AMP-activated protein kinase in human hepatoma cells. Int $J$ Oncol. 2015;47(2):517-526. doi:10.3892/ijo.2015.3023

145. Cao J, Wei R, Yao S. Matrine has pro-apoptotic effects on liver cancer by triggering mitochondrial fission and activating Mst1-JNK signalling pathways. J Physiol Sci. 2019;69(2):185-198. doi:10.1007/s12576-018-0634-4

146. Yang ZY, Wang L, Hou YX, et al. Effects of matrine on oval cellmediated liver regeneration and expression of RBP-JK and HES1. Mol Med Rep. 2013;7(5):1533-1538. doi:10.3892/mmr.2013.1398

147. Lu Z, Xiao Y, Liu X, et al. Matrine reduces the proliferation of A549 cells via the p53/p21/PCNA/eIF4E signaling pathway. Mol Med Rep. 2017;15(5):2415-2422. doi:10.3892/mmr.2017.6331

148. Gu J, Wang X, Zhang L, et al. Matrine suppresses cell growth of diffuse large B-cell lymphoma via inhibiting CaMKII $\gamma / \mathrm{c}-\mathrm{Myc} / \mathrm{CDK} 6$ signaling pathway. BMC Complement Med Ther. 2021;21(1):163. doi:10.1186/s12906-021-03315-0 
149. Khan A, Shal B, Naveed M, et al. Matrine alleviates neurobehavioral alterations via modulation of JNK-mediated caspase-3 and BDNF/VEGF signaling in a mouse model of burn injury. Psychopharmacology (Berl). 2020;237(8):2327-2343. doi:10.1007/s00213-020-05537-5

150. Cai XH, Guo H, Xie B. Structural modifications of matrine-type alkaloids. Mini Rev Med Chem. 2018;18(9):730-744. doi:10.2174/ 1389557516666161104150334

\section{Publish your work in this journal}

Drug Design, Development and Therapy is an international, peer-reviewed open-access journal that spans the spectrum of drug design and development through to clinical applications. Clinical outcomes, patient safety, and programs for the development and effective, safe, and sustained use of medicines are a feature of the journal, which has also been accepted for indexing on PubMed Central. The manuscript management system is completely online and includes a very quick and fair peer-review system, which is all easy to use. Visit http://www.dovepress.com/testimonials.php to read real quotes from published authors.

Submit your manuscript here: https://www.dovepress.com/drug-design-development-and-therapy-journal 